\title{
Polarized Policymaking: The Effect of Ideological Division on Legislative Outcomes in the United States Congress
}

\author{
Aaron Tyler Mentzer \\ atmentzer@mix.wvu.edu
}

Follow this and additional works at: https://researchrepository.wvu.edu/etd

Part of the American Politics Commons

\section{Recommended Citation}

Mentzer, Aaron Tyler, "Polarized Policymaking: The Effect of Ideological Division on Legislative Outcomes in the United States Congress" (2021). Graduate Theses, Dissertations, and Problem Reports. 10304. https://researchrepository.wvu.edu/etd/10304

This Dissertation is protected by copyright and/or related rights. It has been brought to you by the The Research Repository @ WVU with permission from the rights-holder(s). You are free to use this Dissertation in any way that is permitted by the copyright and related rights legislation that applies to your use. For other uses you must obtain permission from the rights-holder(s) directly, unless additional rights are indicated by a Creative Commons license in the record and/ or on the work itself. This Dissertation has been accepted for inclusion in WVU Graduate Theses, Dissertations, and Problem Reports collection by an authorized administrator of The Research Repository @ WVU.

For more information, please contact researchrepository@mail.wvu.edu. 


\title{
Polarized Policymaking:
}

\section{The Effect of Ideological Division on Legislative Outcomes in the United States Congress}

\author{
Aaron Tyler Mentzer \\ Dissertation submitted \\ to the Eberly College of Arts and Sciences \\ at West Virginia University \\ in partial fulfillment of the requirements for the degree of \\ Doctor of Philosophy in \\ Political Science \\ Jason MacDonald, Ph.D., Chair \\ Matthew Jacobsmeier, Ph.D. \\ John Kilwein, Ph.D \\ Lisa Dilks, Ph.D. \\ Department of Political Science \\ Morgantown, West Virginia \\ 2021
}

Keywords: Congress, polarization, legislative productivity, legislative institutions, congressional committees, appropriations, lawmaking

Copyright 2021 Aaron Tyler Mentzer 


\begin{abstract}
Polarized Policymaking:

The Effect of Polarization on Legislative Outcomes in the United States Congress
\end{abstract}

Aaron Tyler Mentzer

Intro: This dissertation examines the effect of political polarization on legislative productivity and policymaking in the United States Congress. As the ideological distance between Republicans and Democrats increases, both parties face pressure to obstruct the legislative process in order to defeat their opponent's policy proposals. This leads to legislative gridlock and alters the means by which Congress can perform its legislative duties. This theory is not a new one, but this dissertation expands on existing literature in several ways. In Chapter 2 I ask: does polarization limit the types of policy that Congress is able to pass, and is Congress restricted in its ability to pass bills that benefit particularized constituencies? Using the work of Arnold (1990), I disaggregate bills promoting the interests of generalized, group, and geographic constituencies. I find that as ideological polarization increases, Congress continues to pass a steady volume of generalized laws each year, but the number of group and geographic laws have decreased in response to a polarized lawmaking environment. In Chapter 3 I shift my focus to the committee system in Congress. Existing literature shows that polarization is affecting the frequency and quality of bill passage. I ask, does polarization affect the productivity of committees as well? I argue that as party control over committees tightens, the gridlock associated with polarization will apply to the regular order of committees as well. I find evidence suggesting that the productivity of committees has decreased as Congress has become more polarized. Finally, in Chapter 4 I examine how Congress can use the appropriations process to bypass gridlock when polarization is high. I argue that appropriations bills are an attractive means through which Congress can make changes to public policy that are unrelated to the appropriations process. While changing the law in this manner is in violation of House and Senate rules, it also allows Congress to circumvent the president's preferences during sessions in which Congress and the president belong to different parties. I create a new dataset that tallies the frequency of changes made to the United States Code that originate from yearly appropriations bills. I find that in sessions in which the government is fully divided, and polarization is high, Congress is more likely to enact substantive policy changes through the appropriations process. This project adds to growing literatures on polarization and congressional productivity, producing new knowledge about the consequences of polarization on congressional politics and lawmaking. 


\section{Acknowledgements}

\section{$\underline{\text { Chair }}$}

Dr. Jason MacDonald - I can't thank you enough for your support throughout this process. I have experienced many hurdles along the way, and you always reassured me that not only was I capable of this work, but also that my research had value. This dissertation is not only the result of my efforts, but also of your encouragement and advice.

\section{Committee}

Dr. Jacobsmeier - Thank you for always supporting my progress, and for being a guide when I found myself sometimes without direction. I want you to know that I always valued our conversations and your willingness to listen to the needs of graduate students.

Dr. Kilwein - Thank you for providing me with so many opportunities in the department and instilling in me an unexpected enjoyment of teaching law. I appreciate how you were a support system when I needed it, especially when I was anxious about my comprehensive exams.

Dr. Dilks - While you and I met near the end of this project, I want you to know how thankful that I am for your feedback and how glad I was to have you on the committee. You were not only enjoyable to chat with, but your perspective was very useful in the crafting of my final document.

\section{Others in the Political Science Department}

Dr. Hauser - You have been such a good friend over the years. When I think of my favorite memories of Morgantown, the ones where we opened a nice bottle of wine on your porch and looked out over the city are at the top of the list. Thank you for everything that you did to help me get here.

Dr. Cassese - Your early contributions to this project were valuable, especially your suggestions regarding my methodology. Also, I appreciated your advice in my early days of teaching, and your suggestions have shaped how I conduct my classes.

Dr. Worsham - I once said that I would never study committees, and it was through your encouragement that I changed my mind. Thank you for your help with the early drafts, and for the mountains of books you were always willing to lend.

Dr Fattore - I am grateful for the time that we spent as office mates, and for all your motivational speeches over the years.

\section{$\underline{\text { Student Colleagues }}$}

There are so many of you that have provided me with support and friendship over the years. To name a few, I want to recognize Franchesca Nestor, Mitch Parlett, Dave King, Brian Fitzpatrick, Kyu Chul Shin, and Mike Jones. Also, I want to thank Liza Gordon for her help in getting some of my early data and coding methods settled. 


\section{$\underline{\text { Family and Friends }}$}

Andrea - I could not have accomplished this without you as my partner. Your support for me has never faltered, and you gave me the strength to continue when I often thought that I couldn't. I can't wait to see what other adventures we will go on together.

Mom - What a long and difficult road we have travelled to get here. We have lost so many along the way and sacrificed so much. Yet you made sure that I never went without, even when there wasn't much to give. We never stopped trying to have a better life, and we never gave up. Thank you for inspiring me to be the man that I am today.

Andy - Little brother, I am so glad that we are close. You have helped to keep me sane during this process, and you always knew how to make me laugh when I needed it.

Fred - The day that you encouraged me to go to college set me down a path that changed my life. I am so glad that I got to see you one last time after I got into undergrad, but it pains me that you can't be here to see the end-result of this journey. I hope that you would be proud of my accomplishments.

Emily - I want to thank you for pointing me in this direction when I was younger. You explained to me the importance of understanding the political system and participating in it. Importantly, you showed me how to take charge of my own life.

Peg and Rob - You never stopped believing in me and my potential. Thanks for being the best in-laws that I could have asked for.

David - Thank you for showing me that there can be a life after this process, always listening to my troubles, and for being such a great friend all these years.

Cooper - It seems like just yesterday that we were playing board games at UPJ, and now look how far we have come. Thank you for always checking in on me, and for making sure that we never lost touch.

Christian, Niqueo, Alex, Kerry, Aaron, John, Geoff, and so many other "internet friends" Thank you for sticking with me through all of this. It was so nice to know that I always had someone to talk to. You truly made this process manageable just by being there for me. 


\section{Table of Contents}

Chapter 1: Introduction / 1

Chapter 2: Polarization and Policy Beneficiaries / 23

Chapter 3: Polarization and Committee Productivity / 51

Chapter 4: Polarization and Appropriation Riders / 80

Chapter 5: Conclusion / 112

Appendixes / 128

References / 148 


\section{List of Tables}

\section{Chapter 2}

2-1: Agriculture Subtopic Codes and Classifications / 33

2-2: Seemingly Unrelated Regression Estimates of Polarization and Beneficiaries / 42

2-3: Seemingly Unrelated Regression Estimates Utilizing Variable for Moderates / 45

2-4: Seemingly Unrelated Regression Estimates Utilizing Variable for Gridlock / 46

2-5: Seemingly Unrelated Regression Estimates with Time Variable / 49

\section{Chapter 3}

3-1: OLS Estimates of House Committee Productivity / 71

3-2: OLS Estimates of Senate Committee Productivity / 72

3-3: OLS Estimates of House Committee Productivity with Time Variable / 75

3-4: OLS Estimates of Senate Committee Productivity with Time Variable / 76

3-5: OLS Estimates of House Committee Productivity with Lagged DV / 77

3-6: OLS Estimates of Senate Committee Productivity with Lagged DV / 77

\section{Chapter 4}

4-1: Negative Binomial Models of Changes Originating from Appropriations Bills / 103

4-2: Negative Binomial Models of Pages Variable / 110

\section{Appendixes}

2-1: Coding Instructions / 129

2-2: Agreement Between Subtopic Coders / 131

2-3: List of Topic Codes Excluded from Chapter 2 / 132

2-4: Two-Tailed Seemingly Unrelated Regression Estimates of Polarization and Beneficiaries / 135

3-1: List of House Committees / 136

3-2: List of Senate Committees / 137

3-4: Two-tailed OLS Estimates of Committee Productivity in the House / 139

3-5: Two-tailed OLS Estimates of Committee Productivity in the Senate / 140

3-6: Negative Binomial Estimates of Indicators of Productivity in the House / 141

3-7: Negative Binomial Estimates of Indicators of Productivity in the Senate / 142

3-8: OLS Estimates of House Committee Productivity with Lagged DV and Time / 143

3-9: OLS Estimates of Senate Committee Productivity with Lagged DV and Time / 144

4-1: Two-Tailed Negative Binomial Estimates of Changes Originating from Appropriations

Bills / 145

4-2: Negative Binomial Estimates of Changes Originating from Appropriations Bills with Time Dummy / 146

4-3: Negative Binomial Models of Changes without Debt Interaction / 147 


\section{List of Figures}

\section{Chapter 1}

1-1: DW-NOMINATE Distance Between Party Means / 13

\section{Chapter 2}

2-1: Frequency of Public Law Passage by Beneficiary / 34

2-2: Proportion of Public Law Passage by Beneficiary / 35

2-3: Proportion of Seats Needed for Party Majority / 38

2-4: Proportion of Generalized Policy by Polarization / 43

\section{Chapter 3}

3-1: Total Legislative Hearings in Standing Committees / 61

3-2: Total Days in Committee Hearings / 63

3-3: Total Bills Reported from Committees / 65

3-4: Committee Productivity Over Time in the House / 67

3-5: Committee Productivity Over Time in the Senate / 68

3-6: House Productivity as a Function of Polarization / 73

3-7: Senate Productivity as a Function of Polarization / 74

\section{Chapter 4}

4-1: Dependent Variables - Code Changes and Page Range / 97

4-2: Changes to the Code as a Function of Polarization / 104

4-3: Effect of Divided Government on Code Changes / 106

4-4: Predictive Margins of Debt Interaction with 95\% CIs / 108

\section{Appendixes}

1-1: Combined DW-NOMINATE Distance Between Party Means / 128

3-3: Productivity of Congressional Committees / 138 


\section{Chapter 1: Introduction}

In the United States Congress, the Democratic Party and the Republican Party have become ideologically distant from each other. These two powerful political entities, which have become central to the American system of policymaking, are increasingly divided in their policy preferences (McCarty, Poole, and Rosenthal 2006; McCarty 2019). With these divisions, members of Congress oppose each other not only on core issues that are central to their party, but also on valence issues that have little substantive content (Lee 2009, 2015). While there have been times in American history in which partisanship was low, in the modern day, gridlock and inaction appear to have become the norm (Barber and McCarty 2015; Binder 1999, 2003; Jacobson 2013).

In this dissertation I ask: how does political polarization affect the productivity of the United States Congress? Do increases in polarization disrupt Congress's ability to create and pass policy? Further, if high polarization leads to disagreement on even the simplest of policy proposals, how does Congress circumvent gridlock in such an environment? These are not new questions, as scholars have written of the effects of polarization for decades. Importantly, research has shown that as polarization has increased, the productivity of Congress has fallen (e.g., Binder 1999; Jones 2001). Evidence suggests that Congress passes less total policy of substance during sessions with high polarization (McCarty 2007), and that it struggles to address major policy issues as they appear (Lapinski 2008).

My work contributes to this literature by examining gaps within our understanding of how polarization affects the legislative process. First, I ask if polarization influences the kind of policy that Congress is able to pass, and whether policy choices are limited during sessions with high polarization. If polarization decreases Congressional productivity, does it affect the passage 
of different types of policy at different rates? Is Congress hindered in its ability to target particularized groups for policy benefits when polarization is high? Further, if polarization is reducing the productivity of Congress, does this reduction occur at all stages of the policymaking process? Is the regular order of congressional committees affected, and have they experienced the same decrease in productivity as their parent chambers?

Finally, when parties are polarized and gridlock is high, does this affect the methods that Congress employs to pass policy? If members cannot achieve their policy goals through traditional means of legislating, do they pursue other methods outside of the normal policy process? There is evidence that during times of high polarization, Congress increasingly turns to unorthodox methods of lawmaking to accomplish its policy goals (Sinclair 2016). One such method is the usage of riders attached to bills, which is increasing in frequency (Casas, Denny, and Wilkerson 2020). Given the "must pass" nature of appropriations policy, such bills are attractive targets for unrelated legislation. Is Congress more likely to attach unrelated legislation into appropriations bills when polarization is high? Does increased polarization increase the likelihood that Congress will utilize the appropriations process to enact substantive changes to the law?

I explore these questions within this dissertation, utilizing a variety of statistical methods to examine this relationship across time. I utilize originally collected data, including a new dataset that tallies the total number of changes made to the United States Code through the usage of appropriations bills. This work suggests that polarization is disrupting the regular order and productivity of Congress. It showcases and examines the ways in which Congress is limited in its policy choices, and the unusual methods that members must use to accomplish their policy goals, including the bundling of unrelated legislation into appropriations bills. I add to a growing 
literature that studies these changes in Congressional policymaking, and how they affect the manner in which Congress responds to policy issues.

\section{Polarization and Policymaking - The Literature So Far}

The following literature review creates the basis for the empirical analyses of the proceeding chapters. I begin by discussing the ways that polarization has been studied, and by defining which definition of polarization I will be using throughout this document. Then, I explore the existing literature, both as a survey of current scholarship, but also to highlight places in which further examination is warranted. Finally, I discuss my contributions to the literature, and preview my findings.

\section{Defining Polarization}

To discuss polarization, it is crucial to understand how it is conceptualized by political scientists, and to establish a working definition to be used in my own scholarship. McCarty (2019) lists several types of polarization that are typically used within political science. "Policy polarization", occurs when extreme views regarding specific policy decisions become commonplace. "Ideological polarization," occurs when the ideology of voters moves away from an ideological center and becomes more bimodal, with voters more likely to sort into one of two distinct ideologies. Further, "partisan polarization" is when the members of two parties (in this case the Democrats and Republicans) are ideologically distant from each other. We might also conceptualize polarization as "affective polarization", which is when partisanship becomes a social identity, and those who adopt it feel hostility for those with opposing identities. Additionally, McCarty makes a distinction between elite and mass polarization. Mass polarization is the polarization of citizens in the populace, and elite polarization is the 
polarization of those we might think of as highly involved in politics, such as elected officials, party leadership, or political activists.

In this dissertation I am interested in the polarization of elites, with a focus on members of the United States Congress. Specifically, I am interested in what McCarty (2019) would call partisan polarization, but I restrict my analysis, and hence the measures that I employ of this phenomenon, to members of Congress and to differences between aggregate indicators of polarization between Congress and the president. I choose to use DW-NOMINATE scores (Lewis et al. 2021) to measure this phenomenon, which are discussed later in this chapter. Differences between members, and institutions, using this indicator reflect both ideological disagreements about what government should be doing, and disagreements driven by partisan motivations to win elections that may have nothing to do with the role of government (Lee 2009). These scores are used as a measure of polarization throughout my work, as they capture both ideological and partisan conflict.

\section{The Causes and Historical Roots of Polarization}

Polarization is not a new phenomenon in American politics, though recent political polarization does have some distinct differences from earlier periods. Throughout history, Congress has experienced periods of divisiveness that have affected the policy-making process. Even from the inception of the United States as a nation, the founders feared the effects of political parties. As John Adams, second President of the United States once wrote: "There is nothing I dread So much, as a Division of the Republick into two great Parties, each arranged under its Leader, and concerting Measures in opposition to each other. This, in my humble Apprehension is to be dreaded as the greatest political Evil, under our Constitution" (Adams 1780). However, it did not take long for partisan division to occur. The first parties in the United 
States appeared early in the days of the republic, dividing between Federalists who supported the adoption of the Constitution and Anti-Federalists who were largely opposed to this adoption (Ryan 1971).

Since those early days, there have been numerous bitter ideological divides that have resulted in mass partisan realignments. One of the most memorable periods of polarization was the partisan divisions and political upheaval that led to the Civil War, and the ensuing changes to parties after the war (Kalmoe 2020). Strong partisanship led to a party revolt against the Speaker of the House Cannon in 1910, yet as Democrats began to ideologically diverge within their own party, voting along party lines began to decline (Cooper and Brady 1981). The 1950s and 60s were dominated by large bipartisan coalitions, and the most recent political realignment occurred during this time, beginning after the passage of Civil Rights Act of 1964, and the subsequent Voting Rights Act of 1965. Democrats had been dominating elections in the southern states, though these representatives were more likely to align with a conservative ideology (Schaffner 2011). Slowly, conservative members began to side with Republicans while more liberal Democrats had been increasing in number throughout the 1950's and 1960's, leading to further ideological splits within the Party. Democrats in the North found themselves both at odds not only with Republicans, but with many members of their own party representing districts in the South. Divided on issues of racial equality, southern conservative Democrats began to leave the party to join the Republicans. (Rohde 1991). The aftermath of this "southern realignment" left the political landscape with better sorted and more ideologically homogenous parties (Jacobson 2000, 2013; Lee 2015).

Typically, these realignments are gradual, taking place over many years (Mayhew 2002). Yet, what causes this sorting? McCarty (2019) suggests two mechanisms in which partisans can 
sort in their views. Voters new to the electorate may choose to join a party if their ideology aligns with the party's platform. Such voters would have a preference on an issue, and then join the party that best aligns with their own views. Alternatively, it is possible that those who have already joined parties simply adopt the positions that the overall party does, especially if they do not have strong political opinions to begin with. In this way, they self-select into parties that represent them, and then allow the parties to fill in the gaps in their ideology. Either way, once people sort into parties, they frequently see the world through the lens of that party (Campbell, Converse, Miller, and Stokes 1960) and over time, switching out of that party becomes relatively rare (Green, Palmquist, and Shickler 2002).

Most scholars of American politics agree that the opinions and ideology of political elites have become increasingly polarized (Barber and McCarty 2015; Hetherington 2001; Jacobson 2013; Lee 2009, 2015; McCarty, Poole, and Rosenthal 2006). Yet there is disagreement among scholars regarding the polarization of the electorate. Partisan sorting undoubtedly created party cohesion, but did it create political polarization? As Frances Lee $(2012,2015)$ notes, this does not necessarily mean that liberals and conservatives became ideologically distant—only that they made parties become more distinct. Fiorina, Abrams, and Pope (2005) claim that ideological divides in the populace are not as stark as they are often portrayed, and that most of this ideological movement is occurring among those who are highly involved in politics. Voting tells us little about how individuals feel, only who they choose to vote for. These authors theorize that our conception of "red states" and "blue states" is flawed, and that these are only representations of which ideological direction in which voters cast ballots.

Abromowitz and Saunders (2008) take issue with the methodology used by Fiorina and his colleagues, demonstrating that partisan division is increasing in both the populace and in 
elites, and has been on a steady climb since the 1970s. Jacobson (2000) writes that the electorate began to polarize not just in the South, but also throughout the entire country. Han and Brady (2007) note that the low levels of partisanship and polarization in the 1950's and 1960's were an anomaly, and that throughout history, parties may have always trended toward polarization. As party priorities shifted and became clearer, some members of Congress were trapped between the cross pressures of the changing ideologies of their parties and their constituencies, behooving them to act more moderately. As those members retired, they were replaced with others who were more likely to vote closer to the ideology of their constituents, leading to the increasing partisanship (and return to normalcy) of the late 1970s and beyond. Further, Abromowitz (2010) notes that individuals who are most likely to participate in politics are those who are the most likely to take extreme positions, meaning that as engagement in politics increases, so too should polarization. These extremists are more likely to vote for further extremists, affecting both mass and elite polarization. While it may appear that there is a large middle-ground between the parties, much of this is due to voters who are uninterested in politics and have not formed concrete opinions. Finally, Mason (2015) notes that sorting has only increased the strength of political identities, further polarizing the political behavior of the public.

I study the behavior of political elites (specifically members of Congress) in chapters 2 through 4. Does it matter to the study of these elites if the public is polarized as well? Theriault (2008) suggests an important link between the polarization of the masses and the elites: voters are driving the polarization of their elected representatives, who in turn become more polarized and give more power to political leaders. Those leaders are then more likely to change the institutional structure of Congress to suit more partisan goals, which further spurs partisan division. Conversely, Barber and McCarty (2015) suggest a different relationship. Voters could 
theoretically sort themselves into parties based on cues from elite polarization. This would create less incentives for parties to take positions that would be appealing to their opponents, which would lead to greater partisan polarization, and further incentives for voters to sort. Essentially, mass polarization has the potential to affect the polarization of elites, and vice versa.

What does this mean for the central themes and questions of this dissertation? For one, I make the assumption that polarization is occurring at both the elite and mass level. If voters are largely polarized, then we should expect that they would vote for and elect candidates who share their ideological preferences. Jacobson $(2000,2013)$ notes that since the 1970s, voters have been splitting their tickets less, and becoming increasingly loyal to their chosen political party.

Additionally, Wolf, Strachan, and Shea (2012) suggest that once these candidates are elected, voters have little desire for their chosen representative to compromise with the opposing party on issues central to their ideologies. Members also have apprehension about publicly compromising with their rivals, lest they face retribution from the voting constituents that elected them.

It appears that there are few electoral incentives to cooperate with the opposing party. In this way, the polarization of the public has a direct effect on the polarization of Congress and the likelihood of legislators to compromise (Boatright 2013). In a system that requires concessions to produce legislation, what happens to policy outcomes when both the public and elites do not wish to find common ground with their opponents? This changes the dynamics of the policymaking process and affects the legislative capabilities of Congress.

\section{Polarization and the Regular Order of Congress}

In the study of Congress, polarization is frequently cited as a leading cause for noted decreases in legislative productivity. In numerous studies, Sarah Binder (1999, 2003, 2015) 
demonstrates that as polarization increases, Congress is more likely to experience gridlock, as well as less likely to produce policy (or respond to issues as they arise). Other scholars mirror these findings. Jones (2001) finds that high levels of polarization increase the likelihood that gridlock will occur, though this is mitigated if parties have large enough majorities to surpass potential vetoes and filibusters. Increasing polarization leads to Congress not only passing less policy, but also less policy of importance (McCarty 2007) and appears to be hampering the ability of Congress to address major policy issues (Lapinski 2008). One example of this is in the work of McCarty, Poole, and Rosenthal (2006), who claim that elites are becoming more polarized and less likely to move policy away from the status quo, pointing to income inequality as a source of this division. As more affluent Americans gain more control over the policy process (and become more firmly conservative in the aggregate), Congress becomes less likely to pass policy that might address income inequality. This creates what they call a "policy paralysis" that makes lawmaking difficult, especially regarding attempts to move away from the status quo.

The tactics that parties employ have changed as well. Sinclair (2006) notes that filibusters and cloture votes have increased, which indicates that the minority parties are more willing to use procedural tools to keep the majority party from accomplishing its goals. Smith (2014) notes that this is especially prominent in the Senate, and when the minority party uses these tactics, it spurs changes by the majority to mitigate gridlock. Changes by the majority spur further retaliation from the minority party, which creates further obstruction in a cycle of policy inaction. For example, high polarization makes judicial nominations by the president problematic. Nominees are less likely to be considered by the Senate at all (Goldman 2003; Binder and Maltzman 2005), and senators are more likely to delay nominations if such appointments would benefit their opponents (McCarty and Razaghian 1999; Bond, Fleisher, 
Krutz 2009). When confirmation hearings do occur, they are more likely to become contentious, and the questions that senators ask nominees have taken a more negative tone (Williams and Baum 2006). This negativity is not restricted to confirmation hearings, as even the civility of floor speeches has declined as polarization increases (Jamieson and Falk 2000). In short, it appears that in many ways, polarization is disrupting the normal policymaking process in Congress.

\section{Measuring Polarization}

If we assume that polarization is occurring and is measurable, the question becomes which metric best captures the concept. McCarty (2019) writes at length on the subject, noting that the measurement of polarization, particularly at the elite level, often relies on the usage of roll-call votes in Congress. One of the oldest and easiest ways to measure polarization is to total the number of party votes (those in which the majority of a party votes against the majority of another). These voting totals are publicly available and easy to collect, yet have inherent limitations, as they do not allow for an understanding of how much individual members contribute to polarization. For this reason, the discipline shifted to utilizing ideology scores created by interest groups as a proxy of polarization. These ratings are created by interest groups that measure the number of times that individual members of Congress voted in favor of their agenda. Again, these measures had methodological flaws that produced unsatisfying results. The small number of votes used to create scores leads to a lack of variation between legislators, the scores are unreliable when used longitudinally, and they may overstate the amount of polarization due to which votes are chosen.

Perhaps the most important development in this measurement comes from Keith Poole and Howard Rosenthal (1984). In their work they developed a measure called "Nominal Three- 
Step Estimation," or as it is commonly referred to, NOMINATE. These scores are again created using roll-call votes in Congress, but their measurement is more sophisticated. First, they assume that the ideological beliefs of members can be mapped onto a two-dimensional plane, ranging from liberal to conservative. On this plane, all members have an ideal point that coincides with their ideology. These ideal points are calculated through the usage of an algorithm that accounts for the multitude of times in which members vote over the course of their careers. How members vote is compared against each other, so if members vote similarly, they are calculated to have similar ideal points. This allows for the estimation of the distance between members on that plane, so that researchers can quantify how ideologically similar or distinct two different members of Congress are. Taking this a step further, this allows for the aggregation of ideal points to understand how liberal or conservative a particular session of Congress was, or the variation in the distance between two political parties when their members are averaged together.

The measure has changed numerous times since it was created, with the most recent (and perhaps most commonly used) version being called Dynamic Weighted Nominal Three-Step Estimation, or DW-NOMINATE (McCarty, Poole, and Rosenthal 1997; Poole and Rosenthal 1997, 2006). These scores are commonly used to measure polarization in the discipline, and the merits of the measure are numerous. Lee $(2009,2015)$ notes that a benefit of these measures is that they correlate well with other measures of political ideology. For example, interest group scorecards highly correlate with estimates from DW-NOMINATE scores, even though such scores are generally focused on specific issues that particular interest groups care about, and only utilize a small number of votes to generate scores. Further, the measure is calculated from freely available data, and allows for meaningful comparisons over time. With such a measure, one can assess the voting habits of members across a variety of issues and generate estimates that are 
consistent throughout their entire careers in Congress. The flexibility of the scores also allows for aggregation for the measurement of political parties, the ideology of the House and Senate, or Congress as a whole. In the analyses of this dissertation, I choose to measure polarization by using first-dimension DW-NOMINATE scores. ${ }^{1}$ Specifically, I calculate the difference between the mean among Democratic members, and the mean among Republican members in both the House and Senate. This allows me to quantify how ideologically distant the two parties have become over time, and to measure variation in this distance across Congressional sessions.

In Figure 1-1, this variable is displayed over time for both the House and Senate, ranging from the 46th Congress to the 116 th (1879 to 2019). ${ }^{2}$ By these metrics, one can see that Congress was once polarized, but then the ideological distance between parties decreased for many sessions. Then, as the literature has mentioned, we can see an increase in polarization that begins a steady climb, culminating in the highest recorded levels in the 115th Congress. Note that the House and Senate follow similar trends, which is unsurprising. ${ }^{3}$ While the Senate was often seen to be more resistant to partisan affairs, empirical evidence shows that the chamber has become just as polarized as the House, and perhaps always was (Han and Brady 2007; Theriault and Rohde 2011).

\footnotetext{
${ }^{1}$ Note that there are two dimensions to Poole and Rosenthal's metric, but here I only use first-dimension scores. This is because the second dimension is typically used for votes that do not map well onto a single dimension; typically votes involving race. However, the utility of the second dimension has waned over time, and so most voting behavior can be explained using the first dimension. As Lee (2015) notes, the first dimension is a strong indicator of member behavior across issues, and across time.

${ }^{2}$ These sessions include the full range of data made available by Lewis et al. (2021). These sessions begin directly after the end of the Civil War, and end in 2019, providing a large range by which to examine polarization over time. ${ }^{3}$ A figure displaying the mean of the scores for both the House and Senate together is available in Appendix 1-1.
} 


\section{Figure 1-1: DW-NOMINATE Distance Between Party Means 46th to 116 th Congress (1879 to 2019)}

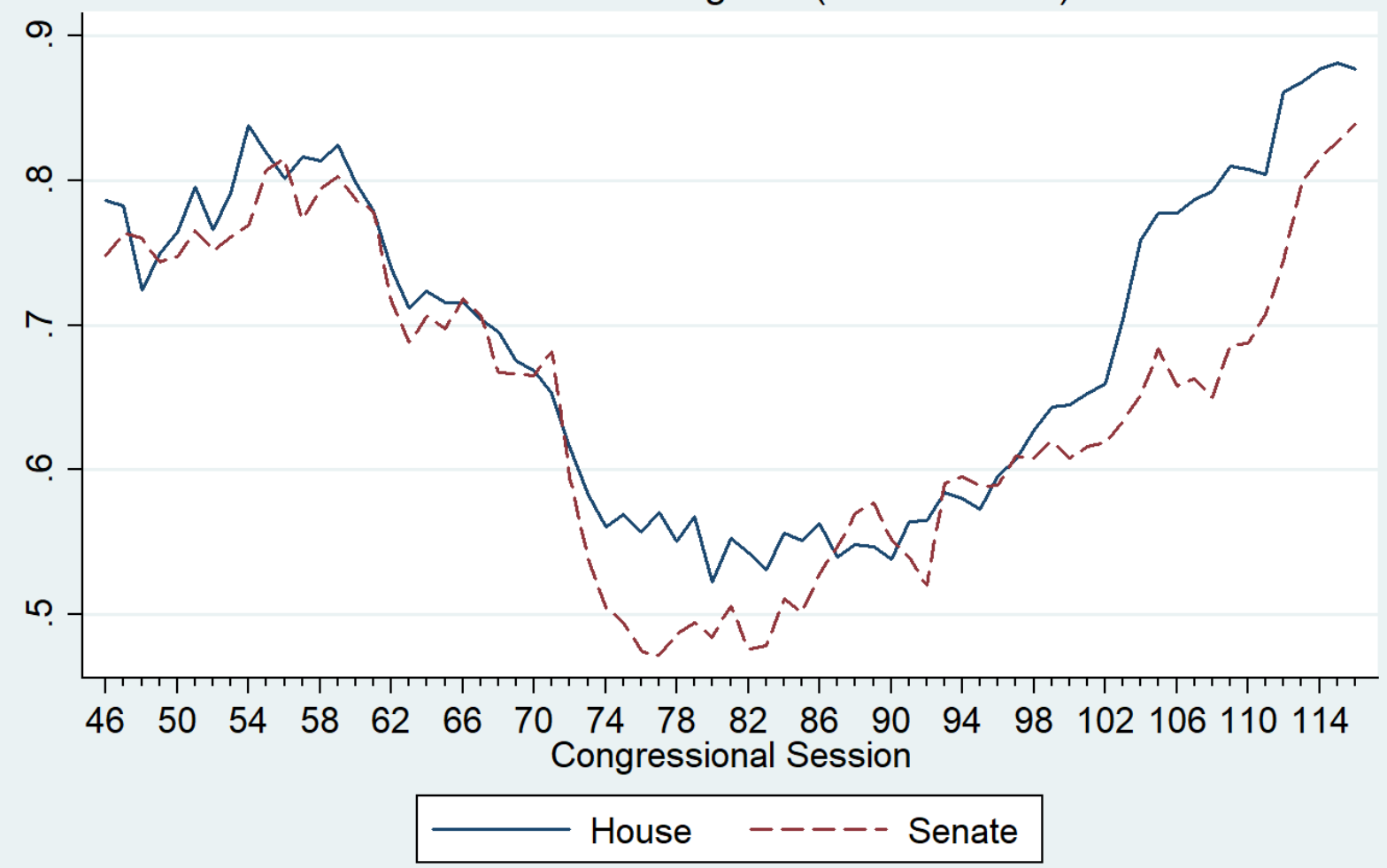

\section{Limitations of DW-NOMINATE}

It is vital to address criticisms directed at DW-NOMINATE before moving forward.

Perhaps the most significant criticism is one of the measure's validity. Specifically, can we truly understand member ideology through voting patterns? As Persily (2015: 6) notes, just because members are numerically further apart in this space does not necessarily mean that they feel any differently about these issues. We as researchers are unable to discern what causes a member to vote in a particular way, and we can only draw inferences. Did they assess the bill, and then vote based on their personal ideology? Did their constituents pressure them to vote in a specific manner? Were their votes made for strategic reasons? Did their party sway them toward a more moderate or extreme position? 
Some authors conceptualize these partisan divisions differently, such as Krehbiel (1991) and Bolton (2020), who utilize gridlock intervals in their work. ${ }^{4}$ These scores are created by measuring the absolute distance between filibuster and veto pivots in the House and Senate, while also adjusting for the president's party affiliation. Others in the discipline have attempted to find suitable replacements. One instance is the work of David Jones (2001), who quantifies polarization by measuring the percentage of Democrats and Republicans that vote "yea" on individual measures, which allows for comparison across specific issues. Yet as Schaffner (2011) argues, there is not a comparable option that is better than what DW-NOMINATE provides. Voting data from which the scores are created is publicly available and is consistent across history. He argues that some have tried to create measures to replace DW-NOMINATE but that comparatively, the amount of research into these alternatives has been significantly less. Similarly, McCarty (2016) argues that many of the suggested alternatives are impractical, and that most of the issues that authors have noted could be resolved with a correct application of the scores.

I believe that the benefits of using DW-NOMINATE outweigh the disadvantages. One of the goals of this dissertation is to examine the effect of polarization on legislative outcomes. Does it matter how members feel about an issue if it doesn't change their vote? Perhaps for definitional purposes it would, for we may not be accurately measuring polarization as intended. Yet for practical purposes, it may matter less. What is important is that we as researchers are aware of the limitations and keep them in mind when examining these statistical relationships. There are very few models in the world that accurately capture the phenomenon that we wish

\footnotetext{
${ }^{4}$ I use Bolton's (2020) variant of these gridlock intervals as a robustness check in the models presented in Chapter 4.
} 
them to. As Binder (2003: 30) reminds us: "Models simplify the world as we know it. They place a few themes in relief, excluding countless others." 5

To summarize, I first make the assumption that partisan polarization is occurring, and that polarization is quantifiable at the elite level. I chose DW-NOMINATE scores as the best way to measure polarization that is available for my research, as it allows for meaningful comparisons across time. Given these assumptions, where does my work fall within the discipline? While many scholars have addressed this phenomenon, there are still several questions in the literature that remain unanswered. Below, I discuss the basic logic and framework for Chapters 2, 3, and 4. I focus on areas in which there is still more to learn about the relationship between polarization and Congressional productivity and explore new ways of assessing how ideological division can affect policy outcomes.

\section{Chapter 2 - Polarization, Agenda-Setting, and Policy Beneficiaries}

For a bill to make it through the policy process and be signed into law, numerous choices and compromises must be made. Yet Congress is limited in how much time can be devoted to its discretionary agenda (Walker 1977), and the institutional structure of the legislative branch can make changes to the status quo difficult (Baumgartner and Jones 2009). What policy proposals make it onto the legislative agenda is wholly up to those elected to Congress, but parties are assuming a larger share of agenda control (Cox and McCubbins 2005). Does a polarized policy environment restrict the policy choices that Congress is able to make? Put another way, does

\footnotetext{
${ }^{5}$ Binder uses DW-NOMINATE scores to measure polarization, though she conceptualizes it differently than I do in the proceeding chapters. In her work, she records the percentage of members in the House and Senate who are closer to the ideological center of the chamber, rather than the ideological center of their party. While these are still derived from DW-NOMINATE scores, they utilize a different metric for measurement, with the notion that low numbers of moderates are indicative of high polarization. For this reason, I use the proportion of moderates in Congress as a robustness check in several of my models.
} 
polarization affect the type of policy that Congress is able to propose, debate, and ultimately pass? There is limited research that examines Congressional productivity through this lens, though some authors have found that, for example, issues regarding economics are more polarizing than others, and take up more agenda time (Bartels 2006; Lee 2008; McCarty, Poole, and Rosenthal 2006).

In Chapter 2, I theorize that polarization is a strong predictor of which kinds of policy Congress can pass, and that Congress is limited in its ability to pass bills with particularized constituencies. First, Members of Congress have incentives to provide policy benefits to the general public if they wish to be reelected (Adler and Wilkerson 2013). Also, as Hopkins (2018, 2019) notes, parties are slowly shifting their platforms to address more nationalized concerns from the populace. As political discourse becomes more focused on issues with wide-ranging constituencies, members face increasing pressure to deal with issues that have broad appeal. As such, I anticipate that as polarization increases, Congress will pass less bills that have overtly particularized beneficiaries. There is substantial evidence to suggest that polarization affects legislative outcomes and productivity. However, I argue that policy is not created equally, and that the topic and intended beneficiary of a bill can affect the outcome of its passage. If so, when polarization is high, then Congress is not only restricted in the amount of policy that it is able to pass, but also what kinds of policy it is able to enact as well. Thus, there is a need for researchers to disaggregate policy if they wish to have a clearer picture of the policymaking process. Additionally, it speaks to the increasing difficulty for Congress to disperse targeted benefits when necessary, and the priorities of party leadership who must attend to an increasingly nationalized political environment.

\section{Chapter 3 - Polarization and Congressional Committee Productivity}


Polarization has been shown to have a negative effect on Congressional productivity, but most studies that examine this dynamic focus on the end of the process (such as the total number of laws passed each session). Yet we know that policy is filtered through various veto points where it can stall. Bills can be further altered and changed throughout the process, creating avenues for division. Given the current state of political parties, and their desire to oppose each other when possible, I ask, how has this division affected policymaking institutions within Congress? In Chapter 3, I focus on one important stage in this process: the committee system.

While congressional committees began mostly as ad-hoc affairs, they had become quite robust and influential in the aftermath of the Civil War (Wilson 1885). Committees were seen to be quite powerful, and had significant autonomy in the policymaking process, with broad influence over the fate of policy under their purview (Young and Heitshusen 2003). Yet several changes to the structure of committees were made by congressional leadership that reduced this coveted autonomy (Aldrich, Perry, and Rohde 2013, Rohde 1991), and control of committees began to shift toward parties and their leadership (Aldrich and Rohde 2000). Committee hearings became open to the public, and committees with more salient topics faced stricter party control (Maltzman 1997).

How have these changes affected the ability of committees to perform their legislative duties? Sinclair (2006) notes that committee hearings are becoming increasingly partisan affairs and have become forums for debate. Compromise is less frequent, and party leaders think strategically regarding their membership to ensure that party goals are accomplished. Others note that ideological extremists are more likely to be appointed as committee chairs (Young and Heitshusen 2003, Becker and Moscardelli 2008), reducing the likelihood that committees will deviate from the preferences of party leadership. These, among other reasons, suggests that 
committees have become an arm of parties, and may be subject to partisan infighting and dilatory tactics that often accompany more polarized sessions. If committees are still addressing bills within their jurisdiction, then we might imagine that they are more resistant to the effects of ideological polarization that have hindered their parent chambers. Conversely, it may be that committees are unwilling (or unable) to remain as productive as they once were, suggesting that they are sheltered from the effects of polarization.

I theorize that polarization is affecting committee productivity, and that as polarization increases, productivity within committees will decrease. Given the growing control over the committee system by party leaders, and the ensuing gridlock that accompanies partisan polarization, I theorize that committees will not be sheltered from the diminishing output that their parent chambers are experiencing. Further, I argue that understanding committee productivity, and the role that polarization plays in it, is crucial to understanding the productivity of Congress as a whole. Committees are often where the heavy lifting of policymaking occurs, and their structure allows Congress to not only manage a larger workload (Deering and Smith 1997), but also to generate policy expertise that can be useful in the creation of legislation (Krehbiel 1991, Maltzman 1998). If the productivity of these committees is declining, and party leadership is taking a greater role in this process, we should expect that such changes would have implications for the amount of policy that they can produce. This research allows for a greater understanding of whether committees still maintain the power that they once did, and what role they continue to play in legislative outcomes in Congress.

\section{Chapter 4 - Polarization and Appropriation Riders}

As mentioned above, as polarization increases, members of Congress struggle to accomplish their policy goals. To circumvent gridlock, unorthodox methods of passing policy are 
becoming increasingly common (Sinclair 2016). In Chapter 4, I examine one such method, which is the addition of legislative riders to appropriations bills. As committees have come further under party control, the appropriations committee has not been spared from increased party oversight. In particular, the 104th Congress saw major changes under the direction of Speaker of the House Newt Gingrich, who targeted the appropriations process as a means by which to advance the Republican party's interests (Aldrich, Perry, and Rohde 2013; Aldrich and Rohde 2000). Once this shift was made, the appropriations process became an avenue in which unrelated policy could be passed, but also opened the door for partisan conflict to occur.

Appropriations bills have become progressively more difficult to pass, and as polarization increases, these bills take longer to produce (Woon and Anderson 2012) and are more likely to be lumped into omnibus bills (Sinclair 2012). Such bills become dense, which makes it easier to hide unrelated legislation within. Additionally, due to the importance of appropriations bills, this tactic can be used to circumvent a sitting president's preferences, increasing the likelihood that unrelated provisions would be signed into law. I theorize that political polarization is increasing the likelihood for members of Congress to use the appropriations process to pass unrelated policy. As the appropriations process has become more open to partisan control, these bills are attractive vehicles for enacting policies to change the status quo, and can be a means by which to bypass the preferences of the president when under divided government.

These legislative tactics generate questions of transparency and accountability regarding the policymaking process. Following the actions of the legislative branch can often be problematic for even the most politically engaged citizens. When unrelated riders are placed within large appropriations bills, it is difficult to track what legislation is being passed and when. Yet there are benefits to using these bills, and they can be a powerful tool to pressure political 
opponents, or a convenient way to obfuscate legislative compromises. However, the additional weight that these bills carry is a double-edged sword. As these riders increase in frequency, so too do appropriations bills become the subject of legislative gridlock, leading to increases in the frequency of government shutdowns. As appropriations bills are used to fund the government's expenditures, any lapse in funding could shut off programs that millions depend upon. Therefore, examining these bills allows us to better understand how members of Congress can still accomplish their legislative goals in a highly polarized environment, albeit through unconventional (and potentially risky) means.

\section{$\underline{\text { A Preview of Findings and Conclusion }}$}

In Chapter 2 my findings show that polarization is a significant predictor of the type of legislation that Congress will pass, and importantly, that polarization affects the passage of different types of policy at different rates. Looking to Arnold's (1990) work, I sort all passed bills in Congress into three categories based on who the bills intended targets are: generalized, group, and geographic. I find that as polarization increases, the proportion of bills with generalized beneficiaries also increases, and subsequently, the proportion of group and geographic bills decreases. Yet when utilizing simple frequency counts, the results tell a different story. Generalized policy is increasing in proportion but has remained relatively stable in frequency of passage. Conversely, the frequency by which Congress passes bills with particularized beneficiaries has decreased substantially, suggesting that Congress is limited in its capacity to pass particularized policy as polarization increases. Interestingly, a variable for

electoral competition was hypothesized to produce a similar effect on this process, but had mixed effects, with results suggesting that increases in competition lead to increases in the amount of policy passed targeting geographic areas. These results require further examination, perhaps with 
a coding scheme that disaggregates bills in a more granular way than the methodology utilized in the chapter.

In Chapter 3 I turn my attention to the effect of polarization on the productivity of committees. I estimate a factor score representing committee productivity using multiple indicators: the number of hearings standing committees held on legislative topics, the number of days that committees spent in those hearings, and the number of bills reported out of committees. I find that as polarization increases, overall productivity decreases within committees. The results are similar in both the House and Senate, though the effects appear to be much more pronounced in the Senate. While the models could benefit from the addition of further indicators of productivity, I add evidence to a growing literature suggesting that committees are no longer as productive as they once were, and provide evidence that polarization is affecting the ability for committees to perform their legislative duties.

Chapter 4 examines how Congress uses the yearly appropriations process as an alternative method of passing legislation to circumvent legislative gridlock. Utilizing a new dataset that tallies changes made to the United States Code, I find that as polarization increases, Congress is more likely to use appropriations bills to make substantive changes to the law. Further, in sessions in which the government is both highly polarized and fully divided (both the House and Senate are controlled by one party, and the presidency is held by its rivals), Congress is more likely to use this process to bypass the policy preferences of the president. The findings showcase the lengths that Congress must undertake in order to pass policy in highly polarized sessions.

As Congress becomes increasingly gridlocked, and struggles to pass meaningful policy, there is still more that we can learn regarding how polarization affects this process. This 
dissertation examines several ways in which polarization is disrupting the regular order of Congress and the creation of policy. The results of my analyses highlight different aspects of how the policymaking process has been affected by polarization. They suggest that polarization and gridlock limit the kinds of policy that Congress is able to pass, that it affects the productivity of committees, and encourages members to accomplish their policy goals through means outside of normal lawmaking process. My work contributes to the greater literature regarding the productivity of Congress and demonstrates with quantitative methods that polarization is having a negative effect on the regular order of the legislative branch in ways that scholars had not previously recognized. Finally, it provides new avenues to further understand Congressional productivity in the future. These insights allow for a clearer view of the ways that Congress has become gridlocked, and the methods by which it can still pass policy within a highly polarized environment. 


\section{Chapter 2: Polarization and Policy Beneficiaries}

\section{$\underline{\text { Introduction }}$}

In a highly polarized political climate, the passage of policy in the United States

Congress can be a difficult and costly task. As polarization has increased, so too has gridlock and Congressional inaction (Binder 1999, 2003). In such a policy environment, what happens to the content of the bills that make it through the legislative process? The attention of members is a limited resource (Jones and Baumgartner 2005), and the creation of bills is a costly exercise (Wawro 2000). As such, members often concern themselves with policy that can make it through the process at all (Sinclair 2006). When opportunities are restricted, members must address the issues that they are able, if they wish to make progress in any policy arena. As the German Chancellor Otto Von Bismark once said: "Politics is the art of the possible, the attainable — the art of the next best" (Bismark 1895: 248). In Congress, "the possible" is rooted in the national policy priorities of parties. As the political climate in the Unites States has changed, parties have pushed for unified policy platforms to address increasingly nationalized issues (Hopkins 2018). Yet when Congress is increasingly focused on the national priorities of parties, this limits its capability to address more particularized issues. I theorize that polarization exacerbates this relationship, making it difficult for Congress to pass bills that do not have broad constituencies.

In this chapter I ask: why are certain types of policy passed? In Arnold's (1990) work, he theorizes that bills can be sorted into categories based on their beneficiaries, with bills falling into generalized, group, and geographic categories. Generalized bills are conceptualized as those that provide benefits to all (or most) of society, while group and geographic bills apply to a nonrandom collection of beneficiaries based on their characteristics and geographic locations, respectively. Does polarization affect how much policy that Congress passes that have 
particularized beneficiaries, or does polarization affect the passage of all types of policy equally? Using Arnold's theory, I create a measurement strategy to answer these questions, and make an argument for its validity while also documenting its reliability. I also argue that the examination of this relationship is important to understanding the productivity of Congress as a whole. Congress is often labeled as being unproductive, but if only certain types of policy are declining in amount of passage, then we as researchers can further understand the effects of polarization on policymaking at a more granular level.

\section{Congressional Agendas and Policy Beneficiaries}

Broadly, the focus of this chapter could be distilled into a few simple questions: Does political polarization restrict the kind of policy that Congress is able to pass? Does polarization limit Congress's ability to pass policy that benefits particularized beneficiaries? To answer these questions requires an understanding of how issues make it onto the Congressional agenda, and how various factors influence which issues Congress is able to address. To begin, there is a plethora of actors inside and outside of the legislative branch that can affect the policymaking process and that compete for Congress's attention. Wolfe (2012) shows that the media can sometimes focus attention on issues, using selective filtering in ways that can either speed up or slow down the policymaking process. The president influences this agenda, leveraging power and choosing which policies to champion (Eshbaugh-Soha 2005). The public can influence the agenda through electoral mandates, be they perceived or otherwise (Peterson et al. 2003, Grossback et al. 2006). Interest groups can lobby Congress to address their preferred issues, or to keep items off the agenda (Bachrach and Baratz 1962). Sometimes Congress's choice of attention is not forced, and a focusing event (such as a natural disaster, for example) can hasten Congress to address an issue that it had previously unforeseen (Birkland 1998). With these, and 
various other pressures that are influencing the policy agenda, it can be a difficult task for Congress to choose where to focus its policymaking efforts.

These choices are not made in a vacuum, and Congress does not simply choose which issues to champion in an arbitrary manner. Even the simplest act of policy change requires a great amount of effort at all stages of the policymaking process if such a change is to succeed. Baumgartner and Jones (2009) conceptualize policymaking as choices between the status quo, and proposals to alter the status quo, with interest groups often forming distinct camps depending on whether they are promoting change or if they wish for policy to remain the same. As alterations to the status quo can be a difficult task, and policymaking often favors the stability of current policy, in most cases it is significantly easier to just leave things as they are. Thus, to make substantive changes to the law, we should expect that doing so would require a substantial amount of focus and effort.

Political parties can be both a boon and a hindrance to this process and possess profound influence over what issues are able to receive consideration in Congress. Cox and McCubbins (2005) show that parties in Congress have the power to not only control the agenda, but with a large enough majority, can alter the rules of the chamber to further party goals. All who belong to a party are assumed to benefit from this agenda control, and so to ensure that their goals get enacted, they vest power in their leaders. These leaders can then further shape the agenda, advancing the goals of their party, and using negative power to keep items off the agenda that could potentially benefit opponents. This perspective has been updated and expanded in other research on agenda control, demonstrating that there are few differences in the frequency of negative agenda control in the House and Senate (Jenkins and Gailmard 2007), and that 
leadership often rewards members for sticking with their party even when it damages their personal policy interests (Jenkins and Monroe 2012).

Given the control of parties over the agenda, and their tendency to oppose one another, how does political polarization affect this process? On the other side of policy development, Sarah Binder $(1999,2003)$ shows that as polarization increases, so does gridlock in Congress, which leads to a decrease in the volume of problems that are addressed through legislation. Evidence also suggests that Congress passes less policy of importance during sessions with high polarization (McCarty 2007) and struggles to address major policy issues (Lapinksi 2008). Much of this is attributed to a culture of political tribalism, where if a member of a party wants to achieve a policy goal, there are incentives for the opposing party to hinder the majority's ability to do so at every step of the policy process (Sinclair 2006). As Lee (2009) discusses, this division has expanded to include not just major policy topics, but even issues that do not have overt ideological underpinnings.

With these ideological divisions also come a shift in the attention and priorities of parties, and issues that were once politically feasible, may no longer be. Over time, the collective political climate in the United States has become concerned less with local politics, and more with national issues. According to Hopkins (2018), there are several reasons for this change. Americans are increasingly focused on media that can arrive instantaneously and is nationalized in scope, and as the voting population shifts in attention, candidates for state-wide races are increasingly echoing the policy priorities of national level parties. Hopkins again echoes that polarization is one such cause for this occurrence, and those who belong to political parties are becoming better sorted into parties that match their ideologies. This is creating a focus on unified party platforms, that are dominated by national party dialogue. He writes: "As the national 
parties have staked out increasingly clear and distinctive ideologies, the state parties and their candidates have less room to craft their own brands" (228).

Given that polarization is increasing, and that the priorities of parties are becoming more nationalized, how does this affect the kind of policy that makes it onto the agenda, and is subsequently passed into law? Walker (1977) argues that Congress is restricted in how much discretionary agenda it has, as the bulk of what Congress focuses on are agenda items that it is required to address. Sinclair (2006) notes that the policy climate in Congress is less diverse in opinion and, in the aggregate, that Congress does not value passing policy of quality. Rather, legislators have begun to focus on finding any policy that can be passed at all in such a contentious policy environment.

This begs the question: how does polarization shape the purpose of laws? As Adler and Wilkerson (2013) show, Congress does try to solve problems, and as an institution there are strong incentives to solve the problems that the general public cares about. When the public has positive views of Congress and its ability to solve issues that the public is experiencing, representatives are more likely to get elected, and so it behooves them to pass such policy. Thus, we should expect that as polarization increases, Congress would be more likely to pass policy that benefits broad constituencies. To quote Hopkins again: “...in a highly nationalized political environment, politicians have strong incentives to fixate on issues that are resonant and evocative nationwide" (2019: 177-178). If the political conversation is becoming nationalized at all levels, then politicians have incentives to focus on policy that addresses wide-ranging issues.

Subsequently, these pressures would theoretically make the passage of particularized interests less politically feasible, leaving Congress with an ever-dwindling number of policy options that can make it through the highly gridlocked process. 
To summarize, in this chapter I am interested in explaining why Congress may be compelled to pass legislation that is beneficial to the country as a whole, at the expense of legislation that provides benefits to particularized interests or stakeholders. As discussed above, scholarship demonstrates that Congress has become highly polarized, with two national parties that are in conflict. This polarization hinders Congress's ability to enact laws in general. It is assumed that members want their parties to succeed in the policymaking process, so as polarization increases, members vest party leaders with further power (Rohde 1991). These leaders have an interest in passing policy that the general population cares about to ensure their party is reelected. Congress has difficulty in altering the status quo, so leaders must focus on the policies that will have broad appeal to ensure such policies are passed. For these reasons, I propose the polarization hypothesis:

Polarization Hypothesis: As polarization increases, Congress will pass a higher proportion of legislation that targets generalized beneficiaries.

Adding another layer to this dynamic, Lee (2016) notes that polarization is due in large part to competitiveness. She discusses how elections in the United States are becoming closer than in previous decades, and that control of Congress is more likely to shift as these elections become more competitive. When the margins of control are wide, partisan cooperation increases, as parties need to focus less on defeating opponents. In such times, it is expected that Democrats and Republicans would be more willing to work together, which would cause less gridlock. Subsequently when these margins are much narrower, parties have more incentives to obstruct opponents. These margins affect how members conduct themselves, and what they choose to focus on. 
From the perspective of this dissertation, it matters little whether the closeness of elections causes close margins, or vice versa. What does matter is that polarization is high when this closeness occurs, and I expect an effect on policymaking because of it. I theorize that the closer these margins of control are, Congress will be more likely to focus on generalized legislation. Given this, I generate the competition hypothesis:

Competition Hypothesis: As party majorities in Congress become smaller, Congress will pass a higher proportion of legislation that targets generalized beneficiaries.

To assess these hypotheses, a more discerning means by which to categorize bills is needed. Is it possible to predict, based on these conditions, what kinds of policy that Congress will pass in a session? Scholars have previously tried to answer similar questions. Lapiski's (2008) work for example, shows that the substance of policy matters, and how significant or trivial a policy is can be a major factor in understanding policy outcomes. Further, Gray and Jenkins (2019) argue that when gridlock is high, Congress is more likely to focus on legislation that is less ideologically laden, turning its attention toward more overtly partisan goals when gridlock is low. For this chapter, I look to the work of Arnold, and his 1990 book, The Logic of Congressional Action. Arnold surmises that legislation passed by the United States Congress can be sorted into three broad categories: generalized policies (that target the entirety of society), group policies (that target specific groups within society), and geographic policies (that target regions or locations). Below, I propose a means to measure the degree to which the enactment of laws across time reflects generalized, particularized, and geographic policy goals.

\section{Data and Methodology}

Creating the Dependent Variable and Bill Sorting 
Data for the dependent variable in this chapter was gathered from the Congressional Bills Project (Adler and Wilkerson 2021). I use a collected listed of all bills passed in Congress, ranging from the 80th to the 114th sessions (or the years of 1947 to 2016). The unit of analysis is one Congressional session, creating a total of 35 observations in the data. To sort the collected bills, two coders analyzed topic codes that the Comparative Agendas Project assigns to each bill. These codes span 21 major topics and 220 subtopics listed in the associated codebook. ${ }^{6}$ The task of the coders was to examine each subtopic code and decide which of Arnold's (1990) policy categories the subtopic would best fit into. To this end, several rules were established to sort each subtopic code (and all ensuing bills) into appropriate categories. These rules were created by first looking to Arnold's descriptions of how bills are sorted into theoretical categories, and then modifying them to apply to topic codes to be sorted. I relied heavily on Arnold's discussion to develop the rules used in this chapter, and the specifics of these rules are available in Appendix 2-1. Also aiding coders in their decisions were descriptions provided in the codebook that described the type of policy included in the subtopic, as well as example policies to examine.

To Arnold, generalized benefits are those that fall "uniformly on members of society." He provides a few examples of such bills, including those involving national security, clean air and water, and economic growth, but so long as everyone benefits from such a policy, then it can be considered "generalized." For the purposes of the dataset, this definition was expanded. When examining a subtopic, if the examples listed were not found to fall uniformly on society, then it was also asked if the benefits in the subtopic brought clear benefits to most of society, so long as they predominantly did not disperse benefits to one specific place, group, or locality. All other

\footnotetext{
${ }^{6}$ For further reference, the most recent codebook is hosted at https://www.comparativeagendas.net/pages/mastercodebook. While the codebook was originally created by Baumgartner and Jones for the Policy Agendas Project, it now spans multiple countries and a myriad of datasets.
} 
policy in Arnold's theory falls into either group or geographic policies. Arnold describes group policy as those that "accrue to particular segments of society," or when "some nonrandom collection of individuals receives disproportionate benefits." In the coding of these bills, subtopics were sorted into the "group" category if a majority of the examples listed were dispersed to a limited subsection of society, and/or if they referred to specific groups or subsections of society. Similarly, Arnold lists geographic policy as a special type of group policy, which he describes as “...policy effects that accrue disproportionately to particular areas, whether regions, states, or localities." For this chapter, coders considered whether the subtopic placed a disproportionate benefit upon specific places in the United States, with consideration of whether those subtopics referred to locations, regions, or territories.

Another notable difference between Arnold's theory and the coding choices made in this chapter is the temporal aspect of bills and their beneficiaries. Arnold does not make a distinction regarding the timeframe in which the effects of these benefits will accrue to their intended targets. Arnold also considers both first and secondary effects in his work, discussing how a policy that brings direct benefits to one category could have secondary effects that benefit another. While these assertions may be true, this creates difficulty in coding subtopics into distinct categories. In this chapter, only the immediate and direct effects were considered when making coding decisions. This allows for greater ease in sorting, at the expense of the secondary effects of bills.

From this, the sorted bills were tallied, generating the frequency of passed bills that fit into each category, sorted by Congressional session. This generated a total of 17,081 bills over 35 Congressional sessions. Regarding similarities between coders, the results of a Kappa test to assess inter-coder reliability can be found in Appendix 2-2. In short, agreement between coders 
was 90.45 , with an expected agreement of 34.81 , and the test was found to be statistically significant, meaning there was a much larger agreement than would have been expected by chance. To provide further context, Landis and Koch (1977: 165) would classify a score of this magnitude as "Almost Perfect." Note that regardless of the efforts to sort bills into distinct categories within Arnold's typology, some bill topics were unable to be coded under this current coding method. These policy topics are listed in Appendix 2-3 for further reference. ${ }^{7}$

To examine the face validity of these coding decisions, I look to the scholarship of other authors. Smith and Deering (1997) for example, classify committees in the Senate into different types, based on whether those committees are focused on policy, constituent work, or a mix between the two. Constituency committees are those that are focused on work that often pertains to particularized constituents, or those that allow them to work with issues that are important to their constituents. If I were to examine these committees and the topics that they cover in the context of this chapter, we might imagine that these committees would predominantly work with bills that have particularized beneficiaries, in either that they affect specific groups, or deal with issues related to geographic locations.

As an example, the Agriculture committee is focused on numerous policies pertaining to Agriculture, with policy that is often considered to be particularized in nature. If the coding done in this chapter has face validity, then we should expect that the subtopic codes pertaining to agriculture would also be coded as particularized as well. As noted below in Table 2-1, of all subtopics that pertain to Agriculture, only one subtopic was coded as generalized: Number 403,

\footnotetext{
${ }^{7}$ Of these topics, most of the unsorted bills related to international affairs and foreign aid, where beneficiaries are difficult to code. Further, the 114th Congress contained 84 bills in the data that were not given topic codes in the original dataset, making them un-codable, and were also excluded. This resulted in a total of 3322 bills that were not included in the current dataset.
} 
topics pertaining to Food Inspection and Safety. All others were coded as group policy, suggesting that there may be some face validity to the measure.

Table 2-1: Agriculture Subtopic Codes and Classifications

\begin{tabular}{|c|l|c|}
\hline Subtopic Number & \multicolumn{1}{|c|}{ Subtopic Name } & Classification \\
\hline 400 & $\begin{array}{l}\text { General (includes combinations of } \\
\text { multiple subtopics) }\end{array}$ & Group \\
\hline 401 & Agricultural Trade & Group \\
\hline 402 & $\begin{array}{l}\text { Government Subsidies to Farmers } \\
\text { and Ranchers, Agricultural Disaster } \\
\text { Insurance }\end{array}$ & Generalized \\
\hline 403 & $\begin{array}{l}\text { Food Inspection and Safety } \\
\text { (including seafood) }\end{array}$ & $\begin{array}{l}\text { Group } \\
\text { and Promotion }\end{array}$ \\
\hline 404 & $\begin{array}{l}\text { Animal and Crop Disease, Pest } \\
\text { Control, and Domesticated Animal } \\
\text { Welfare }\end{array}$ & Group \\
\hline 405 & $\begin{array}{l}\text { Fisheries and Fishing } \\
\text { Agricultural Research and } \\
\text { Development }\end{array}$ & Group \\
\hline 408 & \begin{tabular}{l} 
Agral \\
\hline
\end{tabular}
\end{tabular}

Frequency counts of the sorted bills are displayed in Figure 2-1. In the aggregate, the overall frequency of bill passage has decreased over time, with the greatest reductions being in the group policy and geographic policy categories. Generalized policy follows a less erratic trend, but also slowly slopes downward, with a notable large spike in policy from the 108th to the 111th sessions of Congress (2003 to 2011). As bills involving national security are largely sorted into the category of generalized policy, these observable increases coincide with a time in which national security was a large focus of the government, which may explain this high number of bills passed during this time. 


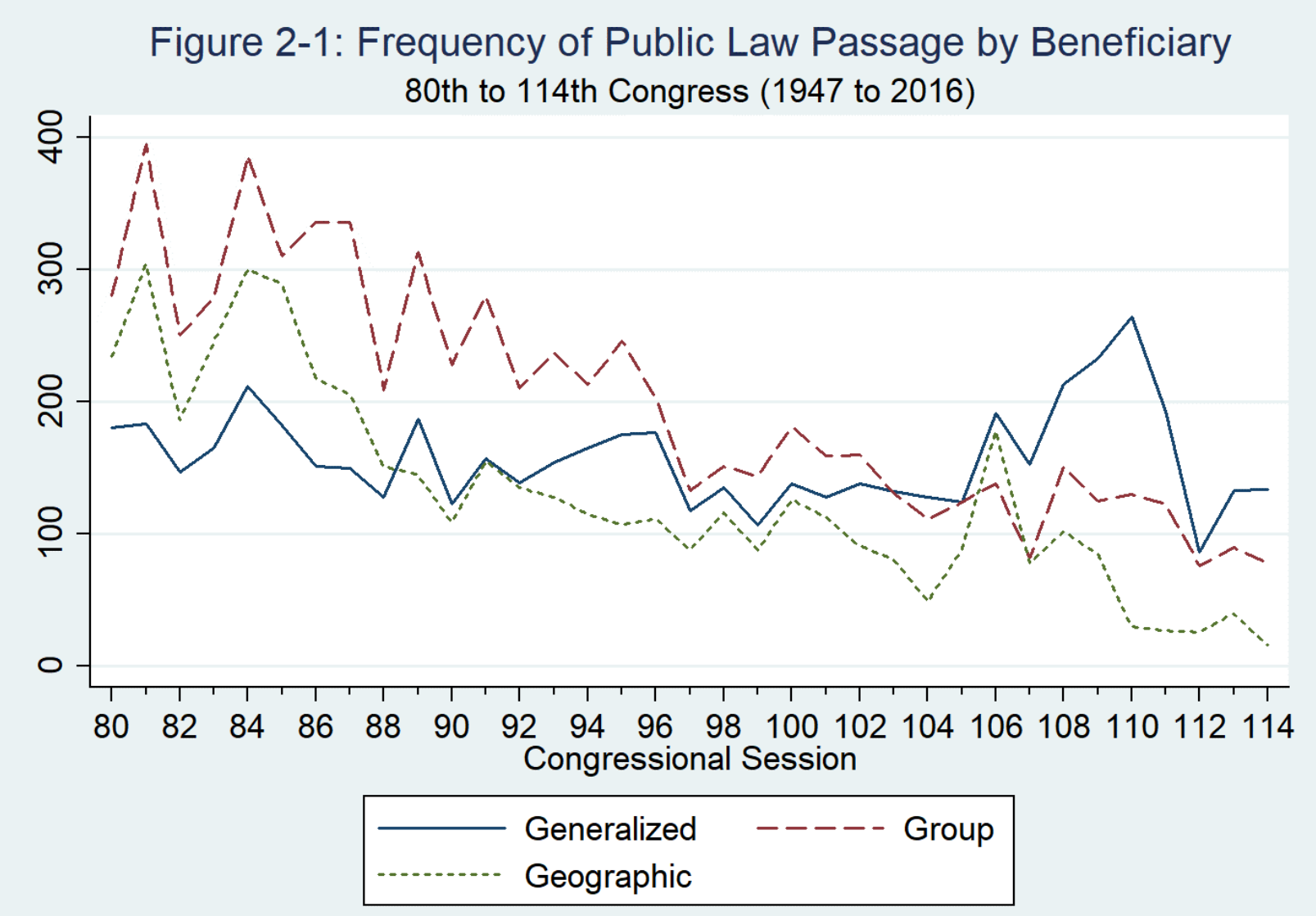

It is also prudent to examine the proportion of bills passed in each category during each session as well. To create this variable, I simply calculate the proportion of the total number of bills passed that fall into each policy category, with all three variables totaling to 1 when combined. These proportions are displayed over time in Figure 2-2. At a cursory glance, it appears that the proportion of generalized bills increases over time, and the proportion of particularized policy decreases. At its highest, generalized bills account for 58.77 percent of the total bills passed in the 111th session of Congress (2009 to 2011). Geographic bills as a category experience the greatest reductions, falling to their lowest rates in the 110th Congress, in which these bills only accounted for 7.02 percent of all bills passed. This further highlights the stark 
differences between the types of policy that Congress prioritizes (or is able to pass at all) during recent sessions of Congress.

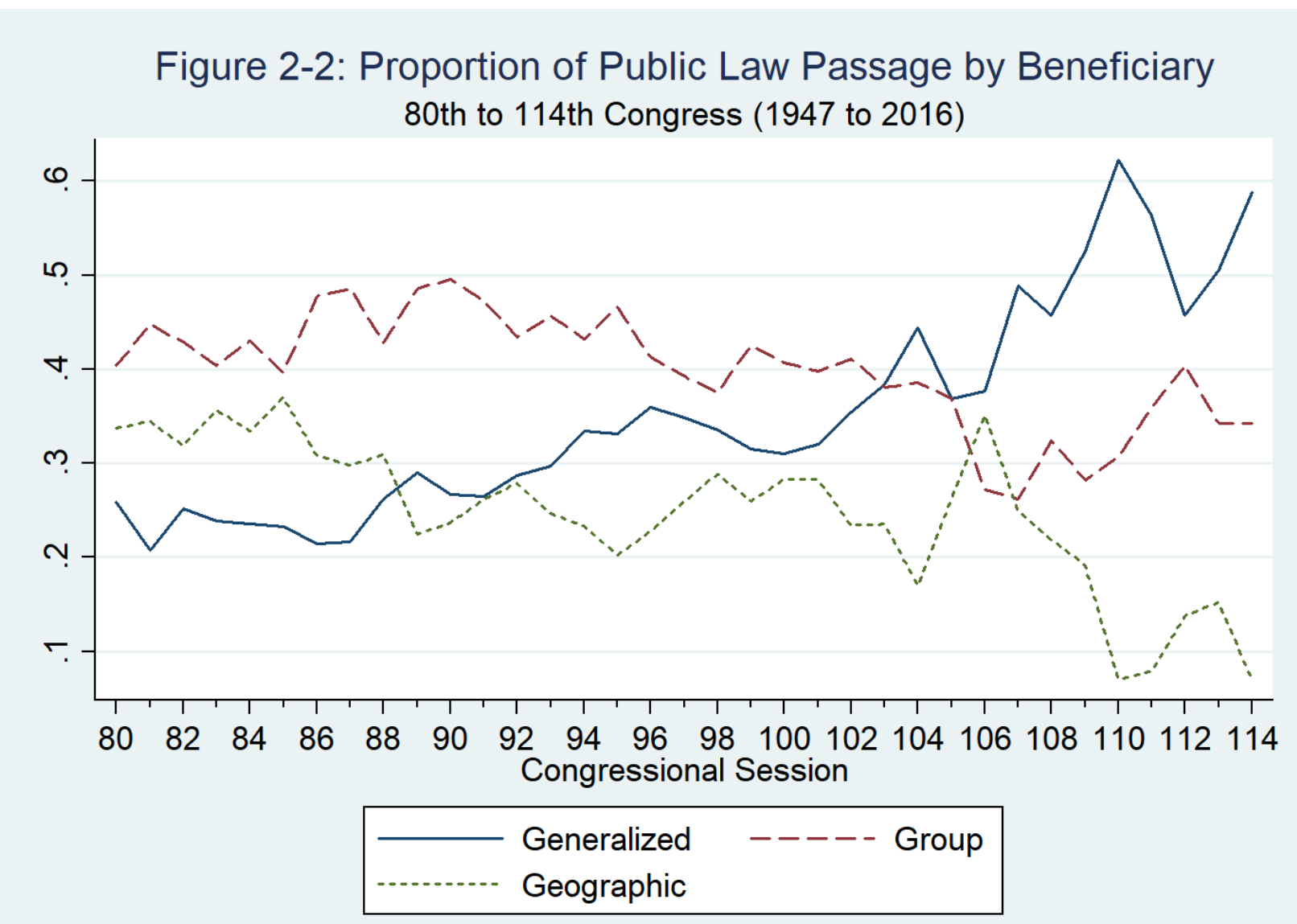

Measuring Independent Variables

The key independent variable in my analysis is political polarization. To measure polarization, I employ DW-NOMINATE scores (Lewis, Poole, Rosenthal, Broche, and Rudkin 2021). As mentioned in Chapter 1 , these scores typically range between -1 and 1 , and each member is assigned a number based on their voting habits. Specifically, I use the distance between the mean member of the Republican party and the mean member of the Democratic Party in both the House and Senate. Then, the absolute value of the numerical distance between these two parties is calculated, providing a polarization score for both chambers. I obtain the 
mean of these two indicators to create one measure of polarization in a Congressional session.

The resulting variable ranges from 0.503 to 0.852 , with a mean of 0.625 , a median of 0.605 , and a standard deviation of 0.098 .

As a robustness check, I use Sarah Binder's $(1999,526)$ variable for the percentage of moderates in Congress as the independent variable in a secondary set of analyses. This measure is created by tallying the number of members who have DW-NOMINATE scores that are closer to the ideological median between the two parties of the chamber than they are to their party's median score. I also employ the gridlock interval used by Bolton (2020) as a third measure of polarization in a final set of analyses. In his work, he examines the effect that polarization and gridlock have on the likelihood that Congress uses non-statutory tools of control to advance its goals. In his analysis, he uses a gridlock interval similar to Krehbiel's (1998), which is created by measuring the absolute distance between filibuster and veto pivots in the House and Senate, while taking into account the president's party affiliation.

It is important to note that Bolton's variant of the gridlock interval utilizes DWNOMINATE Common Space scores instead of the gridlock-change variable that Krehbiel employs in Pivotal Politics. Gray and Jenkins (2019) elaborate on the desirability of measuring the gridlock interval in this manner. First, they note that the scores treat legislators as individuals, and the scores do not require partisan information to function. Second, while Common Space scores do not allow individual members' ideological coordinates to vary across congressional sessions, such scores do allow for the ability to draw comparisons between the House and Senate over time, which allows the creation of a measurable interval. Overall, Gray and Jenkins claim that the assumptions that are inherent in DW-NOMINATE scores are minor compared to those associated with Krehbiel's (1998) variable. These assumptions allow for a measure that more 
closely captures the concept of polarization and allows meaningful comparisons between the House and Senate. This leaves me with three different indicators of polarization-my primary indicator and two variables that are correlated with this indicator, providing for robustness checks on my results.

To assess my second hypothesis, I also include a measure of electoral competition for each session in my models. This variable is created by tallying the proportion of seats that the minority party needs to win a majority in both the House and Senate in order to assume majority status. Then the scores for the House and Senate are averaged together to create a single measure for each session representing the margin of control that the majority party has. This variable is graphed in Figure 2-3. Overall, the margins that each party needs to take control have become narrower over time. I expect that as this number decreases (meaning that elections are closer and therefore the majority is more likely to switch parties), so too will the amount of generalized policy increase. In other words, there will be a negative and significant association between closeness and generalized policymaking. 


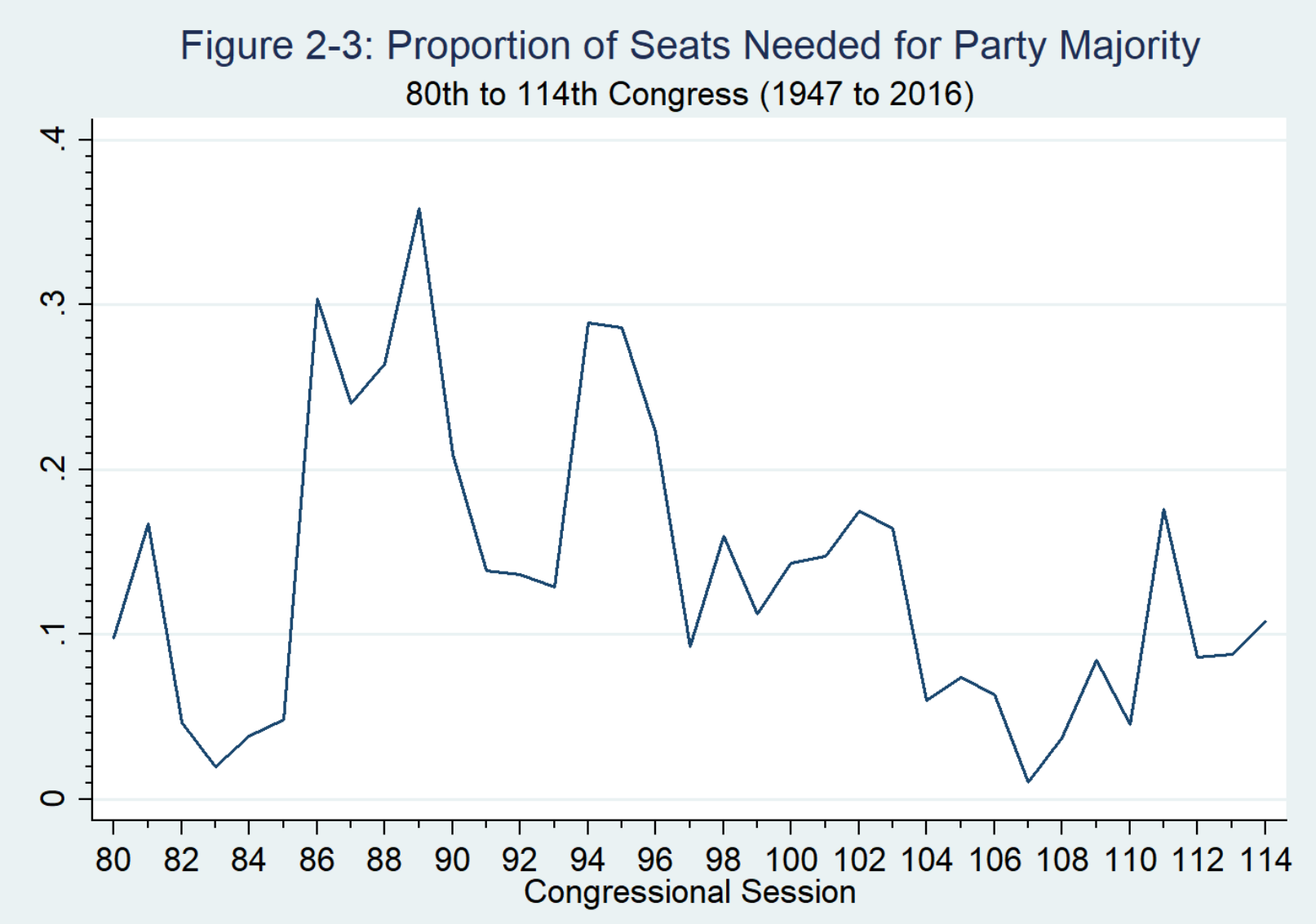

\section{Choosing Control Variables}

While I theorize that polarization and electoral competition are strong determinants of the kind of policy that Congress passes, there are other variables of note that we might expect would influence Congress in this process. First, in the context of this chapter, I expect that when the government is unified (one party controls the House, Senate, and the Presidency), that it will be more likely to pass generalized policy. I expect that the level of cooperation that is required to pass a bill through both chambers and the president will affect what kind of policy will be passed. As such, I control for the effect of divided government in the model. This variable representing whether the government was unified is measured as a simple dummy variable, coded as a 1 if the government was unified. 
Dodd and Schraufnagel (2013) show that when parties gain a Congressional majority, there is often a burst of productivity afterward. How does this apply to the type of policy that is passed? We might expect that the longer that a party is out of power, the more that it would be pressured to accomplish its legislative goals. In the context of this chapter, I expect that when parties switch control, Congress will be more likely to pass generalized policy the longer that a party has been out of power. To represent the length of time that parties have been out of power, I use Binder's measure from her book Stalemate (2003), in which the number of years in which a party has been out of power is totaled for both the House and Senate, and then, the mean of these two variables is found, and used as a single measurement for each congressional session. For similar reasons, I also expect that in sessions in which a new president is elected, there will be increases in the amount of generalized policy that is passed. A dummy variable for whether the session took place during a presidential honeymoon period is also included.

Other factors of note include fluctuations in the United States economy, as well as the growing federal debt. As the economy goes through economic recessions, we should expect alterations to Congressional priorities. In terms of Birkland's (1998) work, we might think of recessions as a focusing event which will force Congress's attention. Economic downturns affect the entire country, and Congress often responds with legislation to assist in recovery. I expect that the longer that recessions occur, the more likely Congress will be to pass generalized legislation that will address these concerns. However, I expect that as the federal debt increases, it will make generalized legislation harder to pass. To measure the variable for debt, I calculate the proportion of national debt as compared to the total GDP of the United States each year. Then, these years are averaged together to create a single variable for each Congressional session. To measure the length of economic recessions in the United States, I use a simple count 
of the total number of months that the US was considered to be in a recession during each Congressional session. ${ }^{8}$

Selecting an Estimator and the Specification of Models

There are several ways that the relationship between polarization and congressional policy priorities could be examined, but as mentioned above, we should expect that as the amount of policy that increases in one category, that less policy would be passed that falls into others. Since the proportion of generalized, group, and geographic policy sum to 1 , an estimator is needed that can account for the ability for these separate DVs to influence one another. In this situation, Seemingly Unrelated Regression Analysis (SUR) is an appropriate estimator for each model, as it allows for the estimation of multiple models that are assumed to be statistically linked (or in this case, it is known that they are) (Zellner 1962). While one could simply use OLS regressions to estimate each model individually, if one assumes that each equation has contemporaneous correlation of errors, it is prudent to utilize an estimator such as SUR. Model 1 uses DW-NOMINATE scores as a measure of polarization, while Model 2 uses Binder's percentage of moderates in place of the independent variable and Model 3 uses Bolton's gridlock interval.

\section{Findings}

\footnotetext{
${ }^{8}$ The data for recessions and debt to GDP ratio in this chapter was gathered from the Federal Reserve Bank of St. Louis, which can be accessed at this link: https://fred.stlouisfed.org/series/USREC. For recession data I specifically used their tool: "NBER based Recession Indicators for the United States from the Period following the Peak through the Trough." For recession data, I also drew data from the website "Longtermtrends", or more specifically: https://www.longtermtrends.net/us-debt-to-gdp/. The website aggregates data from both the Federal Reserve Bank of St. Louis, as well as official historical congressional documentation.
} 
The results of the first analysis are presented in Table $2-2 .{ }^{9}$ In all three models, polarization is significant at the .001 level and moves in the expected direction. However, these results must be interpreted while considering the range of the variable, which is 0.343 , with a standard deviation of 0.099 . This means that adjusting to this scale, a one standard deviation increase in the polarization variable leads to an 11.25 percent increase in generalized policy, a 3.87 percent decrease in group policy, and a 7.38 percent decrease in geographic policy. Examined another way, an increase from the lowest observable amount of polarization to the highest results in a 38.96 percent increase in generalized policy, a 13.41 percent decrease in group policy, and a 25.55 percent decrease in geographic policy.

\footnotetext{
${ }^{9}$ The results in the proceeding tables display one-tailed tests, but the results of additional two-tailed tests are available in Appendix 2-4. Very few changes occur when switching to this method, but there are a few of note. In Model 1, the control variable for the length of time the majority party has been out of government drops one level of significance, and the variable for recessions is no longer significant. In Model 3, the variable for electoral competition drops in significance from the .001 to the .01 level. Otherwise, all variables retain their same level of significance as shown in Table 2-2, and the assessment of my hypotheses do not change in a meaningful way.
} 
Table 2-2: Seemingly Unrelated Regression Estimates of Polarization and Beneficiaries

\begin{tabular}{|c|c|c|c|}
\hline & $\begin{array}{l}\text { Model } 1 \\
\text { Generalized }\end{array}$ & $\begin{array}{l}\text { Model } 2 \\
\text { Group }\end{array}$ & $\begin{array}{l}\text { Model } 3 \\
\text { Geographic }\end{array}$ \\
\hline Polarization (DV) & $\begin{array}{l}\mathbf{1 . 1 3 6}^{* * *} \\
(0.079)\end{array}$ & $\begin{array}{l}-\mathbf{0 . 3 9 1} \\
(0.066)\end{array}$ & $\begin{array}{l}\mathbf{- 0 . 7 4 5} \\
(0.083)\end{array}$ \\
\hline Competition & $\begin{array}{c}0.045 \\
(0.089)\end{array}$ & $\begin{array}{l}-\mathbf{0 . 3 5 1} \\
(0.074)\end{array}$ & $\begin{array}{l}\mathbf{0 . 3 0 6}^{* * * *} \\
(0.094)\end{array}$ \\
\hline Unified & $\begin{array}{c}\mathbf{0 . 0 4 0}^{* *} \\
(0.015)\end{array}$ & $\begin{array}{l}-0.013 \\
(0.013)\end{array}$ & $\begin{array}{l}\mathbf{- 0 . 0 2 7}{ }^{*} \\
(0.015)\end{array}$ \\
\hline Honeymoon & $\begin{array}{c}0.004 \\
(0.012)\end{array}$ & $\begin{array}{l}-0.004 \\
(0.012)\end{array}$ & $\begin{array}{c}0.007 \\
(0.015)\end{array}$ \\
\hline Time Out & $\begin{array}{c}\mathbf{0 . 0 0 3}^{* *} \\
(0.001)\end{array}$ & $\begin{array}{c}0.000 \\
(0.001)\end{array}$ & $\begin{array}{l}\mathbf{- 0 . 0 0 3} * \\
(0.001)\end{array}$ \\
\hline Recession & $\begin{array}{c}\mathbf{0 . 0 0 3}^{*} \\
(0.002)\end{array}$ & $\begin{array}{c}0.000 \\
(0.001)\end{array}$ & $\begin{array}{c}\mathbf{0 . 0 0 1}^{*} \\
(0.002)\end{array}$ \\
\hline Debt & $\begin{array}{c}0.000 \\
(0.000)\end{array}$ & $\begin{array}{c}0.000 \\
(0.000)\end{array}$ & $\begin{array}{c}0.000 \\
(0.000)\end{array}$ \\
\hline Constant & $\begin{array}{l}\mathbf{- 0 . 3 6 2} \\
(0.055) \\
\end{array}$ & $\begin{array}{l}\mathbf{0 . 5 8 3}^{* * * *} \\
(0.046) \\
\end{array}$ & $\begin{array}{l}\mathbf{0 . 7 8 0}^{\text {*** }} \\
(0.058)\end{array}$ \\
\hline $\begin{array}{l}\mathrm{R}^{2} \\
\mathrm{~N}\end{array}$ & $\begin{array}{l}0.883 \\
35\end{array}$ & $\begin{array}{l}0.718 \\
35\end{array}$ & $\begin{array}{l}0.729 \\
35\end{array}$ \\
\hline
\end{tabular}

For visualization purposes, this relationship is plotted in Figure 2-4, which shows the proportion of generalized policy in each session, sorted by polarization. The lowest observation of polarization occurs in the 80th session of Congress (which is also the first observation in the data), and 25.94 percent of policy passed fell into the generalized category. Subsequently, the most polarized session of Congress (the 114th, the last observation in the data) produced 58.77 percent generalized policy. These results clearly suggest that increases in the proportion of 
generalized policy are occurring in tandem with increases in polarization and support the polarization hypothesis.

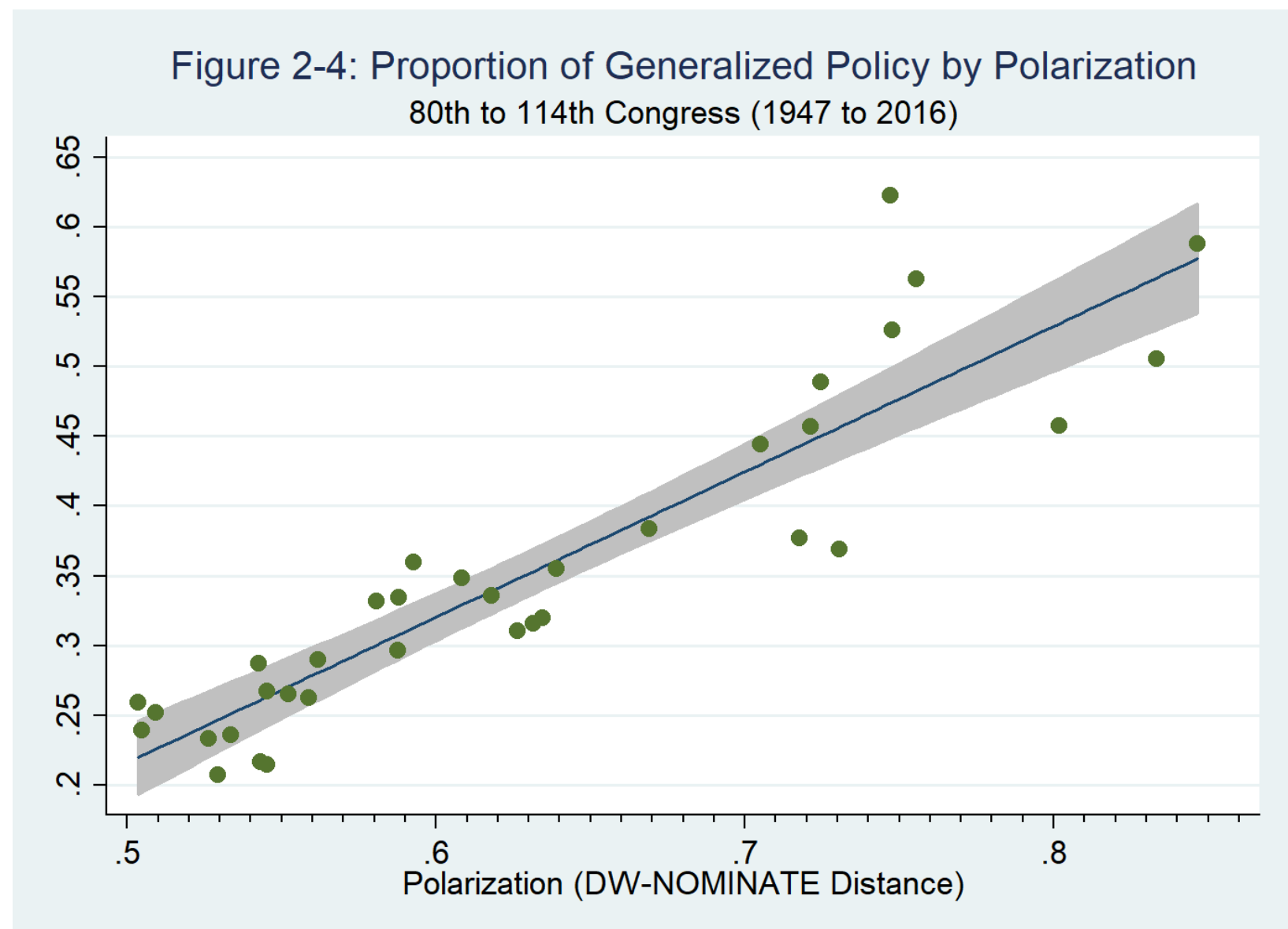

The variable representing electoral competition is not significant in Model 1 but is significant in Models 2 and 3 at the .001 level. ${ }^{10}$ The results suggest that as majorities in Congress become narrower, the proportion of group policy passed decreases, and interestingly, the proportion of geographic policy increases. While the results show a minor increase in

\footnotetext{
${ }^{10}$ For ease of interpretation, the variable for competition has been reversed in scale. As the variable for competition is the number of seats needed for the minority party to take back the majority, a low number of seats should equal a larger amount of competition. Reversing the scaling allows for the visualization of these results in a more intuitive direction.
} 
generalized policy, the variable is not significant, and these results conflict with the competition hypothesis.

Looking to control variables, unified government appears to lead to an increase the proportion of generalized policy passed and a decrease in the amount of group and geographic policy passed (though in Model 2 the variable is not significant). In Models 1 and 3, the variables for time out of government and months of recession have significant but small effects on policy passage. The variables for a presidential honeymoon period, and the proportion of US debt are not significant in any model in Table 2-2. Overall, each control variable seems to have little effect on the proportion of policy passed.

In Table 2-3, the analyses utilizing the percentage of moderates as the independent variable display similar results. ${ }^{11}$ A decrease in the number of moderates in Congress leads to increases in generalized policy passed, and also results in decreases to the proportion of both group and geographic policy. Again, increases in electoral competition appear to decrease the proportion of group policy passed and increase the proportion of geographic policy. The polarization hypothesis finds support again, while the competition hypothesis does not. All control variables yield similar results, with the only notable change being that the variable for debt is now significant at the .05 level, though the effects are small.

\footnotetext{
${ }^{11}$ This measure of moderates is also reversed in scale for ease of interpretation. Binder's measure of polarization is the proportion of ideological moderates in each chamber, so with the expectation that as moderates increase, so too does compromise, leading to lessened gridlock.
} 
Table 2-3: Seemingly Unrelated Regression Estimates Utilizing Variable for Moderates

\begin{tabular}{|c|c|c|c|}
\hline & $\begin{array}{l}\text { Model } 1 \\
\text { Generalized }\end{array}$ & $\begin{array}{l}\text { Model } 2 \\
\text { Group }\end{array}$ & $\begin{array}{l}\text { Model } 3 \\
\text { Geographic }\end{array}$ \\
\hline Moderates (DV) & $\begin{array}{l}\mathbf{0 . 8 9 1}^{* * * *} \\
(0.063)\end{array}$ & $\begin{array}{l}\mathbf{- 0 . 3 1 7} \\
(0.050)\end{array}$ & $\begin{array}{l}-\mathbf{0 . 5 7 6} \\
(0.069)\end{array}$ \\
\hline Competition & $\begin{array}{c}0.026 \\
(0.092)\end{array}$ & $\begin{array}{l}\mathbf{- 0 . 3 2 4} \\
(0.073)\end{array}$ & $\begin{array}{l}\mathbf{0 . 3 5 4} \\
(0.099)\end{array}$ \\
\hline Unified & $\begin{array}{c}\mathbf{0 . 0 3 5}^{* *} \\
(0.015)\end{array}$ & $\begin{array}{l}-0.011 \\
(0.012)\end{array}$ & $\begin{array}{l}-0.025 \\
(0.017)\end{array}$ \\
\hline Honeymoon & $\begin{array}{c}0.005 \\
(0.011)\end{array}$ & $\begin{array}{l}-0.005 \\
(0.011)\end{array}$ & $\begin{array}{c}0.005 \\
(0.015)\end{array}$ \\
\hline Time Out & $\begin{array}{c}\mathbf{0 . 0 0 3}^{*} \\
(0.001)\end{array}$ & $\begin{array}{c}0.000 \\
(0.001)\end{array}$ & $\begin{array}{l}-\mathbf{- 0 . 0 0 3}^{*} \\
(0.002)\end{array}$ \\
\hline Recession & $\begin{array}{c}\mathbf{0 . 0 0 4}{ }^{* *} \\
(0.002)\end{array}$ & $\begin{array}{c}0.000 \\
(0.001)\end{array}$ & $\begin{array}{l}\mathbf{- 0 . 0 0 3}{ }^{*} \\
(0.002)\end{array}$ \\
\hline Debt & $\begin{array}{c}\mathbf{0 . 0 0 1}^{*} \\
(0.000)\end{array}$ & $\begin{array}{c}0.000 \\
(0.000)\end{array}$ & $\begin{array}{l}-0.000 \\
(0.000)\end{array}$ \\
\hline Constant & $\begin{array}{c}\mathbf{0 . 5 6 3}^{* * * *} \\
(0.036) \\
\end{array}$ & $\begin{array}{l}\mathbf{0 . 2 6 1}^{* * * *} \\
(0.028) \\
\end{array}$ & $\begin{array}{l}\mathbf{0 . 1 7 4}^{\text {****}} \\
(0.039) \\
\end{array}$ \\
\hline $\begin{array}{l}\mathrm{R}^{2} \\
\mathrm{~N}\end{array}$ & $\begin{array}{l}0.878 \\
35\end{array}$ & $\begin{array}{l}0.736 \\
35\end{array}$ & $\begin{array}{l}0.704 \\
35\end{array}$ \\
\hline
\end{tabular}

Table 2-4 shows the results of analyses using a gridlock interval in place of the independent variable. In all models, gridlock is a statistically significant predictor of the proportion of generalized, group, and geographic policy that is passed, and when compared to previous models, all three dependent variables behave similarly as polarization increases.

Competition again produces the same level of significance and moves in similar directions when compared to other measures of polarization. Except for the variable for unified government in 
two of the three models, all control variables are not significant when using gridlock to measure polarization.

Table 2-4: Seemingly Unrelated Regression Estimates Utilizing Variable for Gridlock

\begin{tabular}{|c|c|c|c|}
\hline & $\begin{array}{l}\text { Model } 1 \\
\text { Generalized }\end{array}$ & $\begin{array}{l}\text { Model } 2 \\
\text { Group }\end{array}$ & $\begin{array}{l}\text { Model } 3 \\
\text { Geographic }\end{array}$ \\
\hline Gridlock (DV) & $\begin{array}{l}\mathbf{0 . 7 5 6}^{* * *} \\
(0.107)\end{array}$ & $\begin{array}{l}\mathbf{- 0 . 2 8 8}^{* * *} \\
(0.060)\end{array}$ & $\begin{array}{l}\mathbf{- 0 . 4 6 9} \\
(0.091)\end{array}$ \\
\hline Competition & $\begin{array}{c}0.097 \\
(0.155)\end{array}$ & $\begin{array}{l}\mathbf{- 0 . 2 8 5} \\
(0.088)\end{array}$ & $\begin{array}{l}\mathbf{0 . 3 7 7} \\
(0.132)\end{array}$ \\
\hline Unified & $\begin{array}{c}\mathbf{0 . 0 6 2}^{* * *} \\
(0.026)\end{array}$ & $\begin{array}{l}-0.018 \\
(0.015)\end{array}$ & $\begin{array}{l}\mathbf{- 0 . 0 4 1} \\
(0.022)\end{array}$ \\
\hline Honeymoon & $\begin{array}{c}0.019 \\
(0.014)\end{array}$ & $\begin{array}{l}-0.019 \\
(0.014)\end{array}$ & $\begin{array}{l}-0.008 \\
(0.021)\end{array}$ \\
\hline Time Out & $\begin{array}{c}0.003 \\
(0.002)\end{array}$ & $\begin{array}{c}0.000 \\
(0.001)\end{array}$ & $\begin{array}{l}\mathbf{- 0 . 0 0 2} \\
(0.001)\end{array}$ \\
\hline Recession & $\begin{array}{c}0.001 \\
(0.002)\end{array}$ & $\begin{array}{c}0.000 \\
(0.001)\end{array}$ & $\begin{array}{l}-0.002 \\
(0.002)\end{array}$ \\
\hline Debt & $\begin{array}{c}0.000 \\
(0.001)\end{array}$ & $\begin{array}{c}0.000 \\
(0.000)\end{array}$ & $\begin{array}{c}0.000 \\
(0.001)\end{array}$ \\
\hline Constant & $\begin{array}{l}-0.023 \\
(0.071)\end{array}$ & $\begin{array}{l}\mathbf{0 . 4 8 6}^{* * * *} \\
(0.040)\end{array}$ & $\begin{array}{l}\mathbf{0 . 5 3 9}^{* * *} \\
(0.060)\end{array}$ \\
\hline $\begin{array}{l}\mathrm{R}^{2} \\
\mathrm{~N}\end{array}$ & $\begin{array}{l}0.655 \\
34\end{array}$ & $\begin{array}{l}0.661 \\
34\end{array}$ & $\begin{array}{l}0.470 \\
34\end{array}$ \\
\hline
\end{tabular}

All three tables showcase similar results, which suggests that the relationship between these variables is robust to different measurements of polarization. Regarding my hypotheses: the polarization hypothesis finds support from this analysis, as increased polarization is a statistically significant predictor of the proportion of generalized policy that is passed in a session. The competition hypothesis found mixed results but was relatively unsupported. While 
technically an increase in competitiveness was associated with small increase in the amount of generalized policy passed, this result was not found to be significant in any model. The variable representing the proportion of group policy performs as expected, but the large increase in geographic policy found in all three models was unexpected. Is it possible that competition causes Congress to prioritize regional concerns? This seems to contradict the prevailing theories regarding Congressional attention and polarization, as well as the theory developed in this chapter. There may be a few reasons for this finding. First, competition spurs members to turn further inward to consider regional concerns and considerations of how to please voters in those areas. However, it is likely that this is simply a result of how the data is structured. The question remains: would these results remain with the inclusion of more data, or with a more discerning coding scheme? These are questions for future research. Regardless, the electoral competition hypothesis is not supported by the analyses presented above.

There is one omission from these results that must be addressed. In the preceding analyses I do not include a control representing the passage of time. To this end, Table 2-5 displays the results after adding a simple variable coded as zero in the first session covered by the analysis, and which increases by one in each subsequent session. To summarize the results, the inclusion of time reduces the significance of polarization in all models, and the associated polarization hypothesis is not supported. This is of little surprise, as the variables for time and polarization have a correlation of 0.965 . Yet there is an important argument to be made for controlling for temporal dynamics in empirical models. Doing so provides for a robustness check to the effect that the results are not driven by other independent variables that also change as time progresses. Such variables one could reasonably hypothesize to affect the dependent variable - in this chapter, the type of policy that is enacted into law — rather than the independent 
variable of theoretical interest - in this chapter, polarization (I also provide such robust checks in the subsequent chapters). Furthermore, other scholars who have made important contributions to understanding the role of inter-branch and intra-branch conflict on congressional productivity do not include time trend variables in analyses of productivity (Binder 1999; Dodd and Schraufnagel 2013; Krutz 2000). The root of the matter is that polarization has been increasing across time as congressional productivity has changed. Given the evidence presented in this chapter, the question then is what other factors, in addition to (or rather than) polarization could be causing these changes? That is, what other factors can one reasonably hypothesize to have been increasing (or decreasing) over this period that could have reshaped how congressional lawmaking majorities prioritize policymaking? As noted above, prior work provides no other candidates. In the absence of such factors, I offer the findings presented above that lawmakers have increasingly prioritized enacting generalized policy solutions at the expense of group-based and geographic benefits. At the same time, I am forthright that the inclusion of a time-trend variable may cast doubt on this conclusion. My view is that inclusion of the time trend has the effect of measuring polarization twice - once with the indicators of polarization, and again with the time trend. As such, the models presented in tables 2-2 through 2-4 are preferable to the models presented in Table 2-5. 
Table 2-5: Seemingly Unrelated Regression Estimates with Time Variable

\begin{tabular}{|c|c|c|c|}
\hline & $\begin{array}{l}\text { Model } 1 \\
\text { Generalized }\end{array}$ & $\begin{array}{l}\text { Model } 2 \\
\text { Group }\end{array}$ & $\begin{array}{l}\text { Model } 3 \\
\text { Geographic }\end{array}$ \\
\hline Polarization (DV) & $\begin{array}{c}0.319 \\
(0.404)\end{array}$ & $\begin{array}{l}-0.272 \\
(0.359)\end{array}$ & $\begin{array}{l}-0.051 \\
(0.434)\end{array}$ \\
\hline Competition & $\begin{array}{c}0.020 \\
(0.085)\end{array}$ & $\begin{array}{l}-\mathbf{0 . 3 4 5} \\
(0.075)\end{array}$ & $\begin{array}{l}\mathbf{0 . 3 2 4}^{\text {****}} \\
(0.091)\end{array}$ \\
\hline Unified & $\begin{array}{c}\mathbf{0 . 0 3 8}^{* *} \\
(0.014)\end{array}$ & $\begin{array}{l}-0.013 \\
(0.013)\end{array}$ & $\begin{array}{l}\mathbf{- 0 . 0 2 5} \\
(0.015)\end{array}$ \\
\hline Honeymoon & $\begin{array}{l}-0.000 \\
(0.012)\end{array}$ & $\begin{array}{l}-0.000 \\
(0.012)\end{array}$ & $\begin{array}{c}0.014 \\
(0.015)\end{array}$ \\
\hline Time Out & $\begin{array}{c}\mathbf{0 . 0 0 3}^{* *} \\
(0.001)\end{array}$ & $\begin{array}{l}-0.000 \\
(0.001)\end{array}$ & $\begin{array}{l}-\mathbf{0 . 0 0 3} \\
(0.001)\end{array}$ \\
\hline Recession & $\begin{array}{c}\mathbf{0 . 0 0 3}^{*} \\
(0.001)\end{array}$ & $\begin{array}{l}-0.000 \\
(0.001)\end{array}$ & $\begin{array}{l}-\mathbf{0 . 0 0 3} \\
(0.001)\end{array}$ \\
\hline Debt & $\begin{array}{c}0.000 \\
(0.001)\end{array}$ & $\begin{array}{c}0.000 \\
(0.000)\end{array}$ & $\begin{array}{l}-0.000 \\
(0.001)\end{array}$ \\
\hline Time & $\begin{array}{c}\mathbf{0 . 0 0 7}^{*} \\
(0.004)\end{array}$ & $\begin{array}{l}-0.001 \\
(0.003)\end{array}$ & $\begin{array}{l}-0.006 \\
(0.003)\end{array}$ \\
\hline Constant & $\begin{array}{l}-0.025 \\
(0.172)\end{array}$ & $\begin{array}{l}\mathbf{0 . 5 3 3}^{\text {**** }} \\
(0.153)\end{array}$ & $\begin{array}{c}\mathbf{0 . 4 9 3}^{* *} \\
(0.185)\end{array}$ \\
\hline $\begin{array}{l}\mathrm{R}^{2} \\
\mathrm{~N}\end{array}$ & $\begin{array}{l}0.896 \\
35\end{array}$ & $\begin{array}{l}0.717 \\
35\end{array}$ & $\begin{array}{l}0.748 \\
35\end{array}$ \\
\hline
\end{tabular}

Standard errors in parentheses. ${ }^{*} p<0.05,{ }^{* *} p<0.01,{ }^{* * *} p<0.001$ (one-tailed tests)

\section{$\underline{\text { Discussion and Conclusion }}$}

This chapter examined the relationship between polarization and the types of policy that Congress passes. Through the disaggregation of public laws, I find evidence that Congress passes different kinds of bills as polarization increases, with the proportion of bills that target 
generalized beneficiaries increasing during sessions in which polarization is high. It is no accident that these results occurred. Parties in Congress have become increasingly polarized, and this has resulted in changes that have altered the policymaking process. The evidence presented in this chapter suggests that Congress is limited in the kinds of policy it is able to pass when polarization is high. These results also stress the importance of understanding not just how productive Congress is, but also the limitations of which policy Congress can pursue, given the gridlock that it often faces.

While the conclusions in this work are by no means definitive, the findings add to a growing literature that suggests that polarization is altering legislative policy outcomes. Ideological divisions appear to have a mitigating effect on this process, limiting the ability of members to pursue policies with particularized beneficiaries. Political parties have become an increasingly important part of what issues make it onto the agenda, as well as what policies are chosen for passage. As polarization continues to increase, further research into this area is important, as it may shine light onto the priorities which Congress chooses to focus, and how those priorities may or may not align with the policy that it is able to pass. Understanding the capabilities of Congress, and what policies are often filtered out in a polarized and gridlocked environment can guide future work, and this chapter suggests several avenues for such scholarship. 


\section{Chapter 3: Polarization and the Productivity of Congressional Committees}

\section{$\underline{\text { Introduction }}$}

The relationship between high polarization and low legislative productivity is welldocumented in the United States Congress. Binder (1999, 2005, 2015) finds that as polarization increases, so does gridlock in Congress, which leads to a decrease in the proportion of problems on the policy agenda that Congress tries to address through legislation. Others mirror these findings, noting that not only is less policy passed, but also less policy of importance is passed as well (McCarty 2007, Lapinski 2008). This reduction in congressional productivity stems from increases in polarization and the fact that during polarized times, parties have incentives to oppose each other at every stage in the policy process (Lee 2009) which creates legislative gridlock (Sinclair 2006). Frequently this opposition of parties is not on the grounds of policy differences, but rather a desire to deny their political opponents a legislative victory (Lee 2016). Much of the research on Congressional productivity focuses on the final outputs of the policy process in the House and Senate, often by examining the number of bills passed in a Congressional session, or by examining bills deemed to be of importance (Mayhew 2005, McCarty 2007, Lapinski 2008, Dodd and Schraufnagel 2013). Yet there are opportunities to learn more about how polarization affects the productivity of the legislative branch by narrowing one's focus within the policymaking process.

To this end, I turn my focus to the congressional committee system, as understanding the productivity of committees is crucial to gaining a greater understanding of Congressional productivity in the aggregate. Committees in Congress were once considered to be powerful and autonomous, but after several institutional changes that consolidated power into the hands of party leadership (Nelson 1974, Sinclair 1997), these leaders began to appoint more loyalists to 
committees who would mirror national party agendas (Cox and McCubbins 2007, Evans 2013). As such, committees are often viewed by party leadership as avenues for partisan warfare (Sinclair 2006).

Given the role of political parties in Congress, and the current structure of committees, I ask: does polarization influence the productivity of committees in the United States Congress? Evidence suggests that polarization may affect the output of Congress as a whole, but does polarization also spur a loss of productivity at the committee level? Committees may be hamstrung in that party leadership chooses to intrude on the substance of legislation in committees' jurisdictions. However, committees may continue to productively engage policy problems within their jurisdictions. The legislative solutions that committees produce may fail to win enactment into law, but that is not the committee's fault. On the other hand, committees may simply give up and become less productive, becoming part of a greater lawmaking environment that is diminishing in output. I argue in this chapter that polarization affects the regular order of the committee system in the United States Congress, and that as polarization increases, the productivity of committees will decrease in kind.

To examine these questions, I utilize three indicators of committee productivity: the total number of hearings that each committee held each session, the total days that each committee spent in hearings, and how many bills each committee reported to their parent chambers. Using these indicators, I estimate factor scores representing productivity in both the House and Senate. I find that as polarization increases, committees experience a sharp decrease in internal productivity in both chambers across time. I then discuss the implications of these results and suggest further work that could be performed to refine the model. 


\section{Committees and Congressional Productivity: Existing Literature and Theory}

Committees in Congress were once seen to be highly autonomous and held significant power over the policymaking process. Since Woodrow Wilson's (1885) work, scholars have written of the powerful influence of committees over policymaking. To some, the committee system within the United States Congress was considered to be one of the most powerful in the world (Nelson 1974), which was attributed to the autonomy that committees and committee chairpersons were afforded. Further, for most of the 20th century, committees were largely decentralized from their parent chamber, with committee leaders who had a substantial amount of power over their policy jurisdictions (Price 1981, Young and Heitshusen 2003). ${ }^{12}$

A wave of foundational committee scholarship in the 1960's and 1970's emphasized the organization, power, and importance of the committee system (Fenno 1962, 1974, Morrow 1969, Polsby 1968, Price 1972). Yet as Evans (2013) reminds us, the committee-centric lens through which Congress was viewed by these scholars must be tempered by the political environment of the time. Scholars from this era were writing during a period when bipartisanship was at an alltime high, and so cooperation within committees was more likely to occur. Committee chairs held functional policy monopolies over issues, and committees were largely independent and autonomous from parties. Starting in the mid-1970's, Congress passed a series of reforms to the committee system that were intended to increase accountability in the process, and to reduce the power of committee chairs (Sinclair 1997). Large portions of committee activity became available for public oversight, including how committee members vote, and the proceedings of committee sessions (Rohde 1991). These changes allowed for more oversight into the internal

\footnotetext{
12 There is a famous story where Representative John Dingell, who was chair of the House Commerce Committee, is said to have handed out printed pictures of Earth that had been taken from space. He proudly exclaimed to those who were present, "Now there, that is $m y$ jurisdiction." (King 1997: 42)
} 
work of committees, but also made it more difficult for deals to be made between members; behind closed doors and away from the prying eyes of interested constituents.

One consequence of these reforms was a consolidation of committee power toward party leadership, further decreasing the power of committee chairs and increasing party control over the committee process (Aldrich et al. 2013, Barber and McCarty 2015, Rohde 1991). Several of these important modifications to the committee system originated from the Speaker of the House, Newt Gingrich, after being elected in 1995. Importantly, Gingrich presided over the first Republican majority in the House of Representatives in forty years, and there was much pressure to complete his party's "Contract with America." This urgency led to new methods of bypassing the protocols of Congress to accomplish the Republican Party's goals (Sinclair 1997). As Aldrich and Rohde (2000) note, Gingrich used this opportunity to expand his control over the committee system by altering the regular order in which committee chairs were nominated and created a system of nominations in which party loyalty was valued over length of service and experience. In this way, committee chairs were more likely to follow the goals of the party, and less likely to diverge from what Gingrich instructed them to do. ${ }^{13}$

One might expect that such changes would theoretically reduce gridlock in committees by removing chairs who would stifle the progress of bills. Yet a shift away from committee autonomy does not come without cost. As parties assume greater control over the committee process, committees are more likely to be influenced by polarization, and this ideological distance between parties affects the legislative process in several ways. Evans (2013) explains

\footnotetext{
${ }^{13}$ It is also worth noting that through Gingrich's centralization of power, staffing for members of Congress became less of a focus, and funding for the employment of staffers has stagnated in the years since. This has led to a "brain drain" of sorts, where policy expertise among staff is difficult to maintain, which lessens the policy creation capacity of individual members (Drutman et al. 2019).
} 
that as polarization increases, and parties become more homogenous, the autonomy of committees decreases. When members internally disagree within parties, they are more likely to delegate power to committees, where they have a higher likelihood of seeing their preferences achieved. Yet when parties largely agree ideologically, parties centralize their power around party leaders, and committees are weakened in their autonomy (Rhode 1991). Becker and Moscardelli (2008) note that polarization is also resulting in an increasing likelihood for ideological extremists to be appointed as committee chairs, as the constituencies from which members are drawn are also becoming increasingly extreme in ideology. These changes further spur gridlock and diminish the chances for bipartisan cooperation to occur.

Why does committee autonomy matter in the policymaking process? One reason is that increased party control over committees has been shown to have a detrimental effect on committee productivity. Nelson (1974) argues that committees that operate with less party control tend to be more productive and are more effective in both their operations and policy production. He writes: "The most effective committees in Congress are those which have most successfully subdued the spirit of partisanship" (Nelson 1974: 131-132). Similarly, Sinclair (1997) notes that as committees lost their autonomy it became harder to pass legislation, and that committee members increasingly looked toward party leaders for cues. Evans (2013) argues that decreases in committee autonomy are directly related to polarization in the chamber, due to party leaders becoming more central to the legislative process. If parties are operating under a largely unified banner to craft policy, then there is little reason to provide power to committee chairs that could hinder the party's goals, especially if those chairs share different preferences than those of party leadership. Questions remain regarding the implications of the legislative branch trading a system based on expertise and deliberation, for another that has tighter control by parties. 
However, if gridlock is the norm in Congress, perhaps such control over committees is one of the only ways in which policy can make it through the process.

This research poses the question: has political polarization in Congress affected the productivity of committees? Do committees remain productive as polarization increases? By design, committees are bound to their parent chambers due to direct oversight, as well as the fact that committees cannot pass legislation themselves (Deering and Smith 1997). However, Maltzman (1997) notes that as committees become more open to public observation and/or when issues in their jurisdiction become salient, they are more likely to face even stricter control by strong parties. With committee operations being open to greater scrutiny, members are more beholden to party leadership, and committee appointments have become more partisan in nature (Young and Heitshusen 2003, Becker and Moscardelli 2008). This makes it harder for the members of committees to deviate from party priorities.

Yet why should we expect polarization to affect the internal productivity of committees? For one, as parties become more ideologically homogenous, they generally do not wish to allow their opponents to score legislative victories, even on small or inconsequential issues (Lee 2016). To ensure compliance with party ideology within committees, party leaders on both sides try to stack committees with ideological extremists that will further the party's interests, which is easier when party cohesion is high (Young and Heitshusen 2003). There is little to suggest that such ideologues would favor bipartisan cooperation inside of committees if they are unwilling to do so in other legislative venues. In summary, I theorize that as Congress becomes more polarized, committees will become less productive. This leads to the generation of my hypothesis: 
Polarization Hypothesis: As polarization increases, the productivity of committees in Congress will decrease.

Understanding the productivity of committees is crucial to understanding productivity within Congress as a whole. Deering and Smith (1997) argue that committees allow Congress to manage large workloads through a division of labor. If committees are unable to perform such duties, it follows that the greater productivity of Congress would decrease. Importantly, committees also cultivate expertise on topics, and members generate respect in the parent chamber through their work. This information is an important commodity and affects the policy choices made by legislators on the floor (Krehbiel 1991, Maltzman 1998). Committees also have the power to gatekeep specific bills or agency decisions that they do not wish to send to the floor (Ferejohn and Shipan 1990, Young and Heitshusen 2003, Shipan 2004). This negative power allows committees to maintain the status quo by obstructing legislation when they choose to (Deering and Smith 1997). Such power also affords committees the ability to influence the productivity of their parent chamber through selecting which bills they wish to report to the floor. In short, committees have a great deal of influence over the overall productivity of Congress, and through their role in the policymaking process, committees can affect policy outcomes. It is therefore essential to the study of congressional productivity to further understand the role that committees play in aiding or hindering the overall productivity of the chamber.

\section{Data and Methodology}

\section{Measuring Committee Productivity}

In Congress as a whole, there is disagreement regarding which methodology should be used to best capture productivity. Some, such as Mayhew (2005), tally the total number of bills 
that Congress passes over time. Binder (1999) tracks newspaper editorials relating to problems occurring within the nation, and then records the proportion of bills that Congress passed in response. Others who study productivity examine the actions of individual members, and how effective they are at guiding bills through the legislative process (Anderson et al. 2003, Cox and Terry 2008, Volden and Wiseman 2014). As Grant and Kelly (2008:303) write: "Unfortunately, there is little consensus on what should be used as a valid measure of legislative productivity."

There are similar problems associated with examining productivity within committees. Committees perform numerous activities that one could consider to be "productive" and choosing a single indicator would create an incomplete picture. In their work, Grant and Kelly (2008) suggest incorporating several aspects of Congressional productivity into a single variable. Given this, I propose using multiple measures of productivity in my own analyses involving committees. Three metrics were chosen: the frequency of hearings held within a committee, the total number of days that a committee spent in hearings, and the total number of bills that a committee reported out to their parent chamber. This generated a data set in which these metrics could be examined over time, with the unit of analysis being the total output of each committee during each congressional session.

Yet there are other things that committees do in their day-to-day routines that could be considered "productive." Why do I only utilize these three indicators? First, much of what committees do regarding lawmaking is already included in both the action of holding hearings and reporting bills to the House and Senate. For example, the process of marking up and amending a bill is typically performed during the hearings process within committees, and then suggested to a parent chamber through reporting, both of which are utilized here. Further, while much of what committees do is recorded and publicly available, many committee actions are 
unable to be observed or quantified. Other facets of committee work may be relatively banal or have little to do with the process of lawmaking. For the purposes of this analysis, the variables that were chosen needed to be publicly available and substantively important to the process of legislative action that is performed by committees. I explain these indicators in more detail below.

The committees chosen for inclusion in the data were all standing committees in the House and Senate. The only additional committees added to the data were the House Intelligence and Senate Intelligence committees, which were chosen specifically because of their importance and prestige in both chambers. These two committees are also considered to be permanent, even though they do not technically hold the same official standing committee status. This resulted in a total of 22 committees chosen for the House, and 17 committees in the Senate. All committees, as well as the years that they were active, are listed in Appendix 3-1 and Appendix 3-2.

Regarding my chosen indicators of productivity, one of the first and most important actions that a committee can perform in the policy process is to hold a hearing. These hearings are a useful tool for committees to gather information and cultivate expertise (Krehbiel 1991, Deering and Smith 1997) as well as to set the agenda and the committee's attention (May et al. 2009). However, Sinclair (2006) notes that these hearings are slowly becoming less bipartisan, and that party leaders consider this when making policy decisions. Therefore, the inclusion of the variable is warranted, and I utilize the total frequency of hearings that each committee in the House and Senate held each session as an indicator of productivity. Data on hearings held was gathered from the Policy Agendas Project (2021), and spans from the 80th to the 114th session 
(1947 to 2016). ${ }^{14}$ This data was then filtered to include only hearings pertaining to laws or lawmaking. In doing so, the data consists of 39,514 hearings, split between 24,265 hearings in the House and 15,249 hearings in the Senate. In the House, the median number of hearings held per committee in a session is 65 , and 59 in the Senate.

These hearings are displayed over time in Figure 3-1. In the House, there is a large drop in hearings after the early sessions of the data, starting at a high of 1411 hearings in the 80th session of Congress and dropping to 503 hearings by the 86th. ${ }^{15}$ These hearings increase over time, hitting a total of 966 in the 95th session (likely attributable to changes to the committee system, and low levels of polarization in the 1970s), and then begin a gradual decline as the data nears more recent sessions. The House records the lowest number of legislative hearings in the 112th Congress, with 338 legislative hearings recorded. Roughly, the Senate mirrors many of these changes, holding a high of 1485 hearings in the 95th session and a low of 88 hearings in the 114th session. Both chambers appear to have experienced an increase in legislative hearings during sessions of bipartisanship and low polarization, and a decrease in sessions during which there was high polarization.

\footnotetext{
${ }^{14}$ Note that in early Congressional sessions, transcripts for hearings were often not published, and hearings dealing with classified materials often went unrecorded. This has created some small gaps in the hearings data, specifically from the 85th to the 92nd sessions of Congress. More information about the specifics of these limitations can be found within the associated codebook, hosted on the Comparative Agendas Project website, on pages 5-8. https://comparativeagendas.s3.amazonaws.com/codebookfiles/Hearings_Codebook.pdf

${ }^{15}$ In both Figure 3-1 and Figure 3-2, there is an unusually high number of committee hearings held and days spent in hearings in the 80th and 81 st Congress. There are a few reasons that these high numbers might have occurred. First, it could be that these numbers are simply a product of a legislative branch grappling with the aftereffects of World War 2, and this necessitated such a high number of hearings during that time. This could also simply be an issue with how these meetings were recorded, and how the data was collected. Is this an issue with reporting at the committee level? In any case, these hearings were left in the data without alteration, but in future work it may merit further investigation as to why these spikes occurred so early on, and if they are impacting the results of the analyses in a meaningful way.
} 


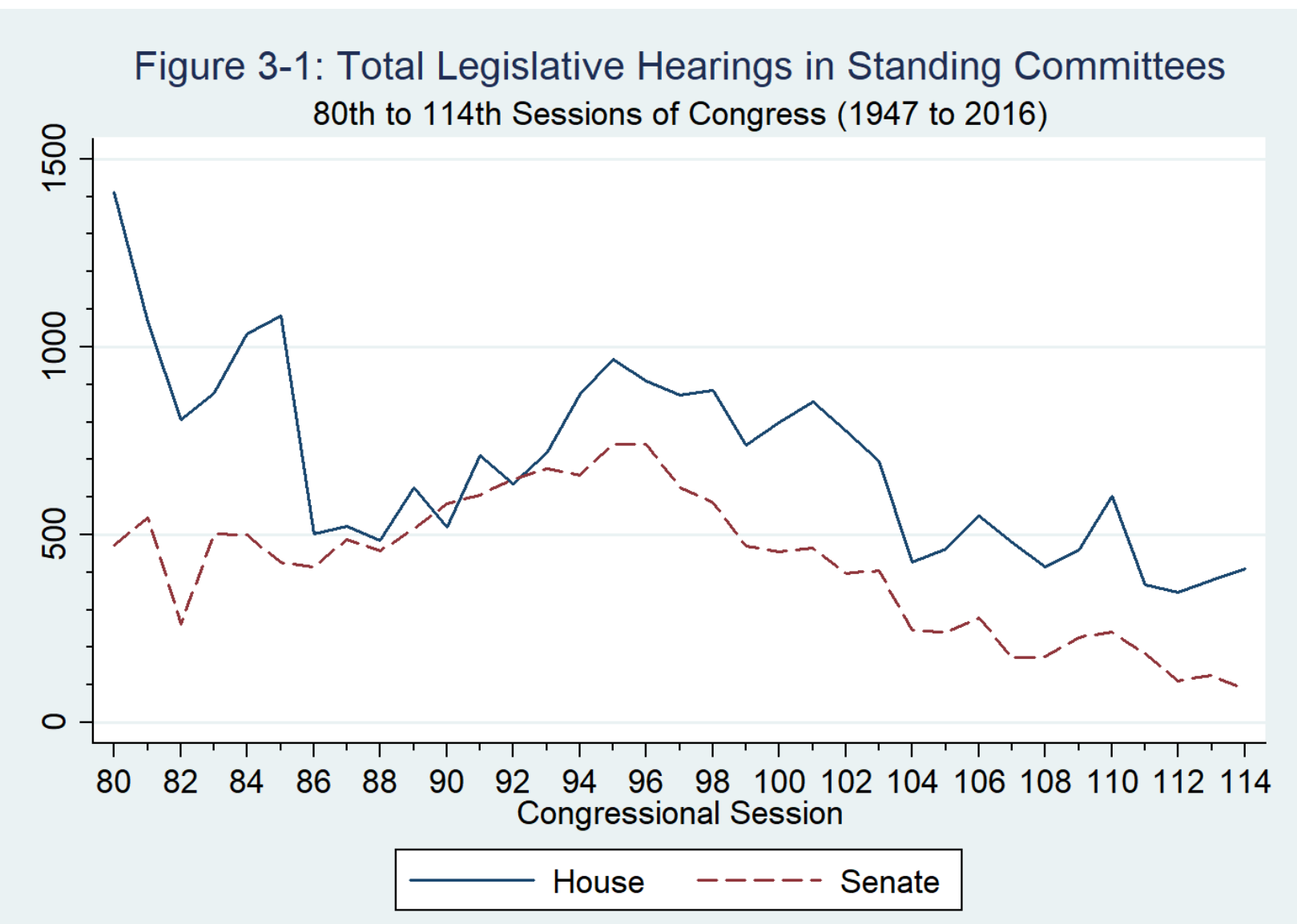

While hearings may showcase one facet of productivity, it is also prudent to consider the length of time that committees spend in these hearings. If there is a noticeable drop in the frequency of hearings in each chamber, could it be because they are spending more time on a small number of issues? Hearings could be short affairs, lasting only an hour or two, or they might last multiple days. If we assume that hearings are longer because Congress needs to gather more information during this time (meaning that they are working), simply tallying the number of hearings alone does not fully capture the amount of work that is being done within committees. Thus, a more precise measure could be created. To this end, I also utilize the total number of days that committees spent in hearings in a session as a second measure of productivity. This data is similarly available from the Policy Agendas Project (2021), and again 
spans from the 80th to the 114th session. The measure was created by simply totaling the number of days that each committee spent in hearings during each Congressional session. ${ }^{16}$ As hearings can last multiple days, this adds further granularity to measures of committee productivity. In the data, there is a recorded total of 92,101 days spent in hearings across 35 sessions, split between 59,573 days in the House, and 32,528 days in the Senate. At the individual committee level, in the House, the median frequency of hearings held per committee is 46 and 32 in the Senate.

These totals are charted in Figure 3-2. The House and Senate mirror many of the trends displayed in the previous measure, with some key differences. First, the total days spent in the House are erratic, with notable spikes in the 103rd and 110th sessions, albeit on a downward trend over time. The Senate is much more consistent in this decline, having only a recorded 41 days of total legislative hearings by the 114th session. It appears that in the aggregate, both chambers are not only holding fewer hearings, but are also spending less time within hearings deliberating on legislation.

\footnotetext{
${ }^{16}$ One clarification about how this measure was created: in the codebook, it is noted that the variable is a "...record of the number of days mentioned in the abstract." This means that regardless of the length of a hearing, hearings will always have a total of at least 1 recorded day but could last several days depending on the needs of the committee. As such, it may be more prudent to consider this variable as the total number recorded days that committees were in hearings in a calendar sense, rather than a total amount of hours physically spent in hearings.
} 


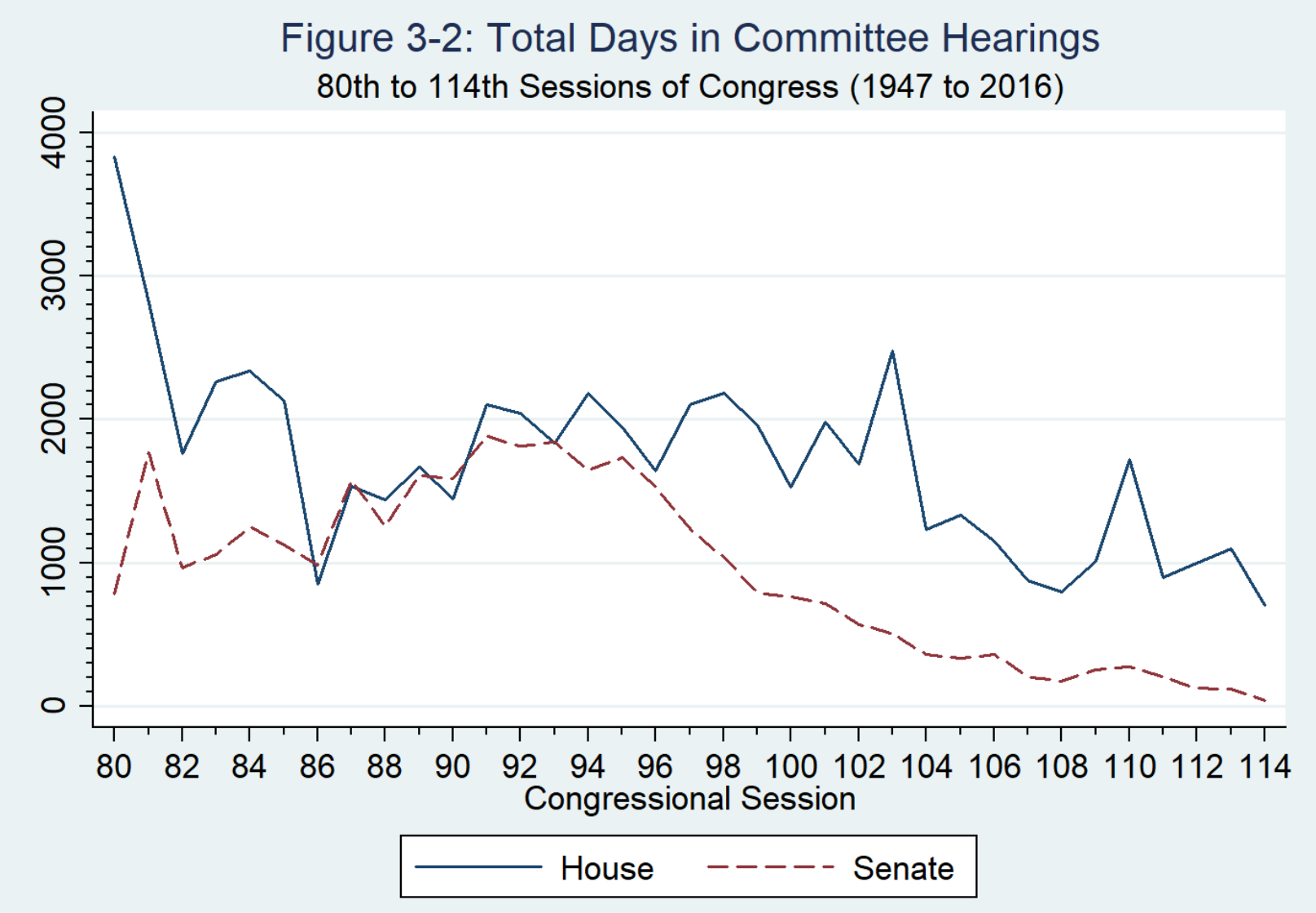

For my third measure, I total the number of bills that all committees report to their parent chamber in each session. Reporting bills is an important step in the legislative process, and committees must send bills to their parent chambers if they are to become law. This requires at least a basic level of effort on behalf of the committee, and so some researchers, such as Cox and Terry (2008), have used such bill reporting as a measure of congressional productivity (albeit with a focus on the productivity of individual members). For inclusion in my research, I collected this data from Congress.gov, and the ensuing variable ranges from the 93rd to the 114th Congress. It includes all bills that made it through the committee process, left the committee, and were sent to the bill's parent chamber. There was a total of 33,414 bills reported out of committees during this time, with the House contributing 17,674 to the total, and the 
Senate contributing 15,740. The House has a median of 810 bills reported per session, while the Senate has a median of 675. At the individual committee level, the House median for each committee is 26 reported bills and the Senate is 27 per session.

Looking to Figure 3-3, both chambers display a gradual (but erratic) reduction in the number of bills reported to the floor by committees. with the 111th displaying the lowest number of reported bills in the House (567 bills), and the 112th being the lowest in the Senate (452 bills). Interestingly, while reporting is down overall as time progresses, there are large spikes of productivity that do not follow a discernable pattern. The implication of these measures is that committees may be still sending a relatively consistent number of bills to their parent chambers, but they are less likely to hold hearings (or spend time in those hearings) to discuss the merits of such bills. It seems that while committees still have strong incentive to report bills, figures 3-1 and 3-2 suggest that they may be involved with the production of bills less than before. ${ }^{17}$

\footnotetext{
${ }^{17}$ Note that Congress.gov does not make a distinction between whether a bill went through the normal committee reporting process or whether it was brought to the floor through the usage of a discharge petition. As such, these totals are likely higher than we would expect if discharged bills were to be removed.
} 


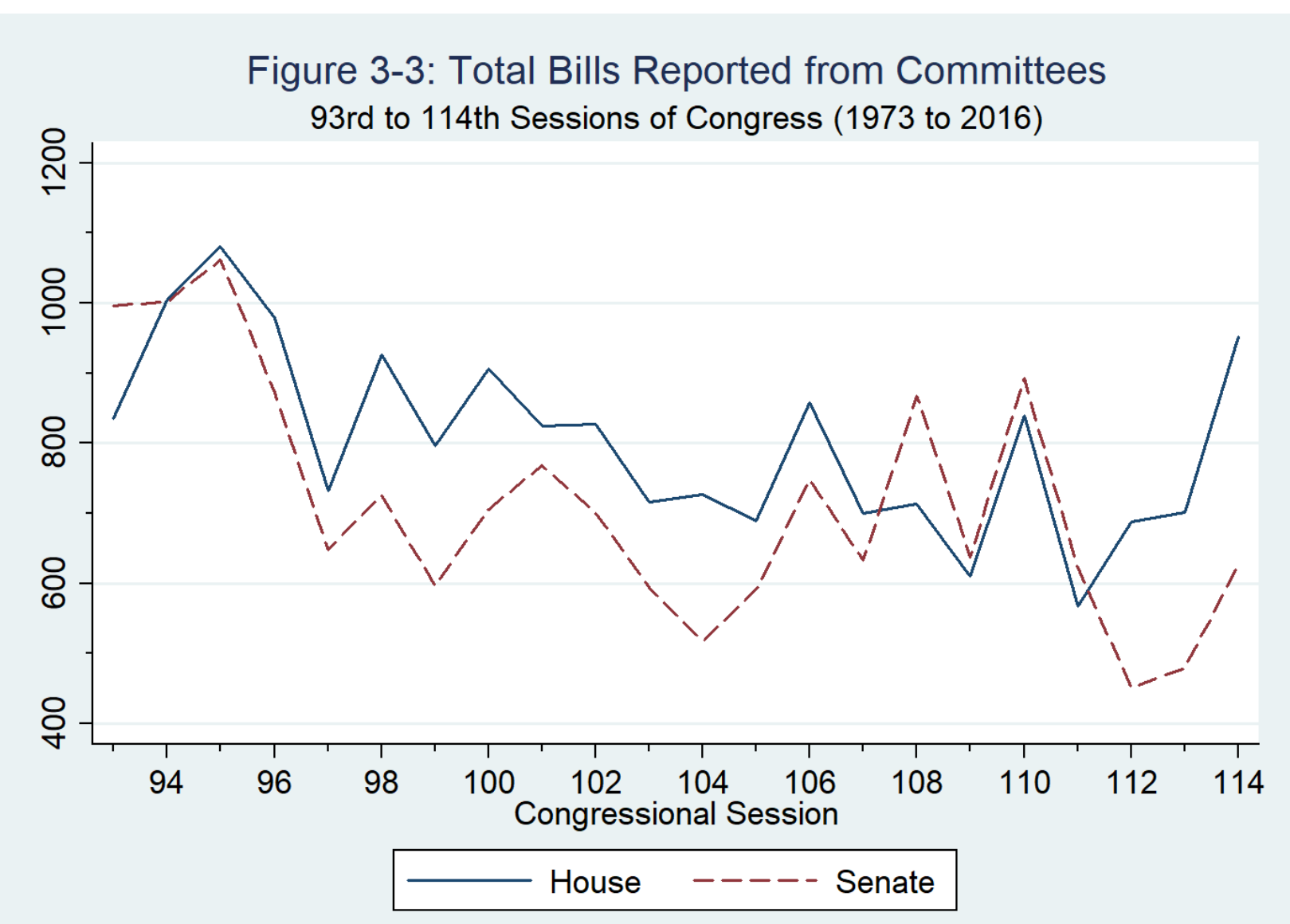

Estimating Productivity Factor Scores

With three measures of productivity established, the next step is to create a factor loading to measure the productivity of committees. Why estimate factor scores instead of choosing a single measure of productivity? The usage of such scores used in times in which researchers may wish to observe an underlying concept that may not be possible to observe directly (Fabrigar and Wegener 2012, Kim and Mueller 1978). Regarding the measurement of productivity, Grant and Kelly (2008) write that some indicators of productivity are better at capturing concepts, and account for different aspects of productivity that one indicator alone cannot. As such, it behooves researchers at times to use multiple measures to estimate a concept, as this ensures that the measurement of these variables is more reliable and valid when compared to analyses that use 
single indicators. Even in the figures displayed above, the productivity of committees varies greatly depending on which metric is chosen.

Further, this form of measurement differentiates my work from that of other scholars. For instance, Lewallen (2020) studies the productivity of committees, creating several models that utilize multiple measures of partisanship. During his examination of ideological polarization in Congress, his work uses both a similar measure of polarization (DW-NOMINATE distance), and two similar, yet distinct, legislative indicators (the proportion of hearings that a committee held that were legislative, and the proportion of bills sent to, and reported out by a committee). Throughout his work, he finds that partisanship is not a significant predictor of productivity. However, there is an opportunity to further examine this relationship through the usage of factor scores, allowing for a broader picture of productivity than individual indicators can provide alone.

When estimating the factor scores, the data for hearings held, days spent in hearings, and bills reported loaded onto a single factor. In both the House and Senate, all three variables load onto this factor at acceptable rates, with an Eigenvalue of 2.06 in the House, and 2.37 in the Senate. The resulting generated variable spans 22 sessions of Congress (the 93rd to the 114th), with 456 observations in the House and 373 in the Senate. The range of the variable is 6.54 in the House, and 4.978 in the Senate, with a standard deviation of 1 for both (due to the nature of how the variable was created). This variable is displayed over time in Figures 3-4 and 3-5, where the 
productivity of each individual committee is plotted by session. There are clear trends in both chambers: that values for the productivity variable decrease in the aggregate over time. ${ }^{18}$

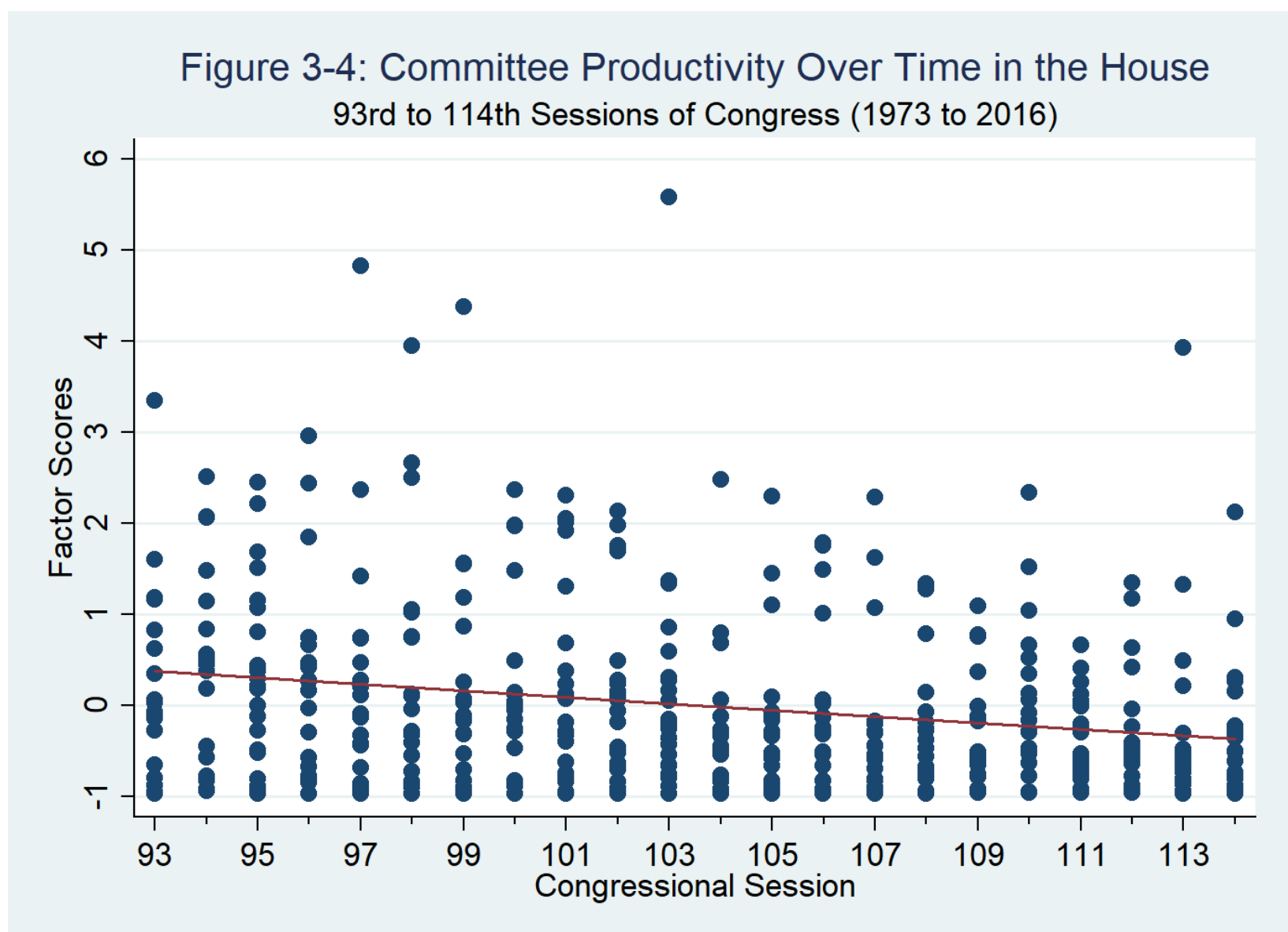

\footnotetext{
${ }^{18}$ For a different interpretation of this data, Appendix 3-3 provides a view of factor scores if they were estimated for the entire chamber, instead of individual committees. The results are largely the same, with productivity decreasing in the aggregate over time.
} 


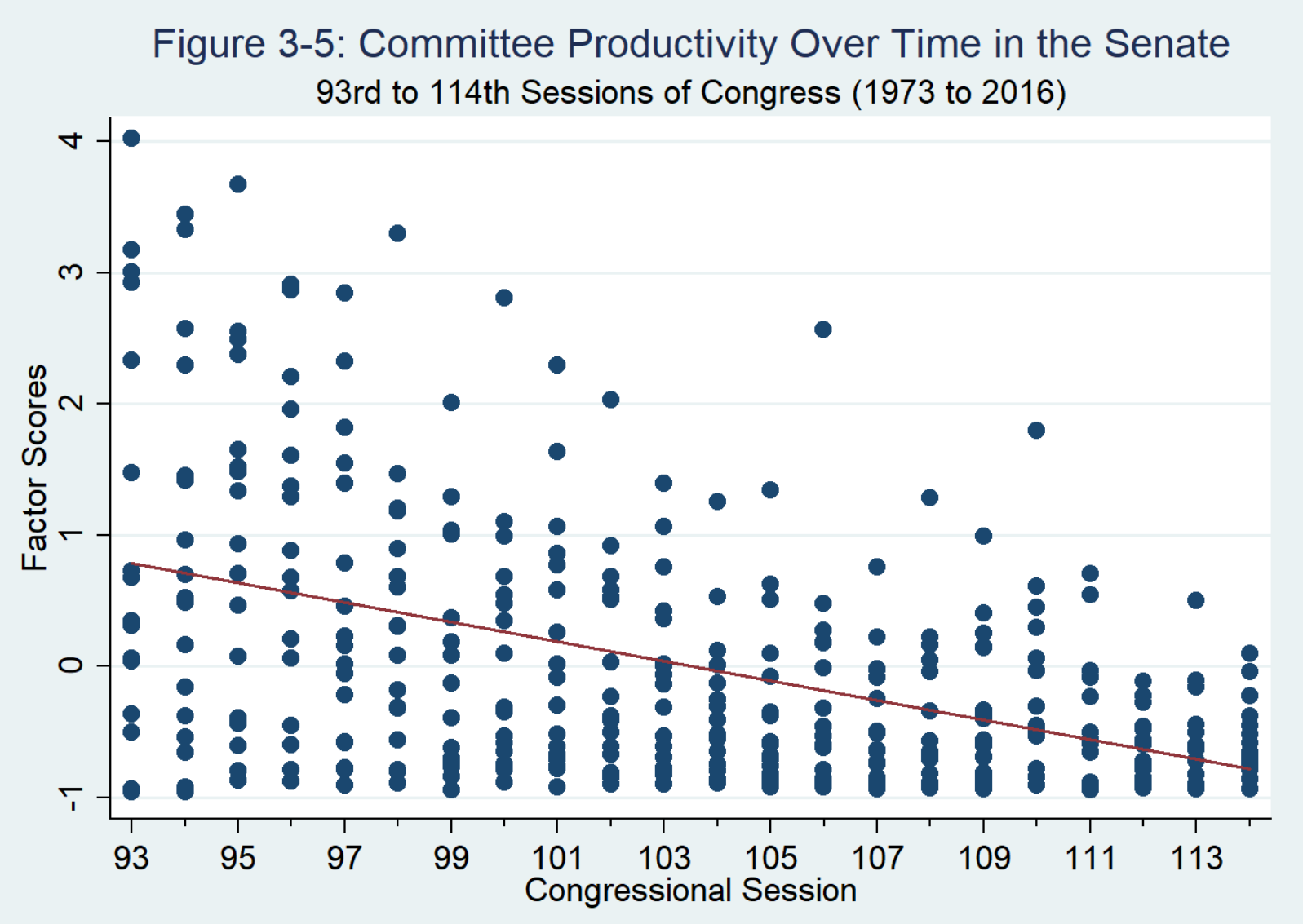

\section{Measurement of Independent and Control Variables}

The independent variable in all models is a measure of political polarization in Congress. As mentioned in Chapter 2, this measure is derived from DW-NOMINATE scores (Lewis et al. 2021), which measure how liberal and conservative members of Congress are, based upon rollcall voting records. The measure ranges from -1 , being the most liberal, and 1, being the most conservative that a member could be. Specifically, the variable used in this analysis is created by recording the absolute value of the distance between the average DW-NOMINATE score of each party in the House and the Senate.

Several control variables were included in the analysis that were theorized to also affect productivity within committees. The first is unified government, measured as a 0 if the 
government was divided and a 1 if the government was unified. The effect of unified government on Congressional productivity has been long debated, and numerous scholars have theorized that divided government has a detrimental effect on the capability of Congress to pass policy (Binder 1999, 2003, Mayhew 2005, Sundquist 1988). Within committees, I expect that unified government would have a positive effect on committee productivity, and divided government to have a negative effect on committee productivity. We should expect that members would be more likely to send bills to the floor if they have a higher likelihood of eventually becoming law.

Dodd and Schraufnagel (2013) theorize that congressional productivity increases when parties regain a majority in either the House or Senate. These sessions typically see a spike in productivity, as parties are eager to enact their legislative agendas. Binder's measure in Stalemate (2003) includes the average number of years that a party has been out of power in both chambers. However, in this chapter, the House and Senate are examined individually, and so the frequencies for each chamber are used without averaging the two variables together. I expect that this increase in activity will apply to committees, as they are the first part in the policy process through which bills are filtered. There is recent evidence to support this, as the early months of the 116th Congress had an increase in committee hearings after Democrats took a majority in the House (Gode 2019). Further, I control for the size of a party's majority in Congress, and expect that as majorities become smaller, productivity within committees will decrease. Hicks (2015) suggests that as party majorities become closer, productivity decreases within legislative bodies, as it is easier for minority parties to disrupt the policy proposals of their opponents. I expect to see the same phenomenon within committees. I also expect that when a new committee chair takes over a committee that productivity may decline in the session afterward, as there is a loss 
of expertise when a new leader takes over the role. I include a dummy variable representing whether a new chair was assigned to a committee in a session.

As mentioned previously, there have been major reorganizations of the committee system that have occurred over the course of Congressional history. To ensure that my results are not simply occurring due to changes in how committees operate, two time periods have been included as dummy variables. The first begins in the 94th session of Congress (1975-1976) after the major changes that were made to the committee system in the House by Democrats. These changes were wide-reaching, including the creation of the Subcommittee Bill of Rights (Rhode 1974), and were referred to as “...the greatest internal revolt in the House since Speaker Joseph G. Cannon was deposed in 1910" (Haeberle 1978: 1054). This period lasts until the 103rd session of Congress, after which the remaining sessions in the data (the 104th to the 114th) are coded as the second period. This second period is also of interest, because it takes place during and after the changes made by the Republican Speaker of the House, including changes to the nomination of committee leadership which consolidated power around the Speaker (Aldrich and Rohde 2000).

\section{$\underline{\text { Results }}$}

Table 3-1 presents the results of two models using data from the U.S. House in which the dependent variable is the estimated productivity variable. Model 1 specifies fixed effects, while Model 2 is a random effects model used for comparison purposes. ${ }^{19}$ The results support my hypothesis, showing that the variable representing polarization is significant at the $\mathrm{p}<0.05$ level

\footnotetext{
${ }^{19}$ As I am using panel data, it is appropriate in most circumstances to use a fixed effects estimator (Collischon and Eberl 2020). Using this estimator is useful if one expects that some unknown individual characteristics of the observations (in this model, the characteristics of the different committees) might be omitted from the model. The random effects models here are shown as a robustness check, and we should expect some slight differences between the two.
} 
in both models. As polarization increases, it appears that the productivity of House committees decreases in kind. Interestingly, no control variables have a statistically significant relationship with committee productivity in either model.

Table 3-1. OLS Estimates of House Committee Productivity

\begin{tabular}{lll}
\hline & $\begin{array}{l}\text { Model 1 } \\
\text { Fixed Effects }\end{array}$ & $\begin{array}{l}\text { Model 2 } \\
\text { Random Effects }\end{array}$ \\
\hline & & \\
Polarization (DV) & $\mathbf{- 1 . 1 6 3 ( \mathbf { 0 . 5 9 4 } ) ^ { * }}$ & $\mathbf{- 1 . 1 6 6 ( \mathbf { 0 . 6 0 4 } ) ^ { * }}$ \\
Unified government & $-0.070(0.052)$ & $-0.071(0.053)$ \\
New committee chair & $-0.036(0.047)$ & $-0.423(0.048)$ \\
Majority size & $-0.001(0.001)$ & $-0.001(0.001)$ \\
Majority years out of power & $0.001(0.003)$ & $0.001(0.003)$ \\
94th to 103rd Session & $0.125(0.118)$ & $0.125(0.120)$ \\
104th to 114th Session & $-0.076(0.178)$ & $-0.076(0.181)$ \\
Constant & $\mathbf{0 . 8 1 0}(\mathbf{0 . 3 6 9})^{*}$ & $\mathbf{0 . 7 7 3}(\mathbf{0 . 4 0 1})^{*}$ \\
& & \\
\hline $\mathrm{F}$ & $\mathbf{1 7 . 7 4}{ }^{* * *}$ & N/A \\
$\mathrm{R}^{2}$ & 0.059 & 0.059 \\
$\mathrm{~N}$ & 448 & 448 \\
\hline Standard errors in parentheses. ${ }^{*} p<0.05,{ }^{* * *} p<0.01,{ }^{* * *} p<0.001$ & (one-tailed tests)
\end{tabular}

Table 3-2 presents the results of the two models representing committees in the Senate, (identical models to the House, but using Senate data). In both models, an increase in polarization leads to a decrease in the estimated productivity variable and is significant at the $p<0.001$ level. This further supports my hypothesis, as in the models for both chambers show that polarization is a statistically significant predictor of committee productivity over time. Further, the control variables for unified government, the size of the party majority in the chamber, and both time controls are statistically significant in the Senate models, and trend in the expected direction. ${ }^{20}$

\footnotetext{
${ }^{20}$ Two-tailed tests are available in Appendixes 3-4 and 3-5. In these tests, the House variable for polarization is not a significant predictor of committee productivity at the .05 level, but is significant at the .1 level, with a $p$-value of .051 in the fixed effects model, and a .054 in the random effects model. The Senate models remain unchanged.
} 
Table 3-2. OLS Estimates of Senate Committee Productivity

\begin{tabular}{|c|c|c|}
\hline & $\begin{array}{l}\text { Model } 1 \\
\text { Fixed Effects }\end{array}$ & $\begin{array}{l}\text { Model } 2 \\
\text { Random Effects }\end{array}$ \\
\hline Polarization (DV) & $-3.491(0.668)^{* * * *}$ & $-3.502(0.669)^{* * *}$ \\
\hline Unified government & $0.644(0.098)^{* * * *}$ & $0.612(0.097)^{* * *}$ \\
\hline New committee chair & $-0.019(0.055)$ & $-0.019(0.055)$ \\
\hline Majority size & $-0.012(0.006)^{*}$ & $-0.012(0.006)^{*}$ \\
\hline Majority years out of power & $0.002(0.005)$ & $0.002(0.005)$ \\
\hline 94th to 103 rd Session & $-0.470(0.091)^{* * * *}$ & $-0.469(0.092)^{* * *}$ \\
\hline 104th to 114th Session & $-0.446(0.168)^{* *}$ & $-0.447(0.169)^{* *}$ \\
\hline Constant & $2.795(0.398)^{* * * *}$ & $2.806(0.440)^{* * *}$ \\
\hline $\mathrm{F}$ & $61.33^{* * *}$ & N/A \\
\hline $\mathrm{R}^{2}$ & 0.181 & 0.185 \\
\hline $\mathrm{N}$ & 373 & 373 \\
\hline
\end{tabular}

These results require interpretation if they are to be understood substantively. The range of the House polarization variable is 0.355 , with a standard deviation of 0.115 , while the Senate variable has a range of 0.402 and a standard deviation of 0.125 . As such, it would be highly unlikely to see an increase in polarization in the real world that is displayed within the model. However, moving from the highest to lowest level of committee polarization in the range of the variable (instead of 1), results in a decrease in committee productivity of $18.95 \%$ in the House, and $28.19 \%$ in the Senate. To visualize this differently, in Figures 3-6 and 3-7, this variable is plotted for both chambers, and is sorted from low to high levels of polarization. In both figures there is a clear relationship between political polarization and the productivity of committees in 
Congress. Levels of productivity are much higher in sessions in which polarization is low and begin to fall as polarization increases. ${ }^{21}$

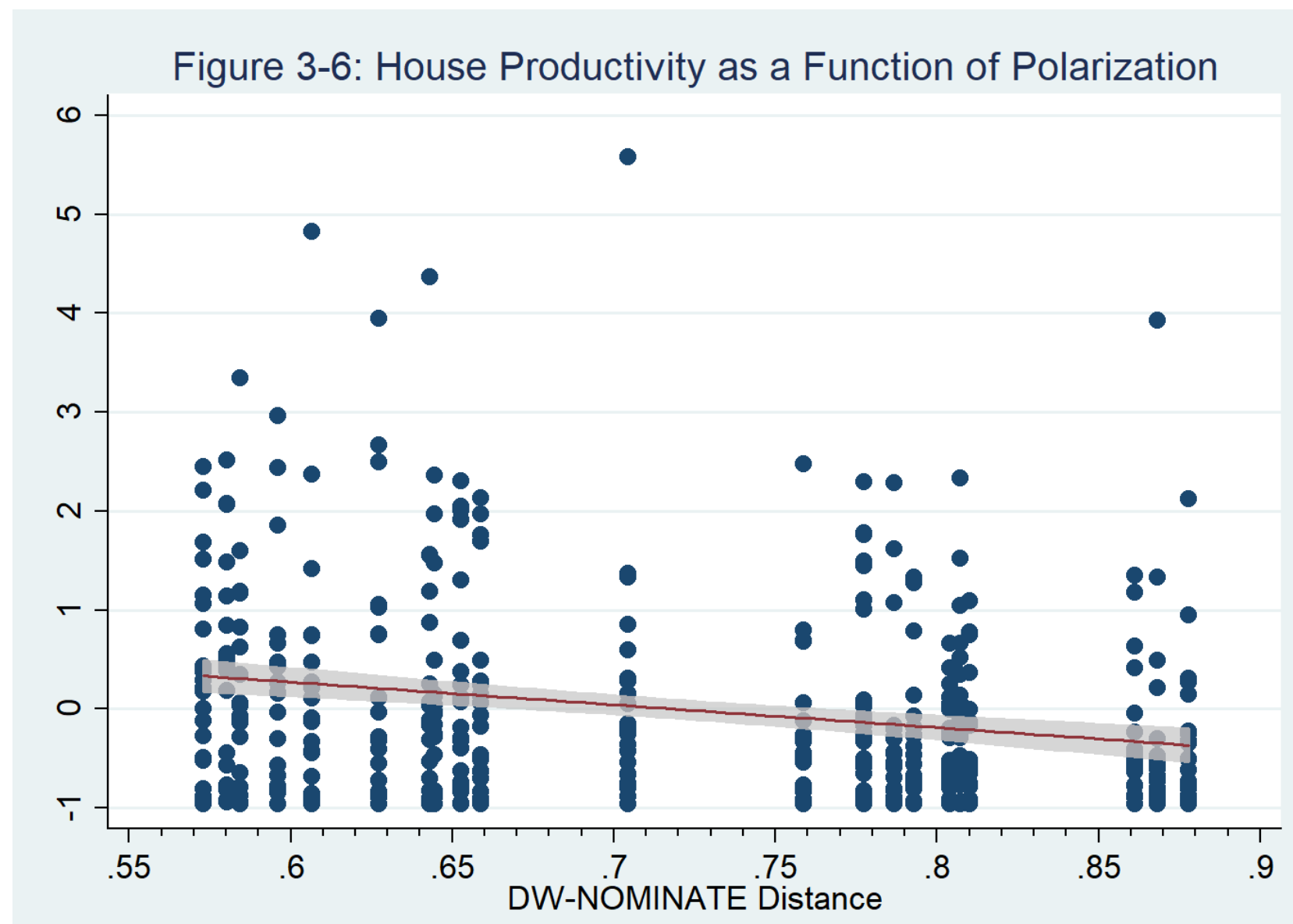

\footnotetext{
${ }^{21}$ Several negative binomial regressions were performed to assess how polarization affects the individual variables used to estimate productivity in this chapter. These are available in Appendixes 3-6 and 3-7. In summary, polarization was significant in only one model in the House, in which the total number of hearings was the dependent variable (significant at the .05 level). In the Senate, polarization is significant at the .001 level in models using both hearings and the total days spent in hearings as the dependent variable. In neither chamber was polarization a statistically significant predictor of the number of bills that were reported out of committees, suggesting that other factors may be more likely to influence this metric. These results also further reinforce the need for multiple measures of productivity when examining committees.
} 


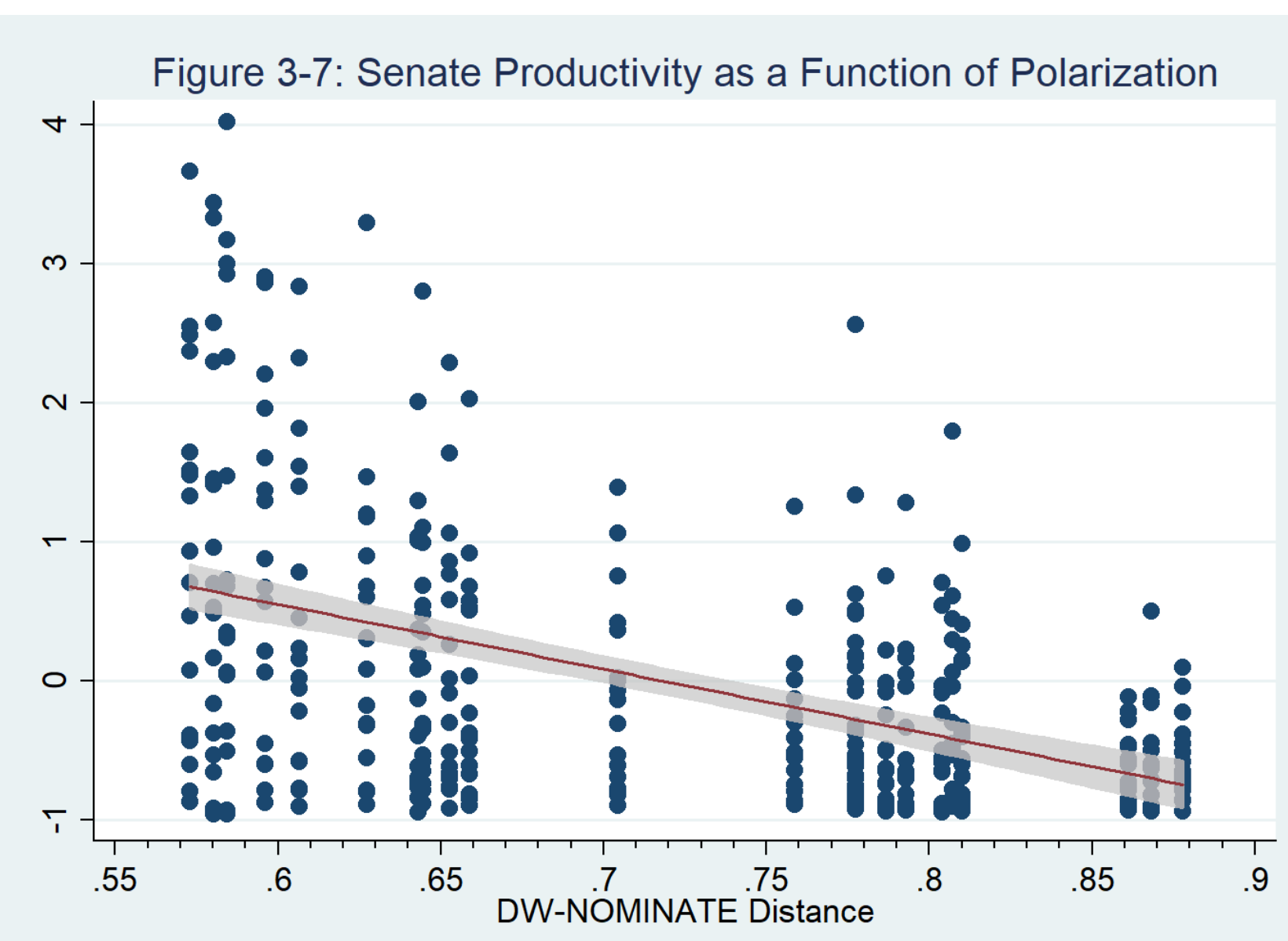

In Tables 3-1 and 3-2, I controlled for two different time periods in which large changes were made to the committee system. In Tables 3-3 and 3-4, I account for time, by including a different time variable that simply increases by one each session. Doing so produces some distinct changes to my results. In Table 3-3 showing the results for the House, the coefficient for polarization in both Model 1 and 2 is negative and remains significant at the $p<0.05$ level, indicating a larger decrease in productivity than shown in Table 1. Curiously, the coefficient for unified government displays a very small decrease in productivity during these sessions, though the sign is in the wrong direction for it to be significant. All other variables are not significant in the model. Table 3-4 displays the results for models of Senate productivity with the included 
time variable. Polarization has a smaller effect and is not statistically significant in both models. The control variables for unified government and the size of party majority perform similarly and remain relatively unchanged with the inclusion of a different metric of time.

These results are noteworthy, as it shows that polarization in the House remains a significant predictor of the productivity of House committees. While the coefficient for polarization in the Senate is not significant, it is unsurprising. As mentioned in Chapter 2, the variables for polarization and time are correlated at high levels (for example: in this chapter they are correlated at 0.97 in the House and 0.95 in the Senate), so it is likely that such results would occur once both polarization and time were included with in the same model. Regardless, the results in the House appear robust using two different measures of time.

Table 3-3. OLS Estimates of House Committee Productivity with Time Variable

\begin{tabular}{lll}
\hline & $\begin{array}{l}\text { Model 1 } \\
\text { Fixed Effects }\end{array}$ & $\begin{array}{l}\text { Model } 2 \\
\text { Random Effects }\end{array}$ \\
\hline Polarization (DV) & & \\
Unified government & $\mathbf{- 2 . 6 1 9}(\mathbf{1 . 4 6 6})^{*}$ & $\mathbf{- 2 . 5 8 2}(\mathbf{1 . 4 9 0})^{*}$ \\
New committee chair & $-0.092(0.050)$ & $-0.093(0.051)$ \\
Majority size & $-0.040(0.047)$ & $-0.047(0.047)$ \\
Majority years out of power & $0.001(0.001)$ & $0.001(0.001)$ \\
Time & $0.000(0.003)$ & $0.001(0.003)$ \\
Constant & $-0.013(0.021)$ & $0.012(0.022)$ \\
& $0.511(1.171)$ & $0.498(1.199)$ \\
\hline $\mathrm{F}$ & & \\
$\mathrm{R}^{2}$ & $\mathbf{2 0 . 0 5}$ & $\mathrm{N} / \mathrm{A}$ \\
$\mathrm{N}$ & 0.058 & 0.059 \\
\hline Standard errors in parentheses. ${ }^{*} p<0.05,{ }^{* * *} p<0.01,{ }^{* * *}$ & 448 \\
\hline
\end{tabular}


Table 3-4. OLS Estimates of Senate Committee Productivity with Time Variable

\begin{tabular}{|c|c|c|}
\hline & $\begin{array}{l}\text { Model } 1 \\
\text { Fixed Effects } \\
\end{array}$ & $\begin{array}{l}\text { Model } 2 \\
\text { Random Effects }\end{array}$ \\
\hline Polarization (DV) & $-1.195(1.345)$ & $-1.231(1.347)$ \\
\hline Unified government & $0.632(0.101)^{* * * *}$ & $0.598(0.099)^{* * * *}$ \\
\hline New committee chair & $0.007(0.056)$ & $0.006(0.056)$ \\
\hline Majority size & $-0.013(0.006)^{*}$ & $-0.012(0.006)^{*}$ \\
\hline Majority years out of power & $-0.005(0.005)$ & $-0.004(0.005)$ \\
\hline Time & $-0.050(0.021)^{* * *}$ & $-0.050(0.021)^{* *}$ \\
\hline Constant & $5.977(1.271)^{* * * *}$ & $5.978(1.287)^{* * *}$ \\
\hline $\mathrm{F}$ & $64.14^{* * * *}$ & N/A \\
\hline $\mathrm{R}^{2}$ & 0.169 & 0.174 \\
\hline $\mathrm{N}$ & 373 & 373 \\
\hline
\end{tabular}

For a final, alternative look at the relationship between polarization and committee productivity, the results of four OLS regressions are displayed in Table 3-5 and 3-6 that include a lagged dependent variable (lagged by one session). As I utilize time-series data, this variable allows one to estimate whether the dependent variable is reliant upon previous recorded values, and to reduce the possibility of omitted variable bias in the model. Looking to the results, in the House when using a model with fixed effects, polarization is significant at the $p<0.001$ level, however it is not significant when using a model with random effects used for comparison purposes. However, the lagged dependent variable is significant in both models, again at the $p<0.001$ level. The results for the Senate in Table 3-6 are largely similar, though in the variable for polarization is significant in both models using fixed and random effects. Again, the lagged dependent variable is significant in both models in the Senate. ${ }^{22}$

\footnotetext{
${ }^{22}$ Models with both a lagged dependent variable and the variable representing time are available in Appendixes 3-8 and 3-9. In short, with the inclusion of both variables in each model, polarization is not significant in both the House and Senate. However, including both is likely unnecessary, as it would be overcontrolling for the effects of time. These models are included simply for comparison purposes.
} 
Table 3-5: OLS Estimates of House Committee Productivity with Lagged DV

\begin{tabular}{|c|c|c|}
\hline & $\begin{array}{l}\text { Model } 1 \\
\text { Fixed Effects }\end{array}$ & $\begin{array}{l}\text { Model } 2 \\
\text { Random Effects }\end{array}$ \\
\hline Polarization (DV) & $-1.187(0.337)^{* * * *}$ & $-0.066(0.367)$ \\
\hline Unified government & $-0.101(0.047)^{*}$ & $-0.119(0.054)$ \\
\hline New committee chair & $-0.024(0.045)$ & $-0.048(0.051)$ \\
\hline Majority size & $0.001(0.001)$ & $0.001(0.001)$ \\
\hline Majority years out of power & $-0.003(0.003)$ & $-0.006(0.003)^{*}$ \\
\hline Lagged dependent variable & $0.351(0.047)^{* * * *}$ & $0.859(0.024)^{* * * *}$ \\
\hline Constant & $0.834(0.280)^{* * *}$ & $0.055(0.310)$ \\
\hline $\mathrm{F}$ & $7.08^{* * * *}$ & N/A \\
\hline $\mathrm{R}^{2}$ & 0.692 & 0.774 \\
\hline $\mathrm{N}$ & 429 & 429 \\
\hline
\end{tabular}

Table 3-6: OLS Estimates of Senate Committee Productivity with Lagged DV

\begin{tabular}{|c|c|c|}
\hline & $\begin{array}{l}\text { Model } 1 \\
\text { Fixed Effects }\end{array}$ & $\begin{array}{l}\text { Model } 2 \\
\text { Random Effects }\end{array}$ \\
\hline Polarization (DV) & $-1.356(0.250)^{* * * *}$ & $-0.521(0.213)^{* * *}$ \\
\hline Unified government & $0.124(0.076)$ & $-0.022(0.041)$ \\
\hline New committee chair & $0.044(0.039)$ & $0.037(0.040)$ \\
\hline Majority size & $-0.001(0.004)$ & $0.001(0.002)$ \\
\hline Majority years out of power & $-0.008(0.003)^{* *}$ & $-0.009(0.003)^{* *}$ \\
\hline Lagged dependent variable & $0.654(0.038)^{* * * *}$ & $0.849(0.020)^{* * *}$ \\
\hline Constant & $0.884(0.182)^{* * * *}$ & $0.313(0.155)^{*}$ \\
\hline $\mathrm{F}$ & $160.75^{* * * *}$ & N/A \\
\hline $\mathrm{R}^{2}$ & 0.849 & 0.868 \\
\hline $\mathrm{N}$ & 358 & 358 \\
\hline
\end{tabular}

\section{$\underline{\text { Discussion and Conclusion }}$}

In this chapter I explored the productivity of congressional committees and theorized that political polarization would influence committee output. Through the estimation of factor scores representing productivity, I provide evidence that suggests that as polarization increases, the 
productivity of committees decreases in kind. These findings are robust across multiple measures, in both chambers, and (with some exceptions), robust across multiple variables representing time. Many have written scholarship that implies that Congress is unable to pass the quantity or quality of legislation that it once was, yet few have examined the productivity of committees within this process. It appears that the once powerful system of committees in Congress has been replaced with one of strict party control and reduced output.

While this chapter implies a bleak outlook regarding the future of the committee system, there is some evidence to suggest that while committees may be less involved in the production of legislation, that they have simply shifted to more of an oversight role (Lewallen 2020). Yet even with such a shift, if committees are steadily performing less of their historical duties, the findings in this chapter have wide-reaching ramifications for the policymaking process. Committees are where Congress generates policy expertise on specific subjects, and this knowledge can help to ensure that bills of quality are produced. If parties are taking over more of this role, and committees are no longer as prominent in the process, has this influenced the quality of legislation? Future work might delve deeper into questions involving policy outcomes when committees do not function as they once did. These results fall within a greater literature of congressional productivity, and this chapter has suggested ways in which we can evaluate the role and output of the committee system in Congress. It shows that polarization does not simply affect the amount of policy that a chamber produces, but that it also affects the productivity of long-standing institutions within Congress as well. The intention of this research was to generate a discussion of whether committees maintain normal levels of productivity as polarization increases, and to empirically test the relationship between polarization and committee productivity. Moving forward, this chapter stresses the importance of examining the component 
parts of the legislative process in Congress, and that committees may be an important part of understanding the reduction in congressional productivity as a whole. 


\section{Chapter 4: Polarization and Appropriation Riders}

\section{$\underline{\text { Introduction }}$}

In the United States Congress, the appropriations process has become a yearly battle between Republicans and Democrats. To this end, members frequently utilize dilatory tactics to hinder the policymaking capabilities of their opponents (Sinclair 2012), in order to keep them from achieving their legislative goals. The annual budget process is becoming more contentious and difficult to maneuver, and this gridlock is leading to extreme outcomes, such as government shutdowns and painful monetary compromises (Meyers 2014). As Representative David Price once commented: “The appropriations process — that hallmark of Congress's constitutional authority and wellspring of our power to conduct oversight and set national priorities — is on life support and in danger of total collapse" (Price 2013).

Amidst this gridlock, the appropriations process is changing. Over time, alterations to the committee system brought transparency to the appropriations process (LeLoup 1984), but these changes also slowly shifted much of the power of the appropriations process into the hands of party leadership (Sinclair 1997). The committee's once prized autonomy has atrophied and has been replaced with a process that is more open to partisan attack. Appropriations bills, once used solely to fund government expenditures, are becoming attractive vessels for members to advance their policy goals. These bills, due to their importance, are viewed as a means by which to bypass the policy preferences of sitting presidents, or to pass legislation that could not make it through the process normally. As such, there is often a strong incentive to include unrelated legislation within these bills (Casas and Wilkerson 2020). 
Have party leaders always used the appropriations process in this way? Aldrich and Rohde (2000) theorize that as parties become more homogenous, they are more likely to funnel power to their leaders, who then use those powers to advance party agendas. In the context of the appropriations process, this power might include the phenomenon of authorizing unrelated policy through appropriations bills. They note that this practice rose to prominence in the mid-1990s during the reforms instituted by Speaker Gingrich, who used the leverage that appropriations bills provided to pass several policy proposals that were favorable to the Republican Party. What is unclear in the literature is if, and how often, previous leaders used this process to enact their party's policy goals. This chapter attempts to answer questions regarding how frequently the appropriations process has been used for the authorization of legislation, and whether polarization has affected the frequency with which this phenomenon occurs.

In this chapter I examine how the appropriations process has become an avenue for policy change. Specifically, I collect all appropriations bills that were passed into law from 1922 to 2018. By tallying the number of changes that these bills made to the U.S. Code, I determine the frequency of lawmaking that occurs by using these bills as vessels for unrelated policy. These dates were chosen because they include all available bills passed after the Budget and Accounting Act of 1921 (PL 67-13), which established much of the protocol of the appropriations process that is still used today, creating a meaningful cutoff point for the data. I theorize that polarization and divided government increase the likelihood that members will use the appropriations process to make substantive changes to the law. Data was collected from all appropriations bills that were passed into law between the 67th and to 115th sessions of Congress (1921 to 2018). Using information obtained from the Office of the Law Revision Counsel, I totaled the number of changes made to the United States Code that originated from 
appropriations bills. Then, I performed negative binomial regressions utilizing multiple specifications of polarization to assess the relationship between polarization and the frequency of changes to the code.

The results suggest that in times of high polarization, and in sessions in which the government is fully divided, legislators are more likely to use appropriations bills as an avenue to accomplish their policy goals. The findings provide further evidence that when members cannot find means by which to pass policy through the enactment of laws, that they will often utilize alternative measures that bypass the regular legislative process.

\section{Appropriations and Policymaking: Literature Review and Theory-Building}

The appropriations process in the United States Congress was once perceived to be largely bipartisan. When Richard Fenno (1966) was writing his seminal book, The Power of the Purse, the House Appropriations Committee was viewed by its members as a guardian against unchecked spending. While the Committee was not without conflict, members of the committee focused on wielding power within the chamber, and on making responsible spending decisions. As Aldrich et al. (2013: 211) note, this autonomy was highly valued, and numerous efforts were made to ensure that the committee maintained a public air of bipartisanship. These efforts included reducing the number of public roll call votes that members had to make and choosing members for the committee that represented safer districts, so that they could make the difficult choices that the House requested of them with less fear of electoral repercussion.

However, over the next few decades, the House Appropriations Committee (and its Senate counterpart) became unable to stop the growth of the federal budget and experienced numerous changes to its hierarchy and meeting requirements. Committee hearings and 
procedures became open to the public, and as such, saw an increase in attendance from interested parties, such as the media, or interest groups associated with the topics being discussed (Schick 1981). This decreased hard bargaining for spending cuts that members would normally perform in relative secrecy, away from the prying eyes of donors or their constituents (Leloup 1984, Arnold 1990:101-102). These changes allowed members to turn the committee into a platform for advocacy, rather than a check on the federal budget.

In particular, the 1990s were a turbulent time for the committee system in Congress, and the appropriations committee was at the forefront. As Aldrich and Rohde (2000) note: The 104th Congress experienced numerous institutional alterations, championed and enacted by the Speaker of the House, Newt Gingrich. Republican leadership had long wanted to break up the existing status quo of the system, and in doing so, funneled power toward the Speaker. Working outside of the seniority system, Gingrich began appointing party loyalists to the Appropriations Committee. As a result, perceptions of the Committee began to change. Members slowly began to seek positions on the Committee to direct funding toward their own interests (Alder 2000), and party leaders soon viewed the Committee as an avenue to advance their partisan goals (Currinder 2009). Alongside these alterations to the Committee also came an increased usage of riders in the appropriations process. ${ }^{23}$ Republican leadership, seeing an opportunity to advance their party platform, tightened control over the agenda, circumvented the standing committee process, and began using appropriations bills as vessels for passing unrelated policy that was favorable to their interests (Aldrich et al. 2013: 203).

\footnotetext{
${ }^{23}$ Debates over the usage of riders in the appropriations process are not new, though the frequency in which they are used has increased over time. As Devins (1994) notes, appropriations riders have been discussed in Congress as far back as the 1830s, but the legislative tactic did not begin to see regular use until the 1970s.
} 
The modern appropriations process is one that is fraught with polarization and conflict. In Congress as a whole, members are finding it difficult to get their preferred policies passed. Polarization is increasing, and so too is the ensuing legislative gridlock, which leads to a decrease in legislative productivity in Congress (Binder 2003, Lapinski 2008, McCarty 2007). Appropriations bills are not excluded from the gridlock that is affecting the legislative branch and have become avenues of partisan warfare. Sinclair (2012: 116-117) writes that in both the House and Senate, the minority party is becoming more frequent in its use of dilatory tactics, which often include proposing large numbers of amendments to appropriations bills. These strategies are utilized to attack the majority party, in an attempt to disrupt their legislative goals within the appropriations process. As such, appropriations bills are becoming more difficult to pass.

Yet without appropriations, there is nothing to fund the government's expenditures, and this makes appropriations bills unique in their importance. These bills have a higher priority than many others, and the need for funding is often immediate. In addition, without agreement on spending bills, unpopular government shutdowns occur, which can create leverage to force opponents to pass bills, lest they portray themselves in an unfavorable light to the public and their constituencies. For some members, this can be an opportunity to pass legislation that is unrelated to the appropriations process. When members cannot accomplish their policy goals in the "normal" way, they often turn to unorthodox methods of doing so (Sinclair 2012). As Casas and Wilkerson (2020) show, the policy process has experienced distinct changes that increased the usage of "hitchhiker bills," in which language is added to an existing bill, either in addition to its original contents, or by removing and replacing the wording of the original bill entirely. They also note that by using these bills, members are able to achieve more of their goals in a bi- 
partisan fashion, even when partisanship may be high. Appropriations bills are often targeted for this legislative tactic.

Passing unrelated bills using appropriations can become a political gamble that does not always pay off. A prominent example occurred early into the Clinton administration, after Republicans had taken control of the House and Senate. In the early 1990s, President Clinton's administration had worked with environmental groups to create what was called the "Northwest Forest Plan." This plan restricted the amount of logging and deforestation that could be done in the Pacific Northwest in an attempt to protect endangered species in the area (Spies et al. 2019). As part of their broader objectives to roll back Environmental Protection Agency regulations, Republicans attempted to pass legislation that re-opened these areas for commercial use, particularly for the salvaging of dead trees and fallen wood from the forest floor (Zellmer 1997). ${ }^{24}$ A secondary provision of the bill included the ability for these companies to cut down old growth trees in these locations (Hodges 1996).

Congress first passed the provisions in a bill that was sent to President Clinton and was promptly vetoed (Zellmer 1997). Shifting tactics, Republican leadership chose to use the appropriations process to pass the policy, creating what would be known as the "Salvage Rider" that would be attached to an appropriations bill. As Aldrich and Rohde (2000: 14-15) explain: Republican leadership utilized this strategy for several reasons, detailed in a 1994 letter sent by Representative Armey (who was the Republican House Majority Leader at the time) to several committee chairmen. He outlined that using riders would allow them to bypass standing

\footnotetext{
${ }^{24}$ Note that there was an associated legal loophole implied in this arrangement, in that there were very few restrictions on what could be labelled as "salvage". As long as a single piece of wood that came from a company's haul could be classified as salvage, logging companies could use this label to have significantly more autonomy in how they conducted their work, and what kind of trees they could harvest (Hodges 1996).
} 
committees that may find their policy preferences objectionable (such as the slashing of EPA regulations), and with much less attention than a normal bill. They would not only avoid coalition-building with Democrats, but most importantly, the process would allow them to bypass the President, with Armey stating: "With the knowledge that President Clinton will have to sign the 13 appropriations bills, it is in our best interest to use these bills to further policies that reflect our party's goals and priorities."

With this in mind, leadership clearly intended to leverage the power and importance of the appropriations process against President Clinton's policy preferences, and they attached numerous riders to appropriations bills ${ }^{25}$ that altered regulations of various agencies, predominantly focusing on the EPA and environmental protections. ${ }^{26}$ Responding to this tactic, the President threatened a veto on any appropriations bills that did not meet the environmental standards his administration wished to maintain (Getstenzang 1995). With a government shutdown looming, and no budget passed, Congress sent the President a temporary budget bill, which was vetoed by President Clinton, as it included numerous unfavorable riders, including changes to Medicare (Fram 1995). The budget standoff led to a 21-day government shutdown, until Republicans eventually compromised and acquiesced to most of the President's preferences (Zurcher 2013).

\footnotetext{
${ }^{25}$ Many of these changes were included in a Veterans-HUD appropriations bill, which Aldrich and Rohde (2000) report had almost 30 pages of added deregulatory material in it. Given the original number of pages of actual appropriations provisions, this meant that after riders were included, roughly $1 / 3 \mathrm{rd}$ of its material originated from such riders.

${ }^{26}$ To give further context, the Interior appropriations bill contained proposed changes that included cutting the Interior Department's funding, using federal land in California for nuclear disposal, opening up logging in a national forest in Alaska, allowing the sale of mining rights on federal land, and limiting how much revenue Native Americans can make from casinos. Also, a measure to study the national park system (with the intent to find places to close) was defeated in the House but then quickly placed into the bill as a rider (Gerstenzang 1995).
} 
What of the aforementioned "Salvage Rider?" The final provision was attached to an emergency supplemental appropriations bill to provide aid to those who had suffered losses in California earthquakes and the Oklahoma City bombing, finally being passed into law in June of 1995 (P.L. 104-19). Once enacted, the rider allowed the Forest Service to alter their previous environmental standards, to ignore the input of other agencies, to double their original output of timber by logging in areas with endangered species and allow removal of both live and dead trees in several previously restricted areas (Hodges 1996). These changes angered environmental groups, and their ire was directed at both Republicans for including the rider, and the Clinton administration for signing the bill and deviating from the previously established protection plans (Zellmer 1997). Numerous protests occurred in response, with some activist groups engaging in civil disobedience in the affected forests (Davis 1996). The backlash, and the ensuing ecological ramifications, led Vice President Al Gore to call the enactment of the rider the "biggest mistake" their administration had made in their first term (Sonner 1996). Efforts to repeal the rider through legislation were submitted in Congress but did not receive enough votes to pass in the Senate.

(Elderkin 1996) While the rider was successful for a time, eventually Agriculture Secretary Dan Glickman (at the behest of the administration) directed the Forest Service to discontinue many of the new logging practices until the provisions expired (Hodges 1996, Elderkin 1996).

Not all riders result in political turmoil, and in theory, members can utilize the appropriations process to bring about favorable policy outcomes with a lower profile than would be expected from a normal bill. For example: major appropriations legislation in recent years has included riders that address everything from how guns are regulated (Keith 2013), to protections for endangered species (Molvar 2015), or even what constitutes a "whole grain" in public school lunches (Aubrey and Charles 2015). In some cases, just the threats of these riders can be used to 
apply pressure to opponents or accomplish a political goal, such as Nancy Pelosi threatening the usage of riders to protect the investigation of Special Counsel Robert Mueller (Pelosi 2019).

Such practices have also made it difficult to pass appropriations bills in their "normal" manner. Woon and Anderson (2012) find that as ideological distance increases between key players in the appropriations process, so too does the length of time that it takes to pass appropriations bills, as these members will use the process to bargain with their opponents. In doing so, the process is more time-consuming, which restricts other work that can be performed by the chamber. As some members of Congress have claimed, these and other issues have led to the usage of large omnibus bills to pass policy (Titus 2016). In general, omnibus bills have gained popularity since the 1980's (Krutz 2000) as a means to increase legislative productivity when policy is difficult to pass. Omnibus bills are dense, easier to bundle legislation in, and often distill a multitude of issues into one binary choice. As Sinclair (2012) notes: while appropriations bills were once passed individually for each agency, they are now typically lumped together into such omnibus bills. As a result, these appropriations bills are often large, and filled with numerous and often unrelated pieces of legislation.

Consider for example, the Cybersecurity Information Sharing Act of 2015 (S.754), or 'CISA': a proposed bill that increased legal protections for companies who share the personal data of their customers with the Federal Government. Originally, the bill had twice been proposed and passed through the Senate Intelligence Committee but failed to make it to a full vote in either the Senate or the House in either instance (McNeal 2014). The bill was reintroduced, and Senate Majority Leader Mitch McConnell attempted to attach the language of the bill to a national defense appropriations bill in the Senate. Later, he was stopped through a filibuster by Democrats who claimed the bill needed to be debated on its own (Kelly 2015). In 
October of 2015 the Senate brought the bill to the floor, debating and passing a version of the bill in a 74 to 21 vote (Peterson 2015). When CISA was eventually signed into law by President Obama, it had been updated with stricter language, and had been quietly introduced as a policy rider to the Consolidated Appropriations Act of 2016 (P.L. 114-113).

Why was this bill attached to, and ultimately passed through, the appropriations process and not through the normal procedures of bill passage? Although the bill had support from the executive branch, as well as major technology companies, the bill would still need to have been debated in the House and had drawn concern from advocacy groups that had lobbied and defeated similar bills in the past (Darrow 2015). Logically, placing the bill within an omnibus appropriations bill accomplished several goals for members who had championed the policy. First, CISA had already been involved in a series of missteps and roadblocks that had kept it from being passed previously. Placing it within appropriations legislation made it more difficult for those opposing the bill to block it from becoming law, as it put them in a position where they would have to convince other members that their concerns were worth voting down funding for the government. This tactic also brought important political cover for members who might normally face the ire of voters and donors who are concerned about data collection. Looking to Arnold (1990: 100-102), such procedural methods allow breaks in the causal chains that voters can trace back to their elected representatives. Further, coalition leaders have capabilities to schedule secret meetings, place restrictive rules on bills, and to bundle bills into larger ones (much like they did with CISA). As such, it allowed members to remain insulated from potential political ramifications if they wished to support it. Finally, the bill avoided debate that could have diluted its provisions through compromise and retained its original functionality. For the reasons outlined in this example, I believe this demonstrates that the appropriations process has 
become a vessel through which members of Congress can accomplish their policy goals by including unrelated legislation within these 'must pass' bills.

To summarize, it appears that polarization is making the normal policy-making process difficult, and that members are increasingly turning to unorthodox methods of passing policy in order to accomplish their policy goals. Members vest more power in party leaders, who are using this power to alter the rules of the legislative process, and use new methods of policymaking, including the usage of appropriations bills to authorize unrelated policy. As a result of polarization, and the difficulty of passing regular appropriations bills, these bills are becoming more likely to be passed as omnibus bills, or in other unorthodox methods of passage. Due to the importance of appropriations and the need for yearly passage, there are strong incentives to place legislation within appropriations bills when polarization is high. These considerations lead to my first hypothesis.

Polarization Hypothesis: As polarization increases, the volume of legislation enacted using appropriations laws will increase.

Regardless of their size, appropriations bills will eventually go to the president to be signed into law or be vetoed. If the president and Congress largely agree on the contents of the bill, we might expect less resistance from the president, and a higher likelihood that the bill would be signed. In such cases we might expect that the president's advisors would engage in negotiations with Congress regarding the president's preferences about what should be included in the bill, making it less likely that he would choose to veto it. Yet what happens when the president and Congress are at odds, for political reasons or otherwise? In such cases, presidents may utilize the threat of a veto to force Congress to remove objectionable riders that have been placed into appropriations bills. As Hassell and Kernell (2015) show, presidents were much more 
likely to threaten a veto if the opposing party was in control of at least one chamber. Similarly, these threats were often successful in moving the legislation toward the president's preferences when the president's party was in control of a chamber.

As Hassell and Kernell demonstrate, if the president's party only has control of the executive branch and does not have control of the House or Senate (a fully divided government), it is logical that the president would have less negotiating power over this policy movement. As such, placing unrelated provisions into "must pass" appropriations bills would be an avenue for members to circumvent the president's preferences, and make it more likely that the president will accept provisions that he dislikes. In this way, Congress can be a check upon the executive branch by bundling legislation together in a way that forces the president to make a choice: accept the provisions or accept the possibility of a government shutdown. As Devins (1994: 64) puts it: "Congress has strong incentive to use this power. Appropriation riders are easier to enact than substantive legislation. Riders too are an effective mechanism to check both the executive and the Supreme Court. That the benefits of Congress's use of appropriation riders may strain the policy-making process does not matter. Congress is unlikely to abandon a policy tool that is as convenient as it is potent." We should expect that divided government would influence this process, especially when the president is of a different party than Congress and would potentially veto such legislation. These bills allow avenues to circumvent polarization-induced gridlock, and to bypass a sitting president's policy preferences. Thus, I generate a second hypothesis:

Divided Government Hypothesis - During congressional sessions in which the government is fully divided (meaning that the House and Senate are controlled by one party, and the president another party), the volume of legislation enacted using appropriations laws will increase. 
Yet these two hypotheses do not create a complete picture. We must also consider how polarization and divided government interact, as the relationship between these two variables is just as important as the variables themselves. We should expect cooperation to be more likely in several circumstances. If the government is unified, they may not need to bypass a president that agrees with them, as presidents from the same party would be unlikely to veto their own party's legislation. We might expect that cooperation could happen in circumstances in which Congress passes policy that was closer to the president's ideology, which would make the president more likely to sign it. Yet when the government is divided, and there is higher polarization, it can be difficult for parties to craft legislation that the president would sign. As Lee shows us (2009, 2016), members are pressured to avoid doing anything that would give their opposing party a 'win.' As such there would be increased pressure in polarized sessions for parties to bypass a president's veto, and the appropriations process is a convenient way to do so. Bolton (2020) also provides evidence suggesting that when gridlock is high and the government is divided, the House and Senate Appropriations Committees increasingly use committee reports to to provide direction to agencies within the executive branch. In this way, the committee has the means by which it can exert power over president. Given the important interaction between polarization and divided government, I generate this hypothesis:

Interaction Hypothesis - During sessions in which polarization is high, and the government is fully divided, the volume of legislation enacted in appropriations laws will increase.

\section{Other Pressures on the Appropriations Process}

We should expect that other variables might affect this process as well. For example, in the session after a president is elected it is possible that there would be a decreased usage of this process by Congress. The literature suggests that presidents have an increased influence over the 
congressional agenda in their first session after taking office (Brody 1992) and more political capital during this time (Light 1999). As such, presidents are more likely to accomplish their legislative goals early in their time in office, rather than later (Dominguez 2005). In the context of this research, these "honeymoon periods" where presidents have a greater control over the actions of Congress and have increased agenda-setting power might require less unorthodox methods of policy passage (especially if the government is unified). On the other hand, there is an urgency associated with the early days of a presidency that could pressure presidents (with the help of party leaders in Congress) to push through legislation quickly, which could increase the usage of the process. Similarly, there is also evidence that when parties have been out of power for a lengthy period of time, they have increased motivation to accomplish their legislative priorities (Binder 2003). I include control variables in my analyses to account for both honeymoon periods and how long a party has been out of power (meaning how many years it has been since they were in control of a chamber of Congress).

It is possible that the increasing Unites States national debt may also affect this phenomenon. The national debt is often of concern to legislators, and in theory, can hinder the efforts of lawmakers in what they are willing to vote for, due to the amount of money it might cost, or an unwillingness to fund new programs when the debt is high. Thus, we might expect that the larger the budget deficit grows, the harder it may become to authorize policy by normal means, because willingness to spend (and therefore the ability to make more legislators happy) would decrease. This would make the appropriations process a more attractive avenue for authorizing policy in sessions in which the national debt is high. Conversely, we might also expect that a higher debt might draw more scrutiny regarding spending, and therefore make it harder to include unrelated riders. In the analyses in this chapter, I account for US debt by 
including the ratio of debt to GDP for each session. In times of high polarization, we might expect legislators to use the threat of the looming deficit as a way to attack political opponents, so it is likely that polarization would have an effect on this relationship. An interaction term between debt and polarization is included as well to account for this dynamic of potentially higher usage in times of high polarization.

\section{Data and Methodology}

The unit of analysis in this chapter is a congressional session, with a total of 49 sessions/observations in the data. ${ }^{27}$ Similar to Bolton (2020) I start my analysis in 1922, as it was the year that the impacts of the Budget and Accounting Act of 1921 (PL 67-13) came into effect. As mentioned above, this act established much of the modern protocol that is used in the appropriations process, and centralized spending from several aspects of the government into the Appropriations Committee. In a sense, the appropriations process was functionally different before its passage, and so it serves as a meaningful cutoff point for the data.

\section{Creating the Dependent Variables}

I utilize two different dependent variables in my analyses: the total number of changes to the United States Code, and the range of pages that those changes occur on. To create both variables, I first generated a list of all appropriations bills from the 67th Congress to the 115th (1921 to 2018). ${ }^{28}$ Once this list was created, the information for each bill was used to find an

\footnotetext{
${ }^{27}$ Note that there is a single exception to this total: Model 4 uses a gridlock interval as an alternative measure of polarization. This measure has a total of 47 observations, as the available data was two sessions shorter than the other two measures of polarization utilized.

${ }^{28}$ The two websites used to generate this list were https://www.loc.gov/law/help/statutes-at-large/ and https://www.govinfo.gov/app/collection/STATUTE/ A read of bill titles and purposes was performed, and a list was generated of all bills that mentioned appropriating funds. While most bills were forthcoming in their purpose, each bill was examined a second time by double-checking the actual text of the bill against the stated purpose of the bill. This helped to reduce coding error, and to help eliminate bills that did not meet requirements.
} 
associated entry of the Table III tool of the Office of Law Revision Council (OLRC 2020). This office allows public access to any bill that has made changes to the United States Code, and the tool catalogs which changes to the code were specifically added by individual bills. Then, I generated a count of the total number of changes to the code that were made from each appropriations bill, which then allowed me to tally the total number of changes that were made in each congressional session. ${ }^{29}$

It is important to clarify what a "change" is in the context of this chapter. When a bill is passed into law (including appropriations bills), it is sent to the Office of the Law Revision Counsel. This office reads the language of the bill, and then updates the code accordingly. A single change to the code could be several things: words added, words that are removed or struck out, and words that are replaced or modified. In the absence of riders, appropriations bills only need to modify the code to be in line with new spending levels for the upcoming fiscal year. Continuing appropriations for example, typically require very few changes to the code (if any), as they simply re-use the previous fiscal year's spending levels. Lengthier bills, such as omnibus appropriations bills, require a much larger number of changes to update the code. If riders are placed within the bills with the intention of authorizing unrelated legislation, so too will the number of changes increase, as those authorizations will need to be added as well. In the data, the changes variable has a mean of 532.80 changes made per Congressional session, with a range of 2,594, and a standard deviation of 552.89 .

\footnotetext{
${ }^{29}$ While I do not account for what kind of changes are made to the code from each appropriations bill, I believe that this is an important avenue for future research. At present, these counts do not have a means to distinguish differences between a bill striking a line from the code, or a bill that adds one. For the purposes of this chapter, I discuss this in terms of activity, meaning that I am only examining how often the process is used. In Chapter 5 of this dissertation, I suggest ways that the data could be made to be more granular, which would allow for more nuanced analyses.
} 
Yet this measure does not explain how lengthy individual changes to the code may be. While some changes could be as simple as replacing a word, others could add hundreds of words or paragraphs to the code. To address this, as a robustness check, I also created a variable representing the range of pages on which changes occurred, meaning that for every page of the code that had at least one recorded change, it was tallied and added to the total. For example, we might imagine a large provision is passed that adds a substantial number of paragraphs to the code. If we were only counting the number of changes, a single change had occurred. By counting the total range of pages, we can discern whether it is a simple change that requires only one page, or if it adds several, providing a different angle by which to measure legislation enacted in this way. This allowed me to generate the total range of pages in appropriations bills that made changes to the code during each session of Congress in the dataset. The two variables representing changes and total pages have a correlation of 0.981 , and it is expected that they will behave similarly when used within models.

Looking to Figure 4-1, we can see both variables plotted by congressional session. After an initial spike in the 98th Congress, these changes become more frequent, hitting a large peak from the 104th to the 106th sessions of Congress and reaching as high as 2704 changes in a single session. The variable for pages largely follows the same spikes as the variable for changes in every recorded session. Why do these particular sessions experience a much higher rate of changes when compared to others? As mentioned above, a simple answer is that this was a time of shifting ideas regarding what could be accomplished through the appropriations process, and that Republican leadership saw it as an opportunity to advance their goals and leverage the appropriations process against the president (Aldrich et al. 2013). This was made easier with the new changes allowing the speaker to install party loyalists in the committee system (Aldrich and 
Rohde 2000). In theory, these changes would make it simpler to add unrelated substantive legislation to these bills, turning the appropriations committee into an arm of party leadership. Given how infrequently this tactic was used in previous sessions, and how aggressively focused the Republican party was on accomplishing their agenda, it is little wonder that these changes spiked at such a rate once the practice became acceptable for use.

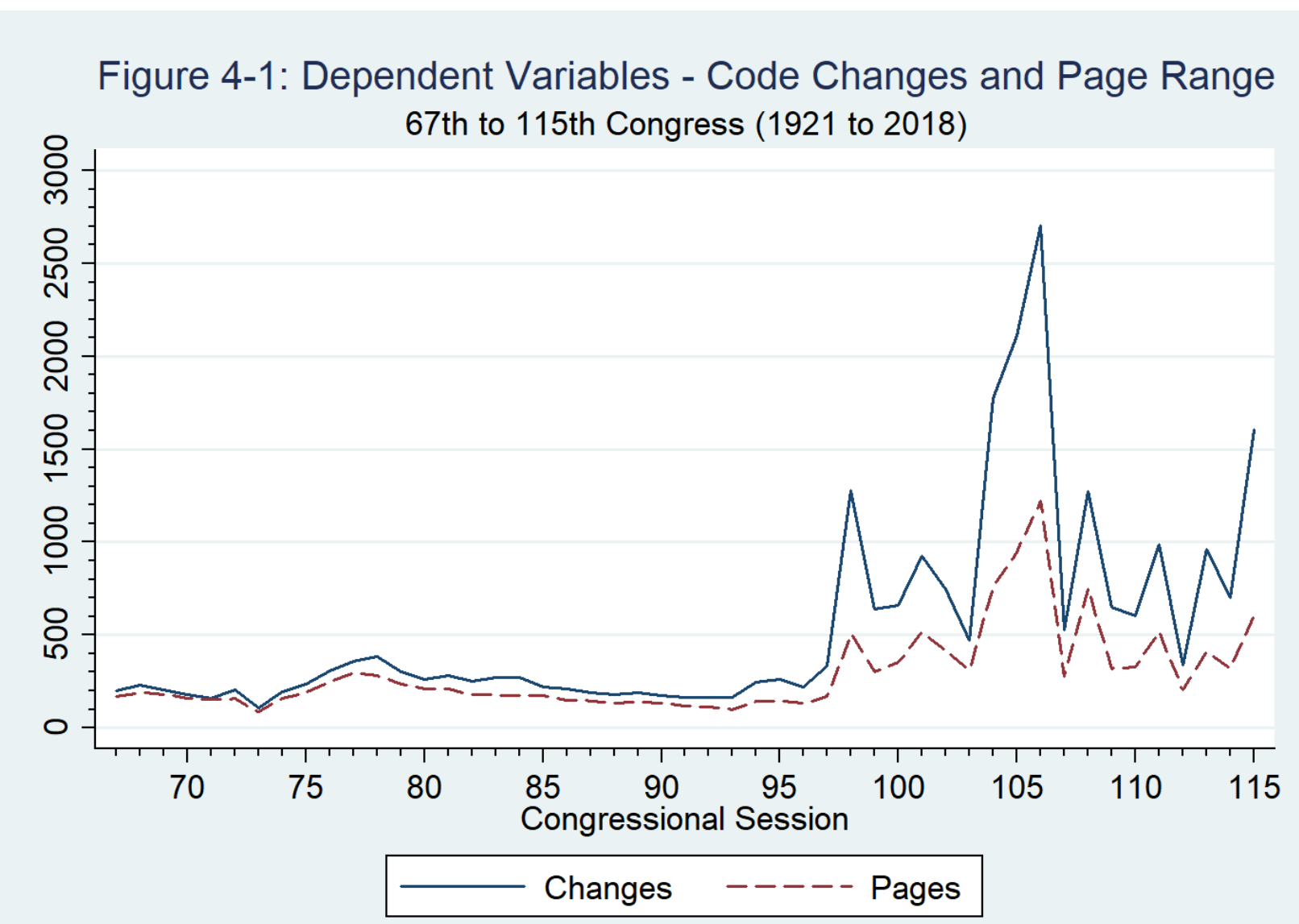

\section{Measuring Independent Variables}

The key independent variable in my analyses is political polarization. To measure polarization, I employ DW-NOMINATE scores (Lewis et al. 2020). As I have done in the previous chapters, I calculate the mean score of all Democrats and the mean score of all Republicans in the House and Senate. Then, I calculate the numeric distance between these two 
means. Finally, I create one measure of polarization in a congressional session by finding the mean value of the House and Senate scores. DW-NOMINATE scores typically range between -1 and 1, and each member is assigned a number based on their voting habits. The resulting polarization variable ranges from 0.503 to 0.852 , with a mean of 0.625 , a median of 0.605 , and a standard deviation of 0.098 . Also, I use two other measures of polarization as robustness checks. Similar to Binder (1999: 526), I use the percentage of moderates in Congress, which is created by tallying the number of members who have DW-NOMINATE scores that are closer to the ideological median between the two parties of the chamber than they are to their party's median score. I also employ a gridlock interval used by Bolton (2020) for similar purposes. In his work, he examines the effect that polarization and gridlock have on the likelihood of Congress to use non-statutory tools of control to advance their goals. In his associated analysis he uses a gridlock interval similar to Krehbiel's (1998), which is created by measuring the absolute distance between filibuster and veto pivots in the House and Senate, while taking into account the president's party affiliation.

It is important to note that Bolton's variant of the gridlock interval utilizes DWNOMINATE scores ${ }^{30}$ instead of the gridlock-change variable that Krehbiel employs in Pivotal Politics. While Krehbiel disliked using the scores in his own work, Gray and Jenkins (2019) support using them for a few reasons. First, they note that the scores treat legislators as individuals, and the scores do not require partisan information to function. Second, while Common Space scores do not allow individual members' scores to change over time, they do allow for the ability to draw comparisons between the House and Senate over time, which allows

\footnotetext{
${ }^{30}$ Specifically, Bolton uses "Common Space" scores. These values are calculated slightly differently by attempting to place all members of the House and Senate on the same ideological scale.
} 
the creation of a measurable interval. Overall, Gray and Jenkins claim that the assumptions that are inherent in DW-NOMINATE scores are minor compared to those associated with Krehbiel's variable.

To measure divided government, a dummy variable was created for when the government was fully divided, meaning that the president's party was different than the party of both the House and Senate. When the government was divided in this way it was coded as a 1 , and when it was not it was coded as a 0 . Then, an interaction term was created to measure the interaction between polarization and the dummy variable for a fully divided government. It is expected that increases in the interaction term will lead to increases in the frequency of legislation that is authorized through appropriations bills. This means that we should expect that in sessions in which polarization is high, and the government is fully divided, members would be more likely to use the appropriations process as a means of legislative passage. All three variables representing polarization were interacted with the dummy variable for divided government in the various models of this chapter.

Looking to control variables: the variable for a honeymoon period is coded as a dummy indicating whether a new president took office during that session. If a president was elected for the first time during that session (called "Honeymoon') it was coded as a 1, and all other sessions were coded as a 0 in the data. ${ }^{31}$ The variable for party time out of power (called "Time Out") is identical to Binder's measure in Stalemate (2003), which is the average number of years that a party has been out of power in both chambers (meaning the House and Senate values are averaged together). The variable for debt is the amount of federal debt, compared to United

\footnotetext{
${ }^{31}$ What of presidents that did not serve a full term? In Dodd and Schraufnagel's (2013) analysis they code both Calvin Coolidge and Lyndon Johnson as a "1", as these incoming presidents took over for a deceased president and then experienced a honeymoon period of their own. I do the same here.
} 
States GDP, expressed as a percentage (for example, a value of 50 would mean that the total US debt would be equivalent to half of the amount of the average US GDP in that session). ${ }^{32}$ Then, an interaction term was created between the variable for polarization and the variable for debt, with the expectation that as this term increases, that Congress would be more likely to rely more on the appropriations process to make substantive changes to the law.

Finally, I control for the effects of time in my analyses. It is important to ensure that my theorized causal relationship between polarization and legislating through the appropriations process is not biased due to the effects of time. By several measures, political polarization has increased over time, and so has the usage of appropriations to enact changes to the law, so it is important to ensure that the association between these two variables is maintained when controlling for the natural passage of time. In short, capturing this time trend as its own variable helps to ensure that the statistical relationship between the two variables is not a spurious one. In my analyses I include a variable that accounts for this time trend in the data.

\section{Selecting an Estimator and the Specification of Models}

Negative binomial regression was chosen for my analyses because the dependent variable is count data (the total number of changes made to the code in each session), and these estimators are appropriate when the data is overdispersed. Tests of the negative binomial models against Poisson reveal that negative binomial is appropriate because the variance exceeds the mean, as shown below. Model 1 uses DW-NOMINATE scores as a measure of polarization and includes all variables, except for the variable representing time. Model 2 is identical to Model 1, but

\footnotetext{
32 This data was gathered from the website "Longtermtrends", or more specifically: https://www.longtermtrends.net/us-debt-to-gdp/ The website aggregates data from both the Federal Reserve Bank of St. Louis, as well as official historical Congressional documentation.
} 
includes time, allowing comparison of the difference in effects that the addition of time has upon the analysis. Model 3 includes all variables but uses the percentage of moderates in Congress in place of DW-NOMINATE scores, while Model 4 similarly substitutes in the aforementioned gridlock interval instead. These robustness checks are included to ensure that my results are not sensitive to variables being moved into and out of the model, and across different measures of polarization. All four models were also run using the variable for page range as the dependent variable, for comparison purposes.

\section{$\underline{\text { Results }}$}

Table 4-1 presents negative binomial estimates of the number of substantive changes to the US code. These changes originate from appropriations bills, from the 67th to 115th sessions of Congress. ${ }^{33}$ The statistically significant log-likelihood in all models (at the 0.001 level of significance) allows for the rejection of the null hypothesis that the variables jointly equal zero. In the results for Model 1, polarization is significant at the 0.001 level $(p=0.00)$ and moves in the expected direction. Yet this number is much higher than we would observe in the real world, due to the scaling of the polarization variable, which only has a range of 0.349. Adjusted for this range, if the model moved from the lowest observation of polarization (0.503) to the highest observation (0.852), we would expect a 322.79 percent increase in the number of changes made. Looking to more specific data, in the session with the lowest amount of polarization (the 80th, starting in 1947), 260 changes were made to the code. However, in the session with the highest polarization (the 115th, starting in 2017), 1605 changes were made. Given these observations,

\footnotetext{
${ }^{33}$ While Table 4-1 shows the results of one-tailed tests, additional two-tailed tests using the same data were performed, the results of which are listed in Appendix 4-1. Very few results change, but of note: In Model 1, the interaction variable for polarization drops in significance, as does the control variable for debt, but both remain significant at the 0.05 level. In Models 3 and 4, the control variable for presidential honeymoon periods also loses significance. Otherwise, the main findings of the chapter remain the same.
} 
and the statistically significant results from the analyses, it appears that polarization has a large effect on the number of changes made to the code.

Polarization is also significant in Model 2 after including the variable for time $(p=0.00)$, and no variables display a reduction in significance after its inclusion. Rather, several variables have observable increases in significance once time has been added (fully divided government, the interaction term between divided government and polarization, debt, and the debt interaction term all rise in significance to the 0.001 level). This bodes well, as it suggests that time itself is not the only reason for the increase in changes to the code. ${ }^{34}$ Regarding polarization, Model 3 using the alternative measure of percentage of moderates yields similar results, and the coefficient is in the anticipated direction (a session with a lower percentage of moderates is more likely to use appropriations for this purpose, meaning that decreases in moderates lead to increases in the changes variable). Interestingly, the base coefficient for Model 4 utilizing the gridlock interval does not achieve acceptable levels of significance for polarization alone.

\footnotetext{
${ }^{34}$ Additional analyses that include a dummy variable for the 104th, 105th, and 106th sessions are available in Appendix 4-2. Due to the large spike in usage of the appropriations process during this time, it is important to ensure this particularly large amount of changes is not skewing the data, so an additional variable was added to represent this time period in Models 2, 3, and 4. As expected, the variable draws away some of the variance of the dependent variable, resulting in reduced significance and effects of most variables in each model. While almost all the findings of this chapter remain the same, it is important to note that the results of Model 4 utilizing the gridlock interval have no significant variables other than time and the dummy. These variables still trend in the expected directions, but this is something that may need addressed in future iterations of this work.
} 
Table 4-1: Negative Binomial Models of Changes Originating from Appropriations Bills

\begin{tabular}{|c|c|c|c|c|}
\hline & $\begin{array}{l}\text { Model } 1 \\
\text { Polarization }\end{array}$ & $\begin{array}{l}\text { Model } 2 \\
\text { Time Added }\end{array}$ & $\begin{array}{l}\text { Model } 3 \\
\text { Moderates } \\
\end{array}$ & $\begin{array}{l}\text { Model } 4 \\
\text { Gridlock Interval }\end{array}$ \\
\hline Polarization (DV) & $\begin{array}{l}\mathbf{9 . 2 4 9}^{\text {***** }} \\
(2.633)\end{array}$ & $\begin{array}{l}\text { 7.701**** }^{* * *} \\
(1.958)\end{array}$ & $\begin{array}{l}\text { 3.271 }^{* *} \\
(1.101)\end{array}$ & $\begin{array}{c}0.382 \\
(0.961)\end{array}$ \\
\hline Fully Divided & $\begin{array}{l}-\mathbf{2 . 3 7 7 ^ { * }} \\
(1.059)\end{array}$ & $\begin{array}{l}\mathbf{- 2 . 9 1 5}^{\text {***** }} \\
(0.812)\end{array}$ & $\begin{array}{l}-\mathbf{1 . 4 6 7} \\
(0.365)\end{array}$ & $\begin{array}{l}\mathbf{- 1 . 9 4 4}^{* * *} \\
(0.479)\end{array}$ \\
\hline Pol. Interact & $\begin{array}{l}\mathbf{4 . 2 5 7}^{* *} \\
(1.661)\end{array}$ & $\begin{array}{l}\mathbf{4 . 7 6 6}^{* * *} \\
(1.267)\end{array}$ & $\begin{array}{l}\mathbf{4 . 4 3 7}^{* * * *} \\
(1.059)\end{array}$ & $\begin{array}{l}\mathbf{4 . 8 2 0}^{* * * *} \\
(1.124)\end{array}$ \\
\hline Honeymoon & $\begin{array}{l}-\mathbf{- 0 . 3 2 8 *} \\
(0.152)\end{array}$ & $\begin{array}{l}-\mathbf{- 0 . 3 2 9 *} \\
(0.124)\end{array}$ & $\begin{array}{l}-\mathbf{- 0 . 3 0 8}^{* * *} \\
(0.126)\end{array}$ & $\begin{array}{l}-\mathbf{- 0 . 2 3 1 *} \\
(0.133)\end{array}$ \\
\hline Time Out & $\begin{array}{l}0.003 \\
(0.015)\end{array}$ & $\begin{array}{l}-0.003 \\
(0.123)\end{array}$ & $\begin{array}{l}-0.0002 \\
(0.013)\end{array}$ & $\begin{array}{l}-0.001 \\
(0.013)\end{array}$ \\
\hline Debt & $\begin{array}{l}\mathbf{0 . 0 5 4}^{* *} \\
(0.022)\end{array}$ & $\begin{array}{l}\mathbf{0 . 0 6 7}^{\text {*****}} \\
(0.017)\end{array}$ & $\begin{array}{l}\mathbf{0 . 0 3 7}^{* *} \\
(0.012)\end{array}$ & $\begin{array}{c}0.004 \\
(0.011)\end{array}$ \\
\hline Debt Interact & $\begin{array}{l}-\mathbf{- 0 . 0 7 8}^{*} \\
(0.034)\end{array}$ & $\begin{array}{l}\mathbf{- 0 . 0 7 0}^{* * * *} \\
(0.026)\end{array}$ & $\begin{array}{l}-\mathbf{- 0 . 0 5 0}^{* * *} \\
(0.018)\end{array}$ & $\begin{array}{c}0.001 \\
(0.019)\end{array}$ \\
\hline Time & & $\begin{array}{l}\mathbf{0 . 0 3 6}^{\text {**** }} \\
(0.006)\end{array}$ & $\begin{array}{l}\mathbf{0 . 0 2 7}^{\text {***** }} \\
(0.007)\end{array}$ & $\begin{array}{l}\mathbf{0 . 0 2 8}^{* * * *} \\
(0.007)\end{array}$ \\
\hline Constant & $\begin{array}{l}-.002 \\
(0.539)\end{array}$ & $\begin{array}{l}-2.048 \\
(1.300)\end{array}$ & $\begin{array}{l}\text { 4.449*** }^{* *} \\
(0.790)\end{array}$ & $\begin{array}{l}\mathbf{2 . 9 0 3}^{* * * *} \\
(0.567)\end{array}$ \\
\hline $\begin{array}{l}\text { Pseudo } \mathrm{R}^{2} \\
\mathrm{~N} \\
\text { Log-likelihood }\end{array}$ & $\begin{array}{l}0.074 \\
49 \\
-327.877^{* * *}\end{array}$ & $\begin{array}{l}0.107 \\
49 \\
-316.504^{* * *}\end{array}$ & $\begin{array}{l}0.104 \\
49 \\
-317.273^{\text {**** }}\end{array}$ & $\begin{array}{l}0.100 \\
47 \\
-303.555^{* * *}\end{array}$ \\
\hline
\end{tabular}

For a more substantive look at this relationship, Figure 4-2 plots the number of changes to the code by the level of polarization (specifically the DW-NOMINATE distance between parties) in each congressional session. In sessions in which polarization is low, these changes are 
infrequent, clustering below 500 changes each session. As polarization increases, these changes become much more erratic, and occur at higher rates, reaching as high as 2704 changes in a single session. At a cursory glance it appears that these two variables are related, and the associated slope trends upward. With my hypotheses in mind, in Models 1, 2, and 3, I find support for the polarization hypothesis, which predicted that increases in polarization would also increase the frequency of changes made to the code. However, I do not find support for the hypothesis in Model 4. It is possible that this is simply due to differences in the data between the multiple measures of polarization.

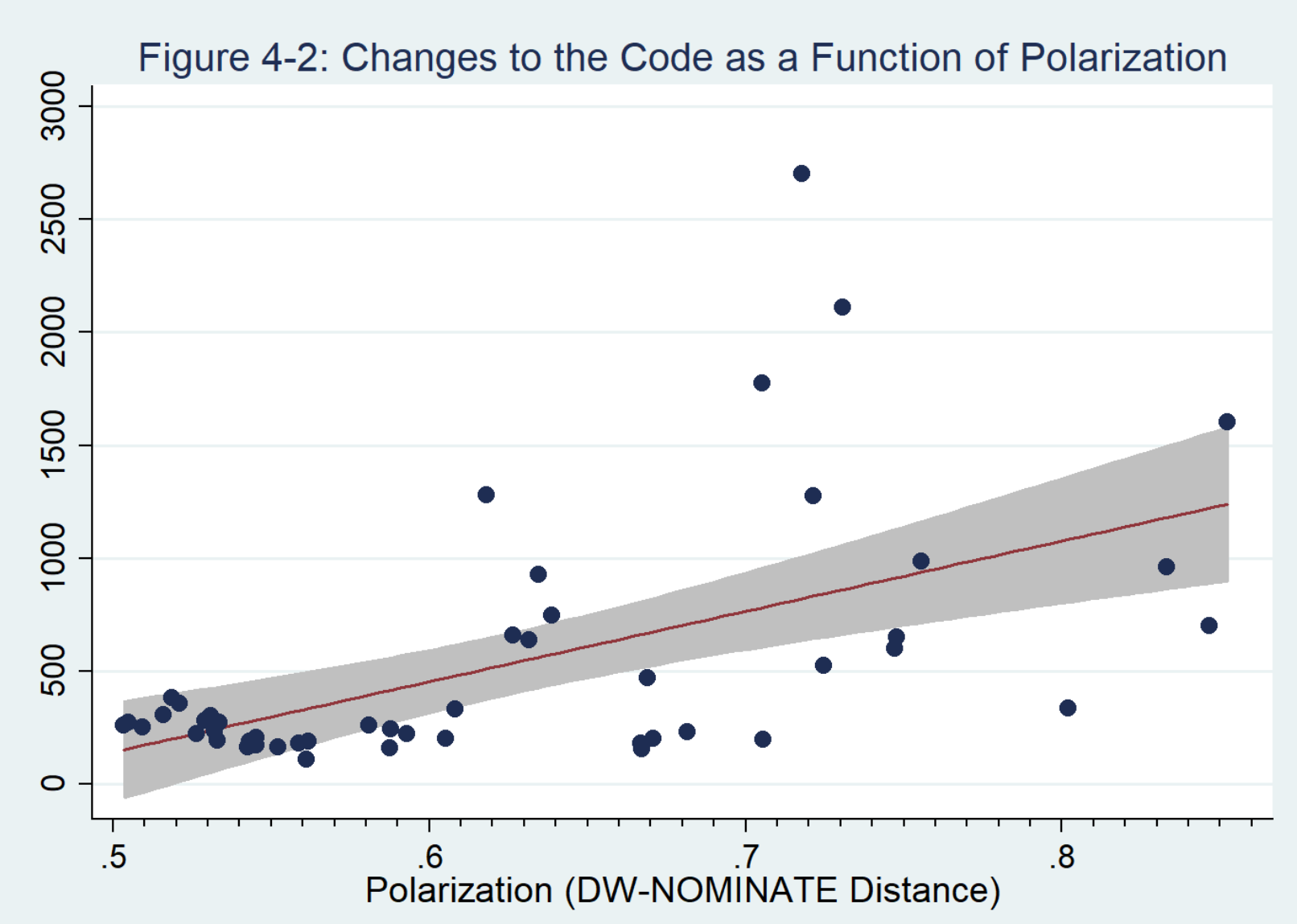

The divided government hypothesis predicted that a fully divided government would result in a higher likelihood for Congress to use this process. In all models, fully divided 
government moves in the opposite direction as expected and is statistically significant (at the 0.05 level of significance in Model 1, and 0.001 in Models 2, 3, and 4). These results require interpretation. Casas et al. (2020) theorize that unified government may increase the likelihood for members to attach "hitchhikers" to bills, because members are more likely to not only coordinate their activities during unified government, but also that they are more likely to use this opportunity to draft omnibus bills that believe are more likely to pass. In this way, members might use the process more when they anticipate that they have a higher chance of a bill passing and see less value in its usage when they know a bill is unlikely to pass at all. It is possible that this is what is being observed in these results. In any case, the hypothesis is not supported by these results.

The interaction between polarization and fully divided government is significant in all models, first at the .05 level in Model 1, and at .001 in Models 2, 3, and 4. This means that in terms in which both the government is fully divided, and polarization is high, the model predicts that the number of changes will increase. Looking to Figure 4-3, we can see the substantive effects that this interaction has on the frequency of changes. In sessions in which the government was divided, the aggregate number of changes made were higher than sessions in which the government was not. Also, the sessions in which the highest frequency of changes occurred were in times of both high polarization and fully divided government. This figure and the results of all four models support the interaction hypothesis: sessions in which the government is both highly polarized and fully divided result in a higher likelihood to utilize the appropriations process to authorize policy. 


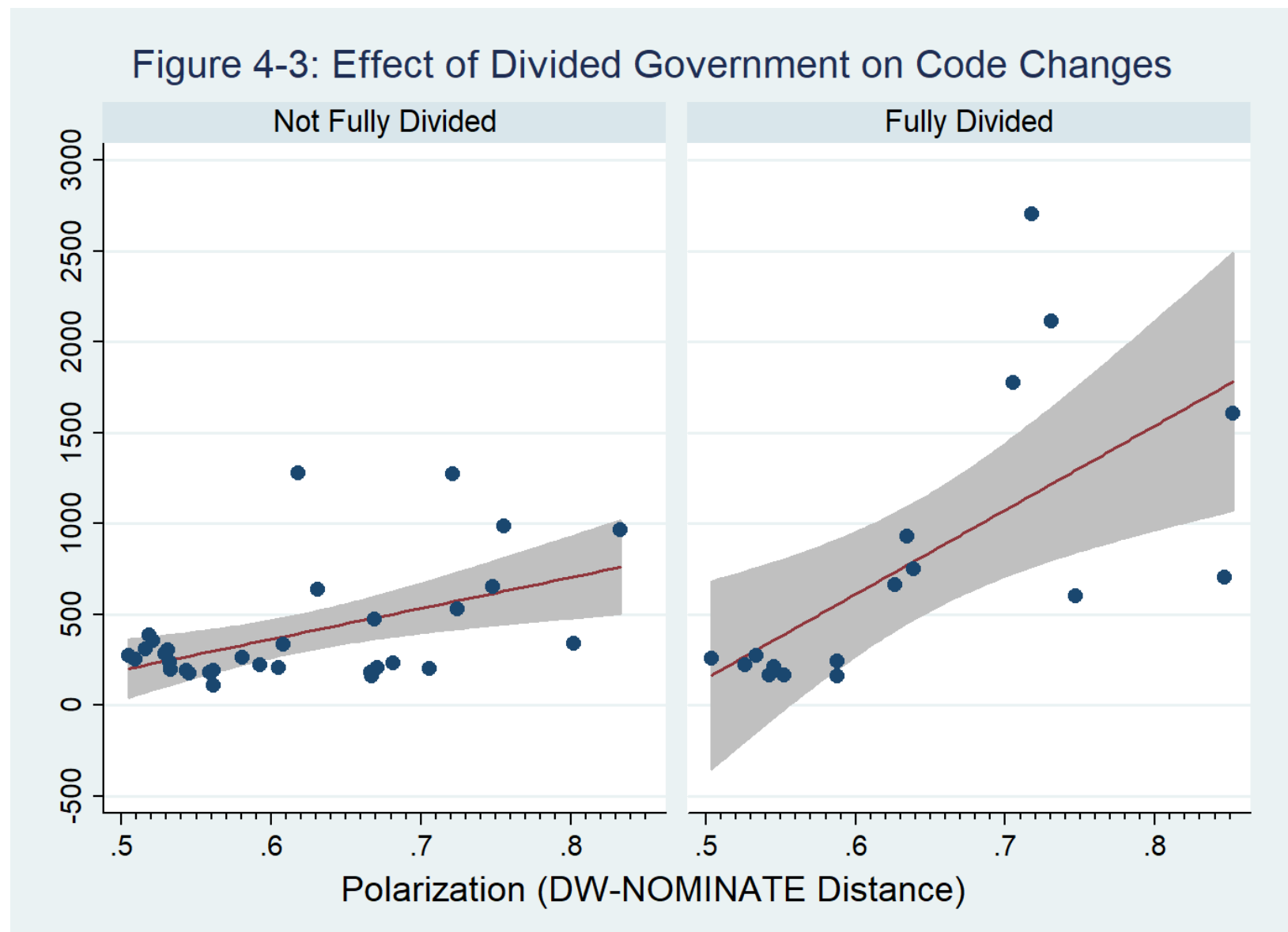

Examining the control variables in each model yields additional interesting findings. The honeymoon period for presidents appears to have a significant and negative effect on the number of changes, indicating that during these sessions there is less usage of the appropriations process for authorization purposes. The length of time that parties did not have control of a chamber had a negligible effect on the number of changes and was not significant in any model. While parties may feel pressure to push through their preferred policies after a lengthy time out of power, they do not appear to be using the appropriations process to accomplish their goals at higher rates during these times.

The coefficient for US debt is significant, both on its own, and when interacted with polarization, in Models 1, 2, and 3, but is not significant in Model 4. Looking to the full Model 
(2), a one-step increase in the variable for debt generates a 6.7 percent increase in the number of changes made. Given that the debt variable has a range of 101.53, this means that high levels of debt have a large and statistically significant effect on the amount of usage of the appropriations process for these purposes. Yet when the interaction term between polarization and the debt is included, the resulting coefficient moves in the opposite direction, with a 7 percent decrease in changes for every increase in the interaction variable. What could account for this change in direction? It could be that the appropriations process gives party leadership (and the members that align with them) a tool to pass policy when it would normally be unpopular, due to debtrelated concerns. However, it is possible that during sessions with high polarization, the debt is a potential avenue to attack political opponents. Melki and Pickering (2014) postulate that in times of low polarization, members may be likely to increase the federal debt, as they use spending to signal their preferences to voters and price out potential challengers. They claim that polarization blunts this relationship, because they need to use the process less to signal to voters when party differences are stark. Relating this to my analyses, we might expect that bills may be watched more closely by opponents in times of high polarization, and members would have to be more careful with what legislation they propose to attach. Thus, we might expect that members may use these tactics less during times of high polarization and a high ratio of debt to GDP. To visualize this relationship differently, Figure 4-4 displays the interaction between debt and polarization, and the effect that it has on the total number of changes to the code. In short, there appears to be no conditional relationship between debt and polarization in driving the inclusion of lawmaking in appropriations bills, as the influence of polarization does not vary at statistically 
significant rates across levels of debt. Regardless, the effect of the debt on this process provides future avenues for study. ${ }^{35}$

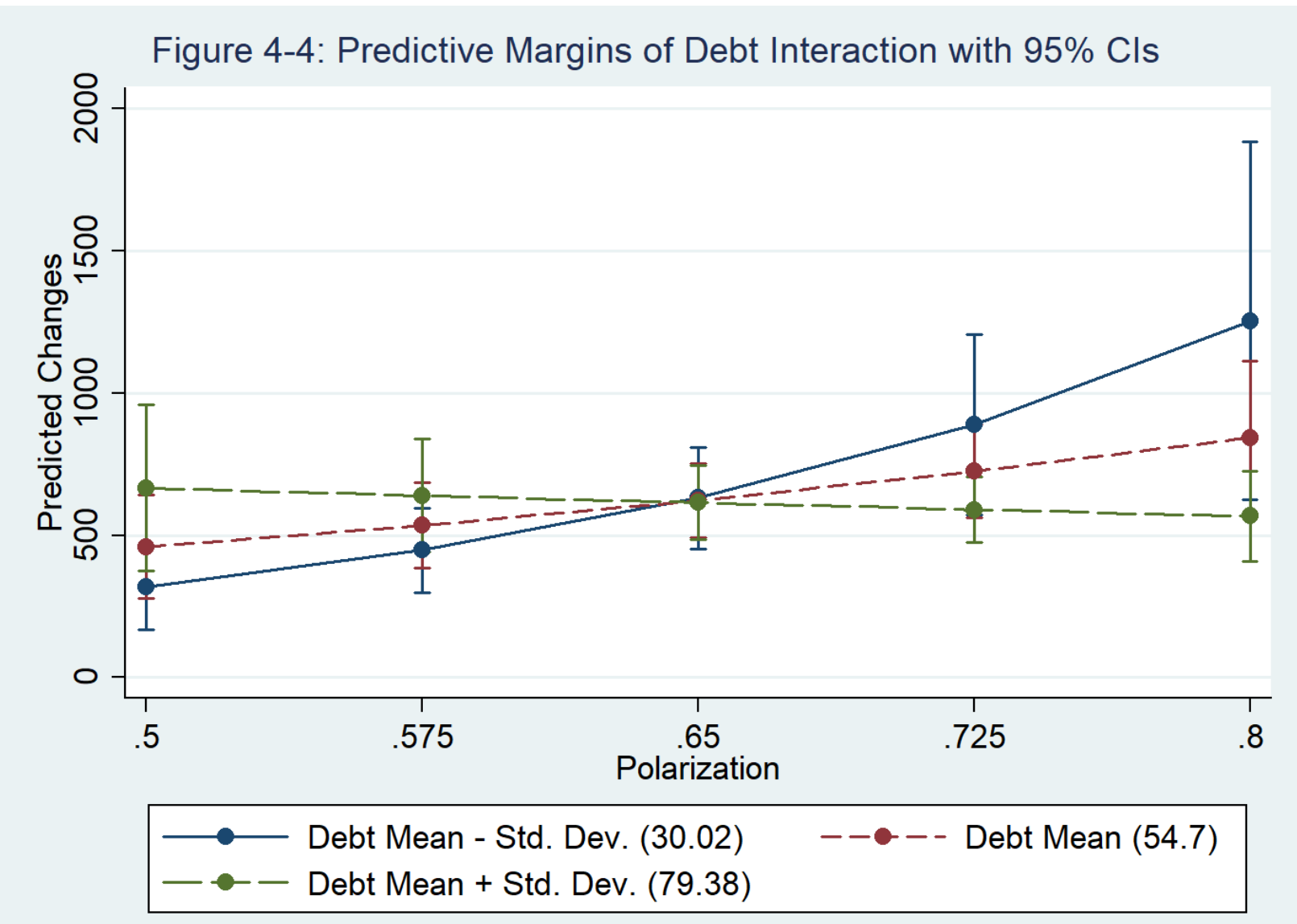

Table 4-2 displays the results of the secondary analyses using the pages dependent variable. In all four analyses I find similar results, and all of the aforementioned findings remain the same. The polarization hypothesis is again supported in Models 1, 2, and 3 (but is not supported in Model 4), with increases in polarization leading to increases in the number of pages.

\footnotetext{
${ }^{35}$ What if the interaction between political polarization and national debt is not included in the model? To answer this question, two models were run that did not include the interaction. These can be found in Appendix 4-3 and display some notable changes. Polarization remains significant in Model 1 but is not significant in Model 2 once time has been added. However, as mentioned in Chapter 2, these results are to be expected, given the high correlation between polarization and time. Regarding control variables, the variable for debt is not significant on its own when the interaction is removed, suggesting that debt may not be a significant predictor of changes made to the code.
} 
The divided government hypothesis is not supported in any models using pages, with all coefficients moving in the opposite direction than theorized. The interaction hypothesis is supported in all four models, with increases in the interaction term leading to increases in the pages DV. All control variables behave similarly to those in Table 4-2, with the only minor change between the results of the two tables is that in Model 4, the control variable for presidential honeymoon periods was not significant. This bodes well for the results, as they remain relatively consistent across two different measures. 
Table 4-2: Negative Binomial Models of Pages Variable

\begin{tabular}{|c|c|c|c|c|}
\hline & $\begin{array}{l}\text { Model 1 } \\
\text { Polarization }\end{array}$ & $\begin{array}{l}\text { Model } 2 \\
\text { Time Added }\end{array}$ & $\begin{array}{l}\text { Model } 3 \\
\text { Moderates } \\
\end{array}$ & $\begin{array}{l}\text { Model } 4 \\
\text { Gridlock Interval }\end{array}$ \\
\hline Polarization (DV) & $\begin{array}{l}\mathbf{8 . 1 6 1} \\
(2.004)\end{array}$ & $\begin{array}{l}\mathbf{7 . 5 0 2}^{* * * *} \\
(1.737)\end{array}$ & $\begin{array}{l}\mathbf{3 . 2 6 2}^{* *} \\
(0.987)\end{array}$ & $\begin{array}{l}0.538 \\
(0.837)\end{array}$ \\
\hline Fully Divided & $\begin{array}{l}\mathbf{- 2 . 0 4 2} \\
(0.830)\end{array}$ & $\begin{array}{l}\mathbf{- 2 . 3 8 1} \\
(0.731)\end{array}$ & $\begin{array}{l}-\mathbf{1 . 2 3 8}^{* * * *} \\
(0.328)\end{array}$ & $\begin{array}{l}\mathbf{- 1 . 7 2 5} \\
(0.430)\end{array}$ \\
\hline Pol. Interact & $\begin{array}{l}\mathbf{3 . 5 8 8}^{* *} \\
(1.302)\end{array}$ & $\begin{array}{l}\mathbf{3 . 9 0 5}^{* * * *} \\
(1.138)\end{array}$ & $\begin{array}{l}\text { 3.739 }^{* * * *} \\
(0.954)\end{array}$ & $\begin{array}{l}\mathbf{4 . 3 1 5} \\
(1.003)\end{array}$ \\
\hline Honeymoon & $\begin{array}{l}\mathbf{- 0 . 2 9 0 *} \\
(0.122)\end{array}$ & $\begin{array}{l}\mathbf{- 0 . 2 9 3}{ }^{* *} \\
(0.111)\end{array}$ & $\begin{array}{l}-\mathbf{0 . 2 7 2} * * \\
(0.114)\end{array}$ & $\begin{array}{l}-0.186 \\
(0.119)\end{array}$ \\
\hline Time Out & $\begin{array}{l}0.009 \\
(0.012)\end{array}$ & $\begin{array}{l}-0.008 \\
(0.111)\end{array}$ & $\begin{array}{l}-0.005 \\
(0.011)\end{array}$ & $\begin{array}{l}-0.007 \\
(0.012)\end{array}$ \\
\hline Debt & $\begin{array}{l}\mathbf{0 . 0 5 7} 7^{* * *} \\
(0.017)\end{array}$ & $\begin{array}{l}\mathbf{0 . 0 6 5}^{* * * *} \\
(0.015)\end{array}$ & $\begin{array}{l}\mathbf{0 . 0 3 7} 7^{* * * *} \\
(0.011)\end{array}$ & $\begin{array}{l}0.005 \\
(0.010)\end{array}$ \\
\hline Debt Interact & $\begin{array}{l}\mathbf{- 0 . 0 8 2} * \\
(0.026)\end{array}$ & $\begin{array}{l}\mathbf{- 0 . 0 9 9}^{* * *} \\
(0.024)\end{array}$ & $\begin{array}{l}\mathbf{- 0 . 0 4 9}^{* *} \\
(0.016)\end{array}$ & $\begin{array}{l}0.002 \\
(0.017)\end{array}$ \\
\hline Time & & $\begin{array}{l}\mathbf{0 . 0 2 1} 1^{* * *} \\
(0.006)\end{array}$ & $\begin{array}{l}\mathbf{0 . 0 1 2}^{* *} \\
(0.006)\end{array}$ & $\begin{array}{l}\mathbf{0 . 0 0 2}^{* * * *} \\
(0.017)\end{array}$ \\
\hline Constant & $\begin{array}{l}0.211 \\
(1.239) \\
\end{array}$ & $\begin{array}{l}-1.058 \\
(1.151) \\
\end{array}$ & $\begin{array}{l}\mathbf{5 . 2 9 8}^{* * * *} \\
(0.717) \\
\end{array}$ & $\begin{array}{l}\mathbf{3 . 9 7 6}^{* * * *} \\
(0.537) \\
\end{array}$ \\
\hline Pseudo $\mathrm{R}^{2}$ & 0.075 & 0.092 & 0.089 & 0.087 \\
\hline $\mathrm{N}$ & 49 & 49 & 49 & 47 \\
\hline Log-likelihood & $-293.923^{* * *}$ & $-288.596^{* * * *}$ & $-289.640^{* * *}$ & $-277.278^{* * *}$ \\
\hline
\end{tabular}

\section{$\underline{\text { Discussion and Conclusion }}$}

The results of this chapter make clear the importance of both polarization and divided government on the frequency with which Congress utilizes the appropriations process to make 
policy changes. Overall, my findings were robust whilst utilizing multiple specifications of polarization. The results suggest that in congressional sessions with high levels of polarization, and in which inter-branch policy conflict is occurring, members are more likely to use appropriations bills to make substantive changes to the law. The evidence presented not only supports my theory, but also generates further interesting questions regarding the appropriations process, and how such an analysis might be improved.

This chapter has shown one avenue in which members of Congress can circumvent the regular policy process to accomplish their goals. The use of these bills, which allow leverage over the president, and create policy outcomes with a lower public profile, allows Congress to push through policy that would normally be stalled. This tool is powerful, and increasingly used in the modern Congress when the regular mechanisms of policy passage have become gridlocked. Whether Congress has the prudence to use these tactics sparingly remains to be seen, but this research opens further avenues for future academic scholarship on the subject. 


\section{Chapter 5: Conclusion}

Congress is often spoken of as an institution that does quite little. The blame for this lack of output is often placed upon increasing ideological differences between Democrats and Republicans. This project examined the productivity of Congress from numerous vantage points, in the hope that the relationship between political polarization and legislative output can be better understood. The findings presented in this dissertation suggest that polarization has furtherreaching effects than just hindering legislative output in Congress. Rather, polarization affects various ways in which Congress can engage with the legislative process, and the lengths that Congress must go to in order to pass policy at all.

Chapter 2 showed that Congress has become limited in its capacity to pass bills with openly particularized beneficiaries, and that these types of bills have declined over time. These findings are interesting, as they imply that polarization does not affect policy equally, and that bills with a narrower focus may be less likely to make it through the legislative process. Chapter 3 provided evidence suggesting that committees have become less productive as polarization has increased, and that they are performing fewer functions associated with the creation of policy. This implies that the long-standing institutions within Congress are also being affected by increasing ideological distance and are less involved with the process of lawmaking than they once were. Finally, Chapter 4 suggests that polarization creates pressure on members of Congress to use legislative procedures to circumvent gridlock, with a particular focus on using the appropriations process to pass unrelated policy. Subsequently, these tactics can be useful to bypass the ideological preferences of the president and to achieve policy goals that may not pass through the normal legislative process. 
In summary, polarization has an effect not only on the productivity of Congress, but also on how Congress conducts legislative business, its method of bill passage, and the policy choices that it is able to make. In this section I discuss my contributions to the literature, potential critiques, limitations of my methodology, and ways that my research could be extended to future work.

\section{Chapter 2}

\section{Contributions to the Literature}

Perhaps the largest contribution of this chapter is simply that it provides evidence suggesting that when policy is disaggregated by beneficiary, polarization affects the productivity of policy passage at different rates. In this chapter, policy was sorted based on Arnold's (1990) classification of bills, falling into generalized, group, and geographic policy categories. I argued that if we assume that Congress has difficulty passing bills in times of high polarization, there is pressure to pass bills that provide benefits to broad constituencies. I find support for this, showing that the frequency of generalized bill passage remains consistent across time, suggesting that these types of bills have been less affected by polarization than others. Conversely, I find that the frequency of group or geographic bills has decreased significantly over time, with the implication that Congress is unwilling (or unable) to pass bills with overtly particularized beneficiaries than it once was.

This is of interest to scholars for several reasons. First, much of the novelty of this research is attributed to how the policy is sorted. Others have written that policy type matters, albeit differently. Several authors have studied which topics are the most polarizing, finding that economic policy tends to cause the most division (Bartels 2006; Lee 2008; McCarty et al. 2006). 
Yet there is still little work that examines how polarization affects the production of policy based on content. Lapinski’s (2008) work is perhaps the most closely related to this chapter, showing that the topic of a bill is directly related to the frequency of legislative accomplishment. We might consider my findings to be a companion a piece to his theory. Not only does the topic and content of bills matter, but the intended beneficiary of those bills does as well, and it behooves researchers to account for this in future work. Pooling all legislation together and measuring raw output can be an important way to understand congressional productivity and should not be discounted. Yet there is more to learn if we examine the nuances of the kinds of policy that Congress is able to produce. Moving forward, researchers should consider disaggregating policy in such a way in order to better understand policymaking limitations in Congress.

\section{Limitations and Future Research}

Regarding future work, there are several other areas in which the analyses in the chapter could be expanded, and many questions that still remain. One goal of my work was to determine if Arnold's theory could be examined using quantitative data. He notes that a common criticism of Congress is that it often passes bills that dispense group and geographic benefits but do little to pass ones that provide generalized benefits (Arnold 1990: 26-27). In this chapter I show evidence that suggests that Congress is limited in its capacity to pass bills that have particularized beneficiaries, but that it continues to pass a steady number of generalized bills each year. On the surface, the criticisms that he notes seem to be unfounded, but is it truly the case that Congress attends less to group interests when polarization is high? Are parties using generalized bills as a strategic choice to placate constituents who have increasingly nationalized interests, or are these bills all that Congress can pass in a highly polarized environment? To this end, have generalized bills changed in topic as polarization has increased? Meaning, have 
generalized bills shifted toward topics that are less politically divisive, in the hopes that they will be more likely to pass through a polarized and gridlocked legislative branch? These questions could be answered in future research pertaining to legislative output.

If passing bills that overtly benefit particularized groups is not politically feasible, then one might imagine that Congress would find other ways to serve those interests. Many group preferences could also be represented simply by Congress leaving existing policy alone, if such preferences are aligned with the existing status quo. Baumgartner et al. (2009) suggest that interest groups not only have the power to influence policy, but also the power to slow down or block bills that may upset their privileged status (through their sway over members). Similarly, McCarty et al. (2013) note that groups will often utilize and leverage the ideologies of members in Congress to benefit their own interests and to stifle legislative change if such change would conflict with their preferred policy or an existing privileged status. Are particularized groups achieving their preferred policy outcomes through other means at a higher rate?

It is also possible that Congress could serve the interests of groups through the bundling of favorable provisions or bills into other unrelated bills, or even generalized bills. If a generalized bill sounds more palatable to the parties in Congress (and the constituents they serve), we might imagine that it would be easier to simply place group or geographic benefits into a bill that is more likely to pass. As such, these group interests could still be represented, but would then be attached onto generalized bills to ease the pressure of passage. Generalized bills might sound more palatable to constituents on their face, while the contents of the bill could please particularized interests that benefit from amendments and provisions within. This fits with Arnold's discussion of legislative causal chains, and how longer causal chains are more difficult for the public to track, making it easier to avoid negative public opinion of an associated bill. I 
address some of these methods of bill passage in Chapter 4 of this dissertation, but there remains room for a more discerning method of examining this relationship.

One question that arises is how bills should be sorted if a bill's topic could fit into multiple categories. In some cases, it could be argued that a bill topic might fit two or three categories (such as the topics in a bill having both generalized and group beneficiaries for different reasons). In this chapter I address this problem through the codification of who coders believe was the primary beneficiary of the bills within a topic, even if it may have multiple beneficiaries. Nevertheless, it is reasonable to expect some mis-categorization with this methodology, as the process distills broad policy topics into distinct categories. A potential solution may be to code by the provisions within bills, rather than the topic of the bill itself. Examining individual provisions, rather than entire bills, would provide further granularity within the data that the current iteration cannot. For example, a bill that appears in topic to target the general public may contain numerous provisions that pursue group or geographic benefits. Taking this a step further, analyses examining provisions could answer questions of whether certain bill topics are more likely to experience the inclusion of provisions from other categories that have been bundled in. Do agriculture bills contain more unrelated content than national security bills? Coding the provisions within bills is a large undertaking, and is beyond the scope of this research, but provides further avenues for study.

Future research could also examine the costs of these bills. Arnold discusses a further layer of his theory that is only lightly touched on in this chapter: that the costs imposed by bills may also fall upon generalized, group, and geographic constituencies. Considering the fiscal ramification of bills opens numerous possibilities for future research. This chapter provides evidence that Congress predominantly passes a higher proportion of generalized bills during 
polarized times, but do such bills also defer the costs to generalized constituencies, or are they more likely to pass costs onto particularized groups? Is one party more likely than another to pass the costs onto particularized groups? One avenue for examining this could be through the usage of Congressional Budget Office reports that estimate the costs of bills and bill proposals, though this would require a substantial amount of effort to determine how the costs are diffused amongst the populace.

\section{$\underline{\text { Chapter } 3}$}

\section{Contributions to the Literature}

The findings described in Chapter 3 regarding committees have a myriad of implications for the literature and future research. Often the focus of scholarship discussing Congressional productivity examines the end result of the entire policy process, and perhaps rightfully so. A passed bill is theoretically more noteworthy than one that stalls and dies at one of Congress's many internal veto points. While examining these outputs is important in assessing the health of the legislative branch of government, there is a larger picture of Congress that can be better understood through the examination of the component pieces that contribute to legislative productivity. This chapter does not fully complete that picture, but it does suggest that committees are doing less work and having less say in the policymaking process than they once did.

Given these findings, several points of discussion are in order. This work may imply that low committee productivity is inherently problematic, but this may not always be true. We should not expect that every bill submitted should be reported out of committee, and bills may stall within the committee process for legitimate reasons. Not all bills submitted to Congress 
merit consideration, and committees arguably exist to determine which bills are worth reporting to their parent chamber. There is also no way to estimate what the productivity of committees would be like if the committee system had not been altered to lessen the autonomy of committees and their chairs. Regardless, there may be circumstances in which lower productivity by the metrics presented would produce higher quality bills. Yet what cannot be discerned in this iteration of the analysis is whether committee productivity is down because bills are becoming higher in quality and could be taking longer to discuss and produce. Nevertheless, there is evidence to suggest that bills are becoming proportionally longer (Brookings 2018), which may explain why some observable measures of productivity are decreasing.

\section{Limitations and Future Research}

Regarding the methodology used in the chapter, the metrics used to estimate the factor scores representing committee productivity all originate from counts of bills or hearings. As mentioned in Chapter 3, these counts do not comment on the inherent quality of bills or hearings, which could be a limiting factor of the data. Barber and McCarty (2015) note that choosing a measure of quality is difficult, but existing evidence suggests that the effects of polarization and changes to the committee system have diminished bill quality overall. In future studies of committee productivity, it may be prudent to account for a measure of bill quality as well. Are committees still performing their role in utilizing policy expertise to create higher quality bills? There is fertile ground for future research in this regard.

There are other factors that may be affecting committee productivity that are difficult to quantify. For one, members of Congress are busier than ever before, and committee work is lower on their list of priorities than it was in the past. As Richard Hall (1996) notes, participation in Congress is not equal, as members in the modern Congress have an increasing number of 
responsibilities that they did not have before. Members decide where to put their time, and in the aggregate, they are often absent from committee meetings, and defer such responsibilities to others. Members also frequently pursue more than one committee position at once, spreading their time even more thinly. Thinking of this in the context of results presented in this chapter, this could potentially be why committees are spending less time on hearings, as there may be less debate occurring and less fact-finding needed when there are fewer members present at such hearings.

Adding first-hand evidence to this explanation, Representative Dana Titus (2016) laments that modern committees are little more than rubber stamps for party leadership, and that the quality of debate in committees has diminished. She notes that bills reported to the floor are unlikely to even be fully discussed in a hearing or even debated. Similarly, as Representative David Price (2016) notes, this hinders committees, and the legitimacy of their legislative output should be called into question. In future studies, it would be interesting to examine whether a committee is simply "rubber-stamping" bills that party leadership wants, and under what circumstances committees might deviate from the wishes of the majority party. For example, an individual committee might appear stable in its productivity but may be participating less in the policymaking process. If parties are becoming more homogenous in ideology, then there may not be a need to hold as many hearings as there once was. When the majority party internally agrees at higher rates, is there a need for discussion?

Further, while this research examines the output of committees, it would be interesting to examine whether some committees are more productive than others. In a relative sense, have all committees fallen in productivity equally? Do some committees withstand partisanship and polarization better than others? For example, Fenno (1974) claims that membership on 
committees is not random, and that members of Congress seek out specific committees that can address their needs. He sorts the committees in his work into three categories: "prestige," “constituency" and "policy," based on the goals of the members that seek them out. Would committees within each of Fenno's categories be affected differently by polarization, or does their output remain constant? Another related change that could be made regarding the methodology of the chapter involves how polarization is measured. When I examine committees, the variable used for polarization is aggregated for both the House and Senate. However, in the chapter I examine the output of individual committees. How would the findings of the chapter change if polarization within each committee was calculated and used as the independent variable? Does the internal conflict within committees mirror the conflict of parties in the chamber? Measuring polarization in this way would allow for more precision in understanding what makes individual committees productive, and these sorts of questions could be expanded in future research.

Finally, these analyses could be expanded with the addition of other measures of productivity and/or party control. For example, one important function that committees perform is to mark up and alter bills. These committee markups would be a useful source of data to further refine measures of productivity and could be used in future factor analyses. There is also research that could be done to examine the usage of discharge petitions and the ability to bring bills out of committee when they have stalled. Are these petitions needed more during polarized times, or does party control over committees mitigate this need? Cox and McCubbins (2007) note that this is one way that the majority party can maintain control over committees, but further research could examine this dynamic more in-depth.

\section{Chapter 4}




\section{Contributions to the Literature}

Chapter 4 contributes to the overall literature by showcasing an important tool for policy passage that operates mostly out of the public eye. It also highlights a gap in current scholarship surrounding Congress: studies that only examine the amount of policy passed by Congress may not be enough to fully understand how members create and pass policy in the modern day. Is Congress truly less productive? In some ways we might think so, but in this way, Congress still has avenues to be productive through unorthodox methods. Yet it also shows us the lengths that members must go to in order to pass basic policy proposals when they cannot break through the divisiveness of a gridlocked party system. Is this the new "normal" of policymaking at the federal level? The evidence presented in this chapter suggests that it may be. If members feel pressure to legislate in this way, we as researchers would be wise to consider this, and other methods of circumventing gridlock, when examining the productivity of Congress in future scholarship. Perhaps self-inflicted appropriations crises are the price that must be paid for productivity in polarized times, but this would also imply that legislative accomplishment comes at the cost of transparency, both in the process of policymaking, and to the public at large. As Arnold (1990) notes, such methods cause breaks in the ability for voters to trace causal chains back to members and their voting patterns. When blame is diffused amongst the entirety of Congress, how can voters sufficiently reward or punish members?

It is also important to consider that appropriations bills serve a necessary function: allocating money to keep the government open. Congress is expected to pass appropriation bills before the beginning of the next fiscal year in order to fund expenditures for the following year. However, Congress frequently finds difficulty in meeting these deadlines, and this creates the potential of fiscal crises and government shutdowns (Barber and McCarty 2015: 46-47). Delays 
in funding the government have direct effects on the lives of Americans, especially those that depend on yearly funding for governmental programs like Social Security (Sinclair 1997). While using these bills as leverage can create policy avenues that would not normally exist, they also come at a price: increased likelihood of shutdowns that can be damaging to the institution of government, and the interests of the public. These shutdowns generate further institutional issues within government agencies when continued funding becomes uncertain, reducing the number of services offered and increasing operating costs (Krause 2018). Thus, it is critical to understand when Congress will be more likely to engage in these legislative tactics. Future scholarship should consider this avenue of policymaking when attempting to quantify congressional productivity.

Understanding this dynamic is important for both the academic merits of such an endeavor, and more broadly for issues of transparency regarding the modern legislative process. How can the voting population hold members accountable for their policy choices when legislation is being obfuscated in this way? Sinclair (2012) notes that through the utilization of discharge petitions, appropriation bills are seldom sent through the process of a committee markup or are never brought to the floor for general consideration. When bills are not debated, it may expedite their passage, but this leaves little room for oversight by the rest of the chamber, and fewer chances for the public to observe (and potentially petition their representatives to intervene in) the process.

Even the members voting on appropriations bills may find themselves with little knowledge of what is in the appropriations that they are voting on. Sometimes members are provided virtually no time to examine or read bills before they are sent to the floor for a vote. In a recent example, the Consolidated Appropriations Act of 2021 (PL 116-133) was an omnibus 
bill appropriating money for all 12 federal agencies. It was sent to the House floor with a quickly scheduled vote, giving members little time to fully comprehend what they were voting on. As Representative Alexandria Ocasio-Cortez wrote of the matter: "Members of Congress have not read this bill. It's over 5000 pages, arrived at $2 \mathrm{pm}$ today, and we are told to expect a vote on it in 2 hours. This isn't governance. It's hostage-taking.” (Jankowicz 2020). The bill was a total of 5,593 pages in length, includes a myriad of unrelated policy riders, and is estimated to be the longest bill that Congress has ever passed (Jalonick 2020).

In such situations, models of policymaking that include legislator preferences are strained. In Krehbiel's (1998) Pivotal Politics model, it is assumed that members wish to vote for policy that is close to their ideal ideological point, yet this also assumes that members are provided adequate information to be able to discern whether policy is close enough to their preferences to earn their vote. In large bills, can rank-and-file members truly understand the scope of what they are voting on? How can a member's ideal point be determined when a bill is essentially numerous other pieces of legislation bundled together, and they are afforded little room for scrutiny? Unless members themselves are directly involved with crafting the final bill, it is unlikely that they would have such knowledge, even in the cases in which they may be briefed on the contents. ${ }^{36}$ If it is assumed that members have perfectly crystalized preferences and have no outside pressures that could affect their vote, without a chance to read and understand the bill they would have little basis by which to form an opinion in a vacuum.

\footnotetext{
${ }^{36}$ Regarding the example above: while members were briefed on what was in the Consolidated Appropriations Act of 2021, this did not assuage those who wished to read it before voting on it. In a later tweet, Representative OcasioCortez wrote of the matter: "It's not good enough to hear about what's in the bill. Members of Congress need to see \& read the bills we are expected to vote on. I know it's "controversial" \& I get in trouble for sharing things like this, but the people of this country deserve to know. They deserve better" (Fung 2020).
} 
Presidents are also constrained in such models for similar reasons. Cameron (2000) extends Krehbiel's model and writes of vetoes as an information gathering tool, even showing times in which the president and Congress engage in back and forth bill passage and vetoes in an information finding exercise. With massive appropriations bills released at the last possible moment, such vetoes would be unlikely, and would have more drastic consequences if they did not pass. In this way the president's preferences are constrained, and Congress utilizes this leverage to try to force the president to allow its preferred provisions to be enacted into law. ${ }^{37}$ When appropriations bills are used in this manner, a president's veto pivot would be difficult to model, as the president may not agree with the contents of the bill but may agree with the basic duty of funding the government for another year. Hassell and Kernel (2015) show that veto threats can bring the contents of these riders closer to the president's preferences, but these threats are best made with information regarding what is in the bill. We might also imagine such threats to be less likely to be followed by an actual veto, depending on the timing of the legislation and the immediate need for funding. As such, presidents may not be able to act in a manner that fits their ideal point in the real world, or such a point may be bypassed altogether. Future models might consider these tactics that operate outside of the normal policymaking process.

In Chapter 3 of this dissertation, I find that increases in polarization lead to decreases in committee productivity. The riders attached to these bills do not have to go through the usual committee markup process and can be used as a means to bypass standing committees when

\footnotetext{
${ }^{37}$ Note that this strategy of forcing a president's hand can sometimes backfire when members cannot agree on a bill to send to the president. When it takes time for Congress to agree and compromise, this leaves an opening for the president and his advisors to obtain more of what they want from legislation. In reference to President Clinton getting many of his preferred outcomes in an appropriation battle in 1998, Representative Mark Edward Sounder once said: "That we waited so long gave the president maximum leverage. That we couldn't figure out what was in the bill made us look a little less than sophisticated back home." (Pianin 1998)
} 
party leadership desires a specific policy outcome. Committee autonomy is slowly eroding in favor of consolidated power among party leadership (Evans 2013), and this research showcases another aspect of that phenomenon. If committees are thought to provide expertise to their parent chamber (Deering and Smith 1997), they would be unable to do so in a formal manner if bills are never sent to them for review. However, this does allow party leadership to expedite legislation that would normally stall within unfavorable committee environments and potentially increase legislative productivity.

\section{Limitations and Future Research}

This chapter also revealed several avenues for future research. First, we know divided government affects the likelihood of this behavior, but do different parties use this process in the same way? For example, do Republicans use this tactic more when Democrats are in control of the presidency, compared to the reverse? While we know that Republicans popularized this process to further their goals in the 90s (Aldrich and Rohde 2000), Democrats have used it similarly to accomplish their party goals in the years after. It would be interesting to know if different parties use the process in different ways. Similarly, does the party composition of the appropriations committee affect the frequency of changes, or is this decision more in the hands of party leadership? Further parsing out who frequently initiates this process would be a step toward a greater understanding of who can affect and control it.

Does using this process affect the usage of other unorthodox legislative tactics in Congress? For example, Sinclair (2012) shows that members are increasingly turning to alternate methods of passing policy, and that when one fails, they may pursue other methods to accomplish their goals. It would be interesting to see if the gridlock in Congress spurs members to use numerous tactics to accomplish goals, or if they have a preferred method. While Sinclair 
touches on some of this in her work, there is a small gap here that could be filled by examining whether gridlock spurs usage of other procedural methods as well.

While I examine the frequency of changes to the code, there is potential in examining the content of those changes, both in the bills that are passed, and the specific changes that are made. Presumably, a portion of these changes to the code should be included during the routine creation of appropriations bills, and if one could find a way to code and separate out the changes that don't pertain to appropriations, it would allow for a closer look at how much the process is affected by polarization and other factors. Thinking back to Chapter 2 of this dissertation, one avenue for future research could be to determine whether certain types of policy are more likely to be attached to appropriations bills than others. Are some types of policy easier to pass through the appropriations process, rather than by getting a bill through the floor? Is the process more likely to be used for publicly unpopular bills, or are party leaders more likely to use this for bills that the public agrees with? To summarize, it would be interesting to determine what this process is being used for in a more specific sense, and whether Congress shifts its focus over time.

\section{Conclusion}

This project explores how political polarization affects the regular order of Congress, with a particular focus on how legislative productivity is changed during periods of high polarization. My work adds to existing literature regarding legislative institutions, party politics, and public policy. I examined how polarization affects the kinds of bills Congress is able to pass, the ability of Congress to pass bills with particularized beneficiaries, the effects on committee system productivity, and how the appropriations process has become a means by which to pass unrelated policy. My results are robust to the use of a variety of statistical methods, in both chambers of Congress, and across time. The findings show the importance of studying various 
angles of congressional productivity, and how political polarization is affecting more than the total output of Congress.

One of the most significant difficulties associated with studying congressional output is that legislation is ultimately produced by people. Congress is a complicated institution, made up of individuals, each with their own goals and desires. These members operate within a system that is difficult to navigate and that constrains policy choices. Partisan politics have provided a simplified way to understand the policymaking dynamics of the legislative branch, but such explanations are hardly exhaustive, and we should not expect that polarization is the explanation for all questions related to productivity. There is still much work that can done to improve the ways in which we can understand polarization and gridlock, and I have suggested several avenues for future research. One may be to simply reconsider how we conceptualize the concept of congressional productivity. Congressional output appears to be dwindling, but there are still methods by which it can produce meaningful policy in a gridlocked system. However, it is clear there are limitations to these methods, and they may change the kind of output that is produced.

This project contributes to the literature by demonstrating ways that we can learn more about the productivity of Congress through the lens of political polarization. While studies of congressional productivity and of polarization are not new, my work stands as a testament that there are still avenues for future research. Moving forward, this work helps to paint a picture of the new regular order of Congress, and the lengths that must be taken by legislators to pass policy in highly polarized times. 


\section{$\underline{\text { Appendixes }}$}

Appendix 1-1: Combined DW-NOMINATE Distance Between Party Means 46th to 116 th Congress (1879 to 2019)

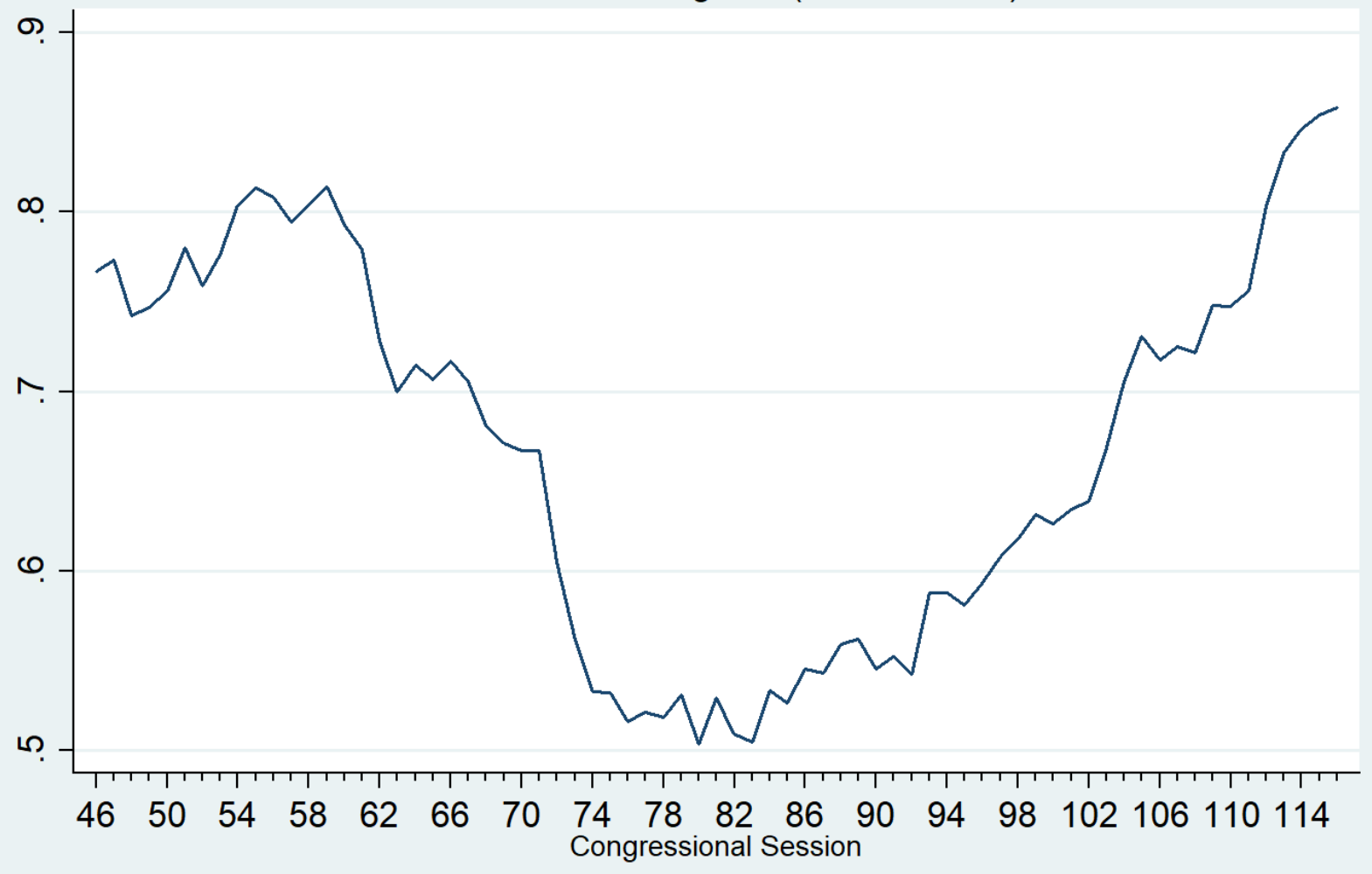




\section{Appendix 2-1: Coding Instructions}

Each bill in the Comparative Agendas Project data has been assigned a topic code, as well as a subtopic code. In this dataset, each subtopic code will be sorted into one of three categories: generalized, group, and geographic beneficiaries. Your task in this sorting process is to determine which category topics best fit into. The description of each category and subcategory, as well as the provided examples within the codebook will aid you in the coding process.

When examining a subcategory, consider who is the main target of the examples listed. Many subcategories will provide examples that pertain to several classifications, and you may have to consider which category a particular example best represents. In this case, choose the subcategory that has a plurality of examples that best fit into a singular category.

When considering the subcategory and examples, focus on the direct benefits that recipients would theoretically receive in these bills. Indirect benefits should not be considered for coding each subtopic, nor should the timeframe that it would take to implement the bill topics listed. For example: while having an educated populace is an indirect benefit to all of society, categories with bills that would disperse benefits to college students would be considered a group benefit, as they are directly affected by such bills.

What comprises a 'benefit' can take various forms, including monetary disbursements, an extension of rights, easing of regulation, a tax cut, or numerous other ways of extending tangible or intangible benefits to a policy's target. Consider this when making your choices.

\section{Generalized}

Do the examples listed disperse benefits that fall uniformly on all members of society?

If not, do the examples in the subtopic bring clear benefits to most of society?

Note: Subtopics coded in this manner should be topics with very broad constituencies that predominantly do not disperse benefits to one specific place, group, or locality.

\section{Group}

Does the subtopic, and/or the examples provided refer to specific industries, groups, or subsections of society?

Are a majority of benefits in the examples being placed upon a limited subsection of society?

\section{Geographic}

Do the examples within the subtopic refer to specific locations, regions, or territories? 
Does the subtopic refer to, or provide examples that would bring disproportionate benefits to specific places within the United States?

Note: If the subtopic does not refer to specific regions or places, consider the context of the topics within. For example: Military base openings may be a targeted benefit that predominantly affects specific geographic locations, even if it does not list specific geographic locations by name. Example language to consider: "Rural areas", "Midwest", "Chesapeake Bay". 
Appendix 2-2: Agreement Between Subtopic Coders

\begin{tabular}{|l|l|l|l|l|l|l|}
\hline Agreement & $\begin{array}{l}\text { Expected } \\
\text { Agreement }\end{array}$ & Kappa & Std. Err. & Z & Prob > Z & N \\
\hline 90.45 & 34.81 & 0.8535 & 0.0481 & 17.75 & 0.0000 & 199 \\
\hline
\end{tabular}




\section{Appendix 2-3: List of Topic Codes Excluded from Chapter 2}

199: Other

Description: Includes issues related to other macroeconomics subtopics

209: Anti-Government

Description: Includes issues related to anti-government activity groups, such as the communist party and local insurgency groups

299: Other

Description: Includes issues related to other civil rights subtopics

399: Other

Description: Includes issues related to other health care topics

499: Other

Description: Includes issues related to other agricultural subtopics

599: Other

Description: Issues related to other labor policy

699: Other

Description: Includes issues related to other subtopics in education policy

799: Other

Description: Includes issues related to other environmental subtopics

899: Other

Description: Includes issues related to other energy subtopics

915: Panama Canal Issues and Other International Canal Issues

Examples: Panama Canal Commission appropriations, strategic importance of the Panama Canal, claims for ship damages in the Panama Canal, Panama Canal treaty issues, Panama Canal traffic and capacity, maintenance and operation of the Canal, development of new transoceanic canal.

1099: Other

Description: Includes issues related to other transportation subtopics

1299: Other

Description: Includes issues related to other law, crime, and family subtopics

1399: Other

Description: Includes issues related to other social welfare policy subtopics

1499: Other

Description: Other issues related to housing and community development

1599: Other

Description: Includes issues related to other domestic commerce policy subtopics 
1606: Military Aid

Description: Includes issues related to military aid to other countries and the control of arms sales to other countries

1699: Other

Description: Includes issues related to other defense policy subtopics

1799: Other

Description: Includes issues related to other space, science, technology, and communication research and development

1899: Other

Description: Includes issues related to other foreign trade policy subtopics

1900: General

Description: Includes issues related to general international affairs and foreign aid, including appropriations for general government foreign affairs agencies

1901: Foreign Aid

Description: Includes issues related to foreign aid not directly targeting at increasing international development

1902: Resources Exploitation

Description: Includes issues related to international resources exploitation and resources agreements, law of the sea and international ocean conservation efforts

1905: Developing Countries

Description: Includes issues related specifically to developing countriesDeveloping Countries Issues (for Financial Issues see 1906)

1906: International Finance

Description: Includes issues related to international finance and economic development, the World Bank and International Monetary Fund, regional development banks, sovereign debt and implications for international lending instututions

1910: Western Europe

Description: Includes issues related to Western Europe and the European Union

\section{1: Specific Country}

Description: Includes issues related specifically to a foreign country or region not codable using other codes, assessment of political issues in other countries, relations between individual countries

\section{5: Human Rights}

Description: Includes issues related to human rights, human rights violations, human rights treaties and conventions, UN reports on human rights, crimes associated with genocide or crimes against humanity 
1926: Organizations

Description: International organizations, NGOs, the United Nations, International Red Cross, UNESCO, International Olympic Committee, International Criminal Court

\section{7: Terrorism}

Description: Includes issues related to international terrorism, hijacking, and acts of piracy in other countries, efforts to fight international terrorism, international legal mechanisms to combat terrorism

\section{9: Diplomats}

Description: Includes issues related to diplomats, diplomacy, embassies, citizens abroad, foreign diplomats in the country, visas and passports

1999: Other

Description: Includes issues related to other international affairs policy subtopics

2010: Scandals

Description: Includes issues related to public scandal and impeachment

2099: Other

Description: Includes issues related to other government operations subtopics

2199: Other

Description: Includes issues related to other public lands policy subtopics

2300: General

Description: Includes issues related to general cultural policy issues 
Appendix 2-4: Two-Tailed Seemingly Unrelated Regression Estimates of Polarization and Beneficiaries

\begin{tabular}{|c|c|c|c|}
\hline & $\begin{array}{l}\text { Model } 1 \\
\text { Generalized }\end{array}$ & $\begin{array}{l}\text { Model } 2 \\
\text { Group }\end{array}$ & $\begin{array}{l}\text { Model } 3 \\
\text { Geographic }\end{array}$ \\
\hline Polarization (DV) & $\begin{array}{l}\mathbf{1 . 1 3 6}^{\text {**** }} \\
(0.079)\end{array}$ & $\begin{array}{l}\mathbf{- 0 . 3 9 1}^{\text {***** }} \\
(0.066)\end{array}$ & $\begin{array}{l}-\mathbf{- 0 . 7 4 5}^{\text {**** }} \\
(0.083)\end{array}$ \\
\hline Competition & $\begin{array}{l}0.045 \\
(0.089)\end{array}$ & $\begin{array}{l}\mathbf{0 . 3 5 1} 1^{* * * * *} \\
(0.074)\end{array}$ & $\begin{array}{l}\mathbf{- 0 . 3 0 6}^{* * *} \\
(0.094)\end{array}$ \\
\hline Unified & $\begin{array}{l}\mathbf{0 . 0 4 0}^{* * *} \\
(0.015)\end{array}$ & $\begin{array}{l}-0.013 \\
(0.013)\end{array}$ & $\begin{array}{l}-\mathbf{- 0 . 0 2 7} * \\
(0.015)\end{array}$ \\
\hline Honeymoon & $\begin{array}{l}0.004 \\
(0.012)\end{array}$ & $\begin{array}{l}-0.004 \\
(0.012)\end{array}$ & $\begin{array}{l}0.007 \\
(0.015)\end{array}$ \\
\hline Time Out & $\begin{array}{l}\mathbf{0 . 0 0 3}^{*} \\
(0.001)\end{array}$ & $\begin{array}{l}0.000 \\
(0.001)\end{array}$ & $\begin{array}{l}-\mathbf{- 0 . 0 0 3}^{*} \\
(0.001)\end{array}$ \\
\hline Recession & $\begin{array}{l}0.003 \\
(0.002)\end{array}$ & $\begin{array}{l}0.000 \\
(0.001)\end{array}$ & $\begin{array}{l}\mathbf{0 . 0 0 1}^{*} \\
(0.002)\end{array}$ \\
\hline Debt & $\begin{array}{l}0.000 \\
(0.000)\end{array}$ & $\begin{array}{l}0.000 \\
(0.000)\end{array}$ & $\begin{array}{l}0.000 \\
(0.000)\end{array}$ \\
\hline Constant & $\begin{array}{l}-\mathbf{0 . 3 6 2} \\
(0.055)\end{array}$ & $\begin{array}{l}\mathbf{0 . 5 8 3}^{* * * *} \\
(0.046)\end{array}$ & $\begin{array}{l}\mathbf{0 . 7 8 0}^{* * * *} \\
(0.058)\end{array}$ \\
\hline $\mathrm{R}^{2}$ & 0.8825 & 0.7176 & 0.7286 \\
\hline $\mathrm{N}$ & 35 & 35 & 35 \\
\hline
\end{tabular}

Standard errors in parentheses. ${ }^{*} p<0.05,{ }^{* *} p<0.01,{ }^{* * *} p<0.001$ (two-tailed tests) 


\section{Appendix 3-1: List of House Committees}

\begin{tabular}{|l|l|}
\hline Committee Name & Sessions in Data \\
\hline Agriculture & 80th to 114th \\
\hline Appropriations & 80th to 114th \\
\hline Armed Services & 80th to 114th \\
\hline Budget & 94th to 114th \\
\hline Education and Labor & 80th to 114th \\
\hline Energy and Commerce & 80th to 114th \\
\hline Ethics & 91st to 114th \\
\hline Financial Services & 80th to 114th \\
\hline Foreign Affairs & 80th to 114th \\
\hline Homeland Security & 107th to 114th \\
\hline House Administration & 80th to 114th \\
\hline Intelligence & 95th to 114th \\
\hline Judiciary & 80th to 114th \\
\hline Oversight and Reform & 80th to 114th \\
\hline Natural Resources & 80th to 114th \\
\hline Post Office and Civil Service & 80th to 103rd \\
\hline Transportation and Infrastructure & 80th to 114th \\
\hline Rules & 80th to 114th \\
\hline Science, Space, and Technology & 80th to 114th \\
\hline Small Business & 80th to 114th \\
\hline Veterans' Affairs & 80th to 114th \\
\hline Ways and Means & 80th to 114th \\
\hline
\end{tabular}




\section{Appendix 3-2: List of Senate Committees}

\begin{tabular}{|l|l|}
\hline Committee Name & Sessions in Data \\
\hline Agriculture, Nutrition, and Forestry & 80th to 114th \\
\hline Appropriations & 80th to 114th \\
\hline Banking, Housing, and Urban Affairs & 80th to 114th \\
\hline Budget & 80th to 114th \\
\hline Commerce, Science, and Transportation & 80th to 114th \\
\hline Energy and Natural Resources & 80th to 114th \\
\hline Environment and Public Works & 80th to 114th \\
\hline Finance & 80th to 114th \\
\hline Foreign Relations & 80th to 114th \\
\hline Homeland Security and Governmental Affairs & 80th to 114th \\
\hline Intelligence & 94th to 114th \\
\hline Judiciary & 80th to 114th \\
\hline Health, Education, Labor, and Pensions & 80th to 114th \\
\hline Rules and Administration & 80th to 114th \\
\hline Small Business and Entrepreneurship & 80th to 114th \\
\hline Veterans' Affairs & 92nd to 114th \\
\hline
\end{tabular}




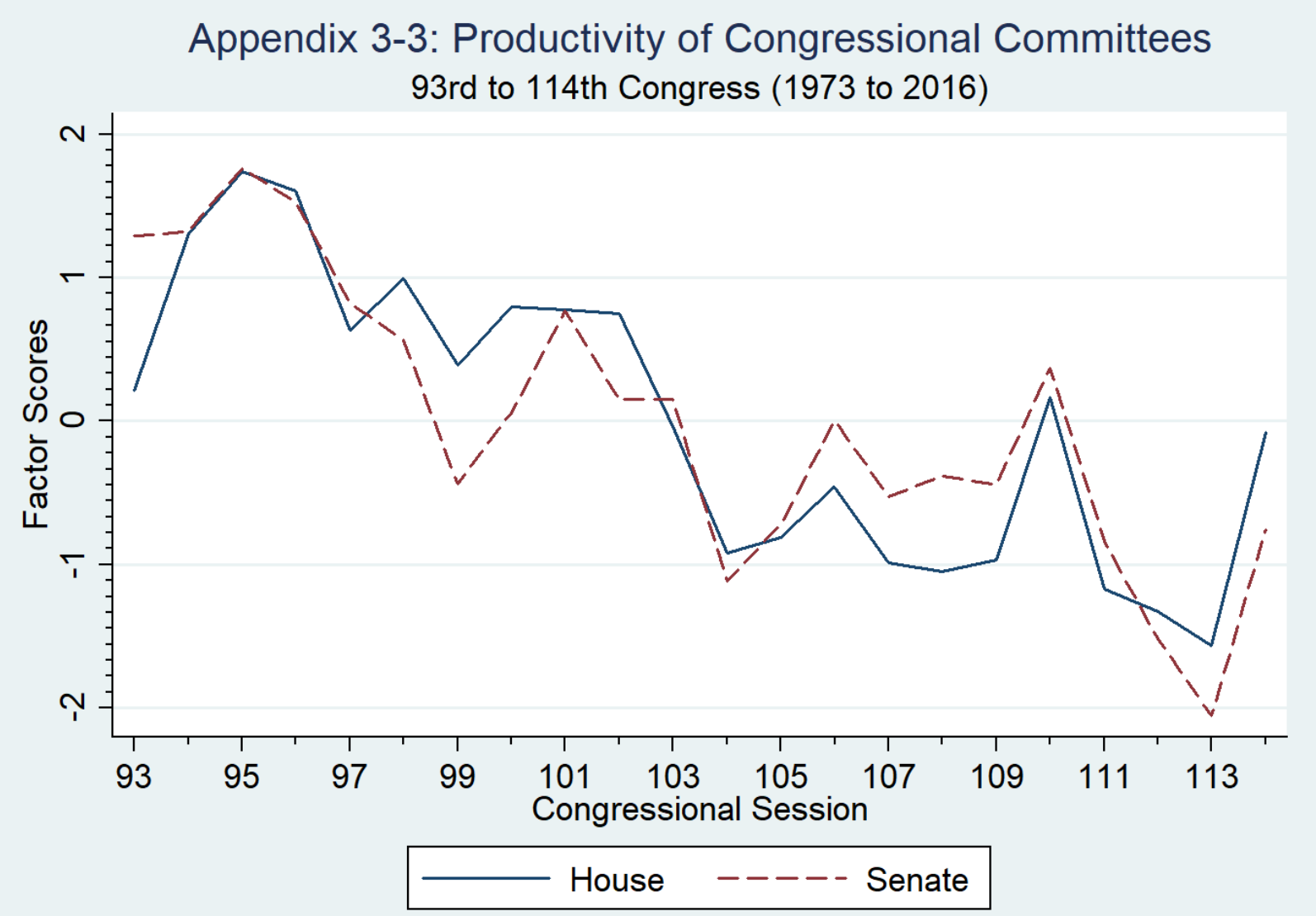


Appendix 3-4: Two-tailed OLS Estimates of Committee Productivity in the House

\begin{tabular}{lll}
\hline & $\begin{array}{l}\text { Model 1 } \\
\text { Fixed Effects }\end{array}$ & $\begin{array}{l}\text { Model 2 } \\
\text { Random Effects }\end{array}$ \\
\hline Polarization (DV) & & \\
Unified government & $-1.163(0.594)$ & $-1.166(0.604)$ \\
New committee chair & $-0.070(0.052)$ & $-0.071(0.053)$ \\
Majority size & $-0.036(0.047)$ & $-0.423(0.048)$ \\
Majority years out of power & $-0.001(0.001)$ & $-0.001(0.001)$ \\
94th to 103rd Session & $0.001(0.003)$ & $0.001(0.003)$ \\
104th to 114th Session & $0.125(0.118)$ & $0.125(0.120)$ \\
Constant & $-0.076(0.178)$ & $-0.076(0.181)$ \\
& $\mathbf{0 . 8 1 0}(\mathbf{0 . 3 6 9})^{*}$ & $\mathbf{0 . 7 7 3}(\mathbf{0 . 4 0 1})^{*}$ \\
\hline $\mathrm{F}$ & & \\
$\mathrm{R}^{2}$ & $\mathbf{8 1 . 4 8}{ }^{* * * *}$ & $\mathrm{~N} / \mathrm{A}$ \\
$\mathrm{N}$ & 0.059 & 0.059 \\
Standard errors in parentheses. $^{*} p<0.05,{ }^{* * *} p<0.01,{ }^{* * *} p<0.001$ (two-tailed tests)
\end{tabular}


Appendix 3-5: Two-tailed OLS Estimates of Committee Productivity in the Senate

\begin{tabular}{|c|c|c|}
\hline & $\begin{array}{l}\text { Model } 1 \\
\text { Fixed Effects } \\
\end{array}$ & $\begin{array}{l}\text { Model } 2 \\
\text { Random Effects }\end{array}$ \\
\hline Polarization (DV) & $-3.491(0.668)^{* * * *}$ & $-3.502(0.669)^{* * * *}$ \\
\hline Unified government & $0.644(0.098)^{* * * *}$ & $0.612(0.097)^{* * *}$ \\
\hline New committee chair & $-0.019(0.055)$ & $-0.019(0.055)$ \\
\hline Majority size & $-0.012(0.006)^{*}$ & $-0.012(0.006)^{*}$ \\
\hline Majority years out of power & $0.002(0.005)$ & $0.002(0.005)$ \\
\hline 94th to 103 rd Session & $-0.470(0.091)^{* * * *}$ & $-0.469(0.092)^{* * * *}$ \\
\hline 104th to 114 th Session & $-0.446(0.168)^{* * *}$ & $-0.447(0.169)^{* * *}$ \\
\hline Constant & $2.795(0.398)^{* * *}$ & $2.806(0.440)^{* * * *}$ \\
\hline $\mathrm{F}$ & $61.33^{* * * *}$ & N/A \\
\hline $\mathrm{R}^{2}$ & 0.181 & 0.185 \\
\hline $\mathrm{N}$ & 373 & 373 \\
\hline
\end{tabular}


Appendix 3-6: Negative Binomial Estimates of Indicators of Productivity in the House

\begin{tabular}{|c|c|c|c|}
\hline & $\begin{array}{l}\text { Model } 1 \\
\text { Hearings }\end{array}$ & $\begin{array}{l}\text { Model } 2 \\
\text { Days }\end{array}$ & $\begin{array}{l}\text { Model } 3 \\
\text { Reported Bills }\end{array}$ \\
\hline Polarization (DV) & $-3.001(1.414)^{*}$ & $-0.988(1.573)$ & $-0.895(1.366)$ \\
\hline Unified government & $-0.099(0.097)$ & $-0.026(0.111)$ & $-0.173(0.122)$ \\
\hline New committee chair & $-0.071(0.095)$ & $-0.052(0.108)$ & $-0.306(0.108)^{* *}$ \\
\hline Majority size & $-0.003(0.001)^{*}$ & $-0.003(0.002)$ & $0.003(0.002)$ \\
\hline Majority years out of power & $0.006(0.008)$ & $0.017(0.009)$ & $0.005(0.007)$ \\
\hline 94th to 103 rd Session & $0.194(0.160)$ & $0.012(0.186)$ & $-0.067(0.276)$ \\
\hline 104th to 114 th Session & $-0.043(0.387)$ & $-0.646(0.429)$ & $0.186(0.413)$ \\
\hline Constant & $5.687(0.809)^{* * *}$ & $5.455(0.899)^{* * *}$ & $4.219(0.848)^{* * * *}$ \\
\hline Pseudo $\mathrm{R}^{2}$ & 0.010 & 0.007 & 0.003 \\
\hline $\mathrm{N}$ & 674 & 674 & 448 \\
\hline Log-likelihood & -2318.905 & -2644.878 & -1758.097 \\
\hline
\end{tabular}


Appendix 3-7: Negative Binomial Estimates of Indicators of Productivity in the Senate

\begin{tabular}{|c|c|c|c|}
\hline & $\begin{array}{l}\text { Model } 1 \\
\text { Hearings } \\
\end{array}$ & $\begin{array}{l}\text { Model } 2 \\
\text { Days }\end{array}$ & $\begin{array}{l}\text { Model } 3 \\
\text { Reported Bills }\end{array}$ \\
\hline Polarization (DV) & $-4.169(1.127)^{* * * *}$ & $-6.121(1.302)^{* * * *}$ & $-1.363(1.486)$ \\
\hline Unified government & $-0.087(0.089)$ & $-0.079(0.099)$ & $-0.265(0.117)^{*}$ \\
\hline New committee chair & $-0.058(0.088)$ & $-0.109(0.096)$ & $-0.051(0.113)$ \\
\hline Majority size & $0.070(0.005)$ & $0.005(0.006)$ & $0.021(0.008)^{* *}$ \\
\hline Majority years out of power & $-0.005(0.008)$ & $-0.007(.009)$ & $-0.002(0.010)$ \\
\hline 94th to 103 rd Session & $0.253(0.154)$ & $0.007(0.173)$ & $-0.316(0.193)$ \\
\hline 104th to 114 th Session & $-0.069(0.302)$ & $-0.399(0.343)$ & $-0.326(0.370)$ \\
\hline Constant & $5.835(0.624)^{* * *}$ & $7.934(0.724)^{* * *}$ & $4.828(0.883)^{* * * *}$ \\
\hline Pseudo $\mathrm{R}^{2}$ & 0.0282 & 0.0468 & 0.0062 \\
\hline $\mathrm{N}$ & 556 & 556 & 373 \\
\hline Log-likelihood & -3056.1766 & -3612.0847 & -2092.8687 \\
\hline
\end{tabular}

Standard errors in parentheses. ${ }^{*} p<0.05,{ }^{* *} p<0.01,{ }^{* * *} p<0.001$ (one-tailed tests) 
Appendix 3-8: OLS Estimates of House Committee Productivity with Lagged DV and Time

\begin{tabular}{|c|c|c|}
\hline & $\begin{array}{l}\text { Model } 1 \\
\text { Fixed Effects }\end{array}$ & $\begin{array}{l}\text { Model } 2 \\
\text { Random Effects }\end{array}$ \\
\hline Polarization (DV) & $-0.867(1.438)$ & $1.441(1.621)$ \\
\hline Unified government & $-0.101(0.048)^{*}$ & $-0.118(0.054)^{*}$ \\
\hline New committee chair & $-0.024(0.045)$ & $-0.049(0.051)$ \\
\hline Majority size & $0.001(0.001)$ & $0.001(0.001)$ \\
\hline Majority years out of power & $-0.003(0.002)$ & $-0.007(0.003)^{*}$ \\
\hline Lagged DV & $0.352(0.047)^{* * *}$ & $0.859(0.024)^{* * *}$ \\
\hline Time & $-0.005(0.021)$ & $-0.023(0.024)$ \\
\hline Constant & $1.105(1.218)$ & $0.024(1.386)$ \\
\hline $\mathrm{F}$ & $27.01^{* * * *}$ & N/A \\
\hline $\mathrm{R}^{2}$ & 0.693 & 0.775 \\
\hline $\mathrm{N}$ & 429 & 429 \\
\hline
\end{tabular}


Appendix 3-9: OLS Estimates of Senate Committee Productivity with Lagged DV and Time

\begin{tabular}{|c|c|c|}
\hline & $\begin{array}{l}\text { Model } 1 \\
\text { Fixed Effects }\end{array}$ & $\begin{array}{l}\text { Model } 2 \\
\text { Random Effects }\end{array}$ \\
\hline Polarization (DV) & $-1.241(0.989)$ & $-0.791(1.016)$ \\
\hline Unified government & $0.125(0.077)$ & $-0.022(0.041)$ \\
\hline New committee chair & $0.044(0.039)$ & $0.037(0.040)$ \\
\hline Majority size & $-0.001(0.004)$ & $0.001(0.002)$ \\
\hline Majority years out of power & $-0.008(0.003)^{* *}$ & $-0.009(0.003)^{* * *}$ \\
\hline Lagged DV & $0.653(0.038)^{* * * *}$ & $0.849(0.020)^{* * * *}$ \\
\hline Time & $-0.002(0.016)$ & $0.004(0.016)$ \\
\hline Constant & $1.000(0.988)$ & $0.044(1.006)$ \\
\hline $\mathrm{F}$ & $137.38^{* * * *}$ & N/A \\
\hline $\mathrm{R}^{2}$ & 0.849 & 0.868 \\
\hline $\mathrm{N}$ & 358 & 358 \\
\hline
\end{tabular}


Appendix 4-1: Two-Tailed Negative Binomial Estimates of Changes Originating from Appropriations Bills

\begin{tabular}{|c|c|c|c|c|}
\hline & $\begin{array}{l}\text { Model 1 } \\
\text { Polarization }\end{array}$ & $\begin{array}{l}\text { Model } 2 \\
\text { Time Added }\end{array}$ & $\begin{array}{l}\text { Model } 3 \\
\text { Moderates } \\
\end{array}$ & $\begin{array}{l}\text { Model } 4 \\
\text { Gridlock Interval }\end{array}$ \\
\hline Polarization (DV) & $\begin{array}{l}\mathbf{9 . 2 4 9}^{\text {***** }} \\
(2.633)\end{array}$ & $\begin{array}{l}\mathbf{7 . 7 0 1}^{* * * *} \\
(1.958)\end{array}$ & $\begin{array}{l}\text { 3.271 }^{* *} \\
(1.101)\end{array}$ & $\begin{array}{c}0.382 \\
(0.961)\end{array}$ \\
\hline Fully Divided & $\begin{array}{l}\mathbf{- 2 . 3 7 7 ^ { * }} \\
(1.059)\end{array}$ & $\begin{array}{l}\mathbf{- 2 . 9 1 5}^{* * * *} \\
(0.812)\end{array}$ & $\begin{array}{l}\mathbf{- 1 . 4 6 7}^{* * * *} \\
(0.365)\end{array}$ & $\begin{array}{l}\mathbf{- 1 . 9 4 4}^{* * * *} \\
(0.479)\end{array}$ \\
\hline Pol. Interact & $\begin{array}{l}\mathbf{4 . 2 5 7}^{*} \\
(1.661)\end{array}$ & $\begin{array}{l}\mathbf{4 . 7 6 6}^{* * * *} \\
(1.267)\end{array}$ & $\begin{array}{l}\mathbf{4 . 4 3 7}^{* * * *} \\
(1.059)\end{array}$ & $\begin{array}{l}\mathbf{4 . 8 2 0}^{\text {****}} \\
(1.124)\end{array}$ \\
\hline Honeymoon & $\begin{array}{l}-\mathbf{- 0 . 3 2 8}^{*} \\
(0.152)\end{array}$ & $\begin{array}{l}-\mathbf{- 0 . 3 2 9}^{*} \\
(0.124)\end{array}$ & $\begin{array}{l}-\mathbf{- 0 . 3 0 8 *} \\
(0.126)\end{array}$ & $\begin{array}{l}-0.231 \\
(0.133)\end{array}$ \\
\hline Time Out & $\begin{array}{l}0.003 \\
(0.015)\end{array}$ & $\begin{array}{l}-0.003 \\
(0.123)\end{array}$ & $\begin{array}{l}-0.0002 \\
(0.013)\end{array}$ & $\begin{array}{l}-0.001 \\
(0.013)\end{array}$ \\
\hline Debt & $\begin{array}{c}\mathbf{0 . 0 5 4}^{*} \\
(0.022)\end{array}$ & $\begin{array}{l}\mathbf{0 . 0 6 7}^{\text {**** }} \\
(0.017)\end{array}$ & $\begin{array}{l}\mathbf{0 . 0 3 7}^{\text {*** }} \\
(0.012)\end{array}$ & $\begin{array}{c}0.004 \\
(0.011)\end{array}$ \\
\hline Debt Interact & $\begin{array}{l}-\mathbf{- . 0 7 8}^{*} \\
(0.034)\end{array}$ & $\begin{array}{l}\mathbf{- 0 . 0 7 0}^{* * * *} \\
(0.026)\end{array}$ & $\begin{array}{l}-\mathbf{- 0 . 0 5 0}^{* * *} \\
(0.018)\end{array}$ & $\begin{array}{c}0.001 \\
(0.019)\end{array}$ \\
\hline Time & & $\begin{array}{l}\mathbf{0 . 0 3 6}^{* * * *} \\
(0.006)\end{array}$ & $\begin{array}{l}\mathbf{0 . 0 2 7}^{* * * *} \\
(0.007)\end{array}$ & $\begin{array}{l}\mathbf{0 . 0 2 8}^{* * * *} \\
(0.007)\end{array}$ \\
\hline Constant & $\begin{array}{l}-0.002 \\
(0.539) \\
\end{array}$ & $\begin{array}{l}-2.048 \\
(1.300) \\
\end{array}$ & $\begin{array}{c}\mathbf{4 . 4 4 9}^{* * * *} \\
(0.790) \\
\end{array}$ & $\begin{array}{c}\mathbf{2 . 9 0 3}^{* * * *} \\
(0.567) \\
\end{array}$ \\
\hline $\begin{array}{l}\text { Pseudo } \mathrm{R}^{2} \\
\mathrm{~N}\end{array}$ & $\begin{array}{l}0.074 \\
49\end{array}$ & $\begin{array}{l}0.107 \\
49\end{array}$ & $\begin{array}{l}0.104 \\
49\end{array}$ & $\begin{array}{l}0.100 \\
47\end{array}$ \\
\hline
\end{tabular}


Appendix 4-2: Negative Binomial Estimates of Changes Originating from Appropriations Bills with Time Dummy

\begin{tabular}{|c|c|c|c|c|}
\hline & $\begin{array}{l}\text { Model } 1 \\
\text { Polarization }\end{array}$ & $\begin{array}{l}\text { Model } 2 \\
\text { Time Added }\end{array}$ & $\begin{array}{l}\text { Model } 3 \\
\text { Moderates } \\
\end{array}$ & $\begin{array}{l}\text { Model } 4 \\
\text { Gridlock Interval }\end{array}$ \\
\hline Polarization (DV) & $\begin{array}{l}\mathbf{9 . 2 4 9}^{\text {***** }} \\
(2.633)\end{array}$ & $\begin{array}{l}\mathbf{5 . 3 8 4}^{* *} \\
(1.905)\end{array}$ & $\begin{array}{l}\text { 2.124* } \\
(1.106)\end{array}$ & $\begin{array}{l}0.447 \\
(0.904)\end{array}$ \\
\hline Fully Divided & $\begin{array}{l}\mathbf{- 2 . 3 7 7 *} \\
(1.059)\end{array}$ & $\begin{array}{l}\mathbf{- 1 . 8 1 9}^{* * *} \\
(0.802)\end{array}$ & $\begin{array}{l}-\mathbf{0 . 0 6 9}^{* * * *} \\
(0.437)\end{array}$ & $\begin{array}{l}-0.919 \\
(0.588)\end{array}$ \\
\hline Pol. Interact & $\begin{array}{l}\mathbf{4 . 2 5 7}^{* * *} \\
(1.661)\end{array}$ & $\begin{array}{l}\mathbf{2 . 8 0 3}^{* *} \\
(1.281)\end{array}$ & $\begin{array}{l}\mathbf{2 . 3 7 7 ^ { * * * * }} \\
(1.233)\end{array}$ & $\begin{array}{l}1.877 \\
(1.486)\end{array}$ \\
\hline Honeymoon & $\begin{array}{l}-\mathbf{- 0 . 3 2 8 *} \\
(0.152)\end{array}$ & $\begin{array}{l}\mathbf{- 0 . 2 0 6 *}^{*} \\
(0.118)\end{array}$ & $\begin{array}{l}-0.195 \\
(0.123)\end{array}$ & $\begin{array}{l}-0.171 \\
(0.126)\end{array}$ \\
\hline Time Out & $\begin{array}{l}0.003 \\
(0.015)\end{array}$ & $\begin{array}{l}-0.016 \\
(0.013)\end{array}$ & $\begin{array}{l}-0.013 \\
(0.013)\end{array}$ & $\begin{array}{l}-0.012 \\
(0.014)\end{array}$ \\
\hline Debt & $\begin{array}{l}\mathbf{0 . 0 5 4}^{* *} \\
(0.022)\end{array}$ & $\begin{array}{l}\mathbf{0 . 0 4 7}^{* *} \\
(0.017)\end{array}$ & $\begin{array}{l}\mathbf{0 . 0 2 4}^{*} \\
(0.013)\end{array}$ & $\begin{array}{l}0.006 \\
(0.011)\end{array}$ \\
\hline Debt Interact & $\begin{array}{l}-\mathbf{- 0 . 0 7 8}^{*} \\
(0.034)\end{array}$ & $\begin{array}{l}-\mathbf{- 0 . 0 7 0}^{* *} \\
(0.026)\end{array}$ & $\begin{array}{l}-0.029 \\
(0.019)\end{array}$ & $\begin{array}{l}-0.004 \\
(0.017)\end{array}$ \\
\hline Time & & $\begin{array}{l}\mathbf{0 . 0 3 3}^{\text {**** }} \\
(0.006)\end{array}$ & $\begin{array}{l}\mathbf{0 . 0 2 8}^{* * * *} \\
(0.006)\end{array}$ & $\begin{array}{l}\mathbf{0 . 0 3 0}^{\text {*****}} \\
(0.007)\end{array}$ \\
\hline Time Dummy & & $\begin{array}{l}\mathbf{0 . 9 4 6 * * *} \\
(0.297)\end{array}$ & $\begin{array}{l}\mathbf{0 . 9 1 6}^{* *} \\
(0.336)\end{array}$ & $\begin{array}{l}\mathbf{1 . 0 5 1}^{\text {******}} \\
(0.390)\end{array}$ \\
\hline Constant & $\begin{array}{l}-.002 \\
(0.539)\end{array}$ & $\begin{array}{l}-\mathbf{0 . 4 6 7} \\
(1.266)\end{array}$ & $\begin{array}{l}\text { 3.967**** } \\
(0.750)\end{array}$ & $\begin{array}{l}\mathbf{2 . 9 0 3}^{\text {****** }} \\
(0.567)\end{array}$ \\
\hline $\begin{array}{l}\text { Pseudo } \mathrm{R}^{2} \\
\mathrm{~N}\end{array}$ & $\begin{array}{l}0.074 \\
49\end{array}$ & $\begin{array}{l}0.120 \\
49\end{array}$ & $\begin{array}{l}0.114 \\
49\end{array}$ & $\begin{array}{l}0.109 \\
47\end{array}$ \\
\hline
\end{tabular}


Appendix 4-3: Negative Binomial Models of Changes without Debt Interaction

\begin{tabular}{|c|c|c|}
\hline & $\begin{array}{l}\text { Model } 1 \\
\text { Polarization } \\
\end{array}$ & $\begin{array}{l}\text { Model } 2 \\
\text { Time Added }\end{array}$ \\
\hline Polarization (DV) & $3.789(1.068)^{* * * *}$ & $1.041(1.105)$ \\
\hline Fully Divided Government & $-2.162(1.157)^{*}$ & $-2.394(0.975)^{* *}$ \\
\hline Polarization Interaction & $3.924(1.817)^{*}$ & $4.004(1.530)^{* *}$ \\
\hline Honeymoon & $-0.323(0.160)^{*}$ & $-0.295(0.142)^{* * *}$ \\
\hline Majority years out of power & $-0.002(0.015)$ & $0.005(0.014)$ \\
\hline Debt & $0.006(0.004)$ & $0.002(0.003)$ \\
\hline Time & & $0.029(0.007)^{* * * *}$ \\
\hline Constant & $3.367(0.669)^{* * *}$ & $2.665(0.615)^{* * * *}$ \\
\hline Pseudo $\mathrm{R}^{2}$ & 0.068 & 0.088 \\
\hline $\mathrm{N}$ & 49 & 49 \\
\hline
\end{tabular}




\section{References}

Adler, E. Scott. 2000. "Constituency Characteristics and the "Guardian" Model of Appropriations Subcommittees, 1959-1998." American Journal of Political Science 44 (1): 104-114.

Aldrich, John H., Brittany N. Perry, and David W. Rohde. 2013. "Richard Fenno's Theory of Congressional Committees and the Partisan Polarization of the House." In Congress Reconsidered, 10th Edition, eds. Lawrence C. Dodd and Bruce I. Oppenheimer. CQ Press.

Aldrich, John H. and David W. Rohde. 2000. "The Republican Revolution and the House Appropriations Committee". The Journal of Politics 62(1): 1-33.

Adler, E. Scott, and John D. Wilkerson. 2013. Congress and the Politics of Problem Solving. New York: Cambridge University Press.

Adler, E. Scott and John D. Wilkerson. 2021. "Congressional Bills Project." http://congressionalbills.org/index.html

Abramowitz, Alan I. and Kyle L. Saunders. 2008. "Is Polarization a Myth?" The Journal of Politics 70 (20): 542-555.

Abromowitz, Alan I. 2010. The Disappearing Center: Engaged Citizens, Polarization, and American Democracy. New Haven, CT: Yale University Press.

Adams, John. 1780. "From John Adams to Jonathan Jackson, 2 October 1780". https://founders.archives.gov/documents/Adams/06-10-02-0113

Aldrich, John H., Brittany N. Perry, and David W. Rohde. 2013. "Richard Fenno's Theory of Congressional Committees and the Partisan Polarization of the House." In Congress Reconsidered, 10th Edition, eds. Lawrence C. Dodd and Bruce I. Oppenheimer. CQ Press.

Aldrich, John H. and David W. Rohde. 2000. "The Republican Revolution and the House Appropriations Committee". The Journal of Politics 62(1): 1-33.

Anderson, William, Janet M. Box-Steffensmeier, and Valeria Sinclair-Chapman. 2003. "The Keys to Legislative Success in the U.S. House of Representatives." Legislative Studies Quarterly 28(3): 357-386.

Arnold, R. Douglas 1990. The Logic of Congressional Action. Yale University Press.

Aubrey, Allison and Dan Charles. 2015. "Follow The Money: Congress Uses Budget Bill To Rewrite Food Policies." NPR, December 16th. https://www.npr.org/sections/thesalt/2015/12/16/459986395/follow-the-money-congressuses-budget-bill-to-rewrite-food-policies/

Bachrach, Peter and Morton S. Baratz. 1962. "Two Faces of Power," American Political Science Review 56(4): 947-952 
Barber, Michael J. and Nolan McCarty. 2015. "Causes and Consequences of Polarization." In Solutions to Political Polarization in America. Ed. Nathaniel Persily. New York: Cambridge University Press: 15-58.

Bartels, Larry M. 2006. "What's the Matter with What's the Matter with Kansas?" Quarterly Journal of Political Science 1(2): 201-226.

Baumgartner, Frank R., Jeffery M. Berry, Marie Hojnacki, David C. Kimball, and Beth L. Leech. 2009. Lobbying and Policy Change: Who Wins, Who Loses, and Why. Chicago: University of Chicago Press.

Baumgartner, Frank and Bryan Jones 2009. 2nd ed. Agendas and Instability in American Politics. Chicago: University of Chicago Press.

Becker, Lawrence A. and Vincent G. Moscardelli. 2008. "Congressional Leadership on the Front Lines: Committee Chairs, Electoral Security, and Ideology." PS: Political Science and Politics 41(1): 77-82.

Binder, Sarah A. 1999. "The Dynamics of Legislative Gridlock.” American Political Science Review. 93(3): 519-534.

Binder, Sarah A. 2003. Stalemate: Causes and Consequences of Legislative Gridlock. Washington, D.C.: Brookings Institution Press.

Binder, Sarah A. 2015. “The Dysfunctional Congress.” Annual Review of Political Science. 18(1): 85-101.

Binder, Sarah A., and Forrest Maltzman. 2002. "Senatorial Delay in Confirming Federal Judges, 1947-1998.” American Journal of Political Science 46(1): 190-199.

Birkland, Thomas A. 1998. "Focusing Events, Mobilization, and Agenda Setting." Journal of Public Policy 18(1): 53-74.

Bismark, Otto Von. 1895. Fürst Bismarck: neue Tischgespräche und Interviews, Volume 1. Stuttgart Deutsche Verlags-Anstalt.

Boatright, Robert G. 2013. Getting Primaried: The Changing Politics of Congressional Primary Challenges. Ann Arbor: University of Michigan Press.

Bolton, Alex. 2020. "Agency Problems, Gridlock, and Non-Statutory Policymaking in Congress" Presented at the annual meeting of the Southern Political Science Association, San Juan.

Bond, Jon R., Richard Fleisher, and Glen S. Krutz. 2009. "Malign neglect: Evidence that delay has become the primary method of defeating presidential appointments." Congress \& the Presidency 36 (3): 226-243.

Brody, Richard. 1992. Assessing the President: The Media, Elite Opinion, and Public Support. Stanford: Stanford University Press.

Brookings Institution. 2018. "Vital Statistics on Congress” https://www.brookings.edu/wpcontent/uploads/2017/01/vitalstats_ch6_full.pdf.

Budget and Accounting Act of 1921, Pub. L. No. 67-13, 42 Stat. 20 (1921). 
Casas, Andreu. Denny, Matthew J., Wilkerson, John. 2020. "More Effective Than We Thought: Accounting for Legislation Hitchhikers Reveals a More Inclusive and Productive Lawmaking Process.” American Journal of Political Science 64(1): 5-18.

Campbell, Angus, Phillip E. Converse, Warren E. Miller, and Donald E. Stokes. 1960. The American Voter. New York: John Wiley and Sons.

Collischon, Matthias and Andreas Eberl. 2020. "Let's Talk About Fixed Effects: Let's Talk About All the Good Things and the Bad Things." KZfSS Kölner Zeitschrift für Soziologie und Sozialpsychologie 72(2): 289-299.

Consolidated Appropriations Act, 2016, Pub. L. No. 114-113 (2016).

Consolidated Appropriations Act, 2021, Pub. L. No. 116-133 (2020).

Cooper, Joseph and David W. Brady. 1981. "Institutional Context and Leadership Style: The House from Cannon to Rayburn.” The American Political Science Review 75 (2): 411 425.

Cox, Gary W., and Matthew D. McCubbins. 2005. Setting the Agenda: Responsible Party Government in the U.S. House of Representatives. Cambridge: Cambridge University Press.

Cox, Gary C., and Mathew D. McCubbins. 2007. Legislative Leviathan: Party Government in the House, 2nd ed. New York: Cambridge University Press.

Cox, Gary W. and William C. Terry. 2008. "Legislative Productivity in the 93rd-105th Congresses." Legislative Studies Quarterly 33(4): 604-618.

Currinder, Marian. 2009. Money in the House: Campaign Funds and Congressional Party Politics. Boulder Colorado: Westview Press.

Cybersecurity Information Sharing Act of 2015, S.754, 114th Cong. (2015).

Darrow, Barb. 2015. "Apple, Microsoft, others slammed for supporting cybersecurity bill.” Fortune, September 24th. http://fortune.com/2015/09/24/tech-vendor-cybersecurity-bill/

Davis, Tony. 1996. "Last Line of Defense: Civil disobedience and protest slowdown 'lawless logging"” High Country News https://www.hcn.org/issues/89/2747

Deering, Christopher J and Steven S Smith. 1997. "Committees in Congress" in Committees in Congress, CQ Press.

Devins, Neal. 1994. “Appropriation Riders.” In Encyclopedia of the American Presidency. ed. by Leonard Levy and Louis Fisher. New York: Simon \& Schuster: 67-69.

Dodd, Lawrence C. and Scot Schraufnagel. 2013. "Party Polarization and Policy Productivity in Congress: From Harding to Obama" In Congress Reconsidered, 10th Edition, eds. Lawrence C. Dodd and Bruce I. Oppenheimer. CQ Press.

Dominguez, Casey Byrne Knudsen. 2005. "Is It a Honeymoon? An Empirical Investigation of the President's First Hundred Days." Congress \& the Presidency 32(1) 1: 63-78. 
Drutman, Lee, Larry Evans, Bruce M. Patton, Ruth Bloch Rubin. 2019. Modernizing Congressional Capacity: A Report of the APSA Presidential Task Force Subcommittee on Congressional Capacity.

Elderkin, Susan. 1996. "What a difference a year makes" High Country News https://www.hcn.org/issues/89/2748

Emergency Supplemental Appropriations for Additional Disaster Assistance, for Anti-terrorism Initiatives, for Assistance in the Recovery from the Tragedy that Occurred at Oklahoma City, and Rescissions Act, 1995, Public Law No: 104-19 (1995).

Eshbaugh-Soha, Matthew. 2005. “The Politics of Presidential Agendas.” Political Science Research Quarterly 58(2): 257-268.

Evans, C. Lawrence. 2013. "Congressional Committees" In Congress Reconsidered, 10th Edition, eds. Lawrence C. Dodd and Bruce I. Oppenheimer: CQ Press: 396-425.

Fabrigar, Leandre R. and Duane Theodore Wegener. 2012. Exploratory Factor Analysis (Understanding Statistics). New York: Oxford University Press.

Fenno, Richard F., Jr. 1962. "The House Appropriations Committee as a Political System: The Problem of Integration." American Political Science Review. 56(2): 310-324.

Fenno, Richard F. 1966. The Power of the Purse: Appropriations Politics in Congress. Boston: Little, Brown and Co.

Fenno, Richard F. 1974. Congressmen in Committees. New York: Little, Brown and Co.

Ferejohn, John, and Charles Shipan. 1990. “Congressional Influence on Bureaucracy.” Journal of Law, Economics, and Organization 6(1): 1-20.

Fiorina, Morris P., Samuel J. Adams, and Jeremy C. Pope. 2005. Culture War? The Myth of a Polarized America. New York: Longman.

Fram, Alan. 1995. "Clinton Vetoes Borrowing Bill -- Government Shutdown Nears As Rhetoric Continues To Roil." Seattle Times https://archive.seattletimes.com/archive/?date=19951113\&slug=2152355

Fung, Katherine. 2020. “AOC Says Lawmakers Don't Have Time to Review \$2.5T Spending Bill Before Voting on It." Newsweek. https://www.newsweek.com/aoc-says-lawmakers-donthave-time-review-25t-spending-bill-before-voting-it-1556496

Gerstenzang, James. 1995. "White House Threatens Veto of Environmental Measure.” Los Angeles Times. https://www.latimes.com/archives/la-xpm-1995-09-23-mn-49153story.html

Gode, Jackson. 2019. "More productive, more diverse: What 'Vital Stats' tells us about the new Congress" https://www.brookings.edu/blog/fixgov/2019/03/13/more-productive-morediverse-what-vital-stats-tells-us-about-the-new-congress/

Goldman, Sheldon. 2003. "Assessing the State Judicial Confirmation Process: The Index of Obstruction and Delay. Judicature 86(2): 251-257. 
Grant, J. Tobin and Nathan J. Kelly. 2008. "Legislative Productivity in the U.S. Congress, 17892004." Political Analysis 16(3): 303-323.

Gray, Thomas R. and Jeffery A. Jenkins. 2019. "Pivotal Politics and the Ideological Content of Landmark Laws." Journal of Public Policy 39(1): 115-142.

Green, Donald, Bradley Palmquist, and Erick Shickler. 2002. Partisan Hearts and Minds. New Haven, CT: Yale University Press.

Grossback, Lawrence J., David A.M. Peterson and James A. Stimson. 2006. Mandate Politics. Cambridge University Press.

Haeberle, Steven H. 1978. "The Institutionalization of the Subcommittee in the United States House of Representatives.” The Journal of Politics 40(4): 1054-1065.

Hall, Richard 1. 1996. Participation in Congress. New Haven: Yale University Press.

Han, Hahrie and David W. Brady. 2007. "A Delayed Return to Historical Norms: Congressional Party Polarization After the Second World War.” British Journal of Political Science 37(3): 505-531.

Harbridge, Laurel and Neil Malhorta. 2011. "Electoral Incentive and Partisan Conflict in Congress: Evidence from Survey Experiments." American Journal of Political Science 55(3): 494-510.

Hassell, Hans J.G. and Samuel Kernell. 2016. "Veto Rhetoric and Legislative Riders." American Journal of Political Science 60(4): 845-859.

Hetherington, Marc J. 2001. "Resurgent Mass Partisanship: The Role of Elite Polarization". The American Political Science Review Vol. 95(3): 619-631.

Hicks, William D. 2015. "Partisan Competition and the Efficiency of Lawmaking in American State Legislatures, 1991-2009.” American Politics Research 43(5):743-770.

Hodges, Glenn. 1996. “Dead Wood”. Washington Monthly 28(10): 12-18.

Hopkins, Daniel J. 2018. The Increasingly United States. Chicago, IL: University of Chicago Press.

Hopkins, Daniel J. 2019. "Response to Thomas K. Ogorzalek's review of The Increasingly United States: How and Why American Political Behavior Nationalized. " Perspectives on Politics 17(1): 177-178.

Jacobson, Gary C. 2000. "Partisan Polarization in National Politics: The Electoral Connection." In Polarized Politics: Congress and the President in a Partisan Era. Ed. Jon R. Bond and Richard Fleisher. Washington, DC: Congressional Quarterly Press.

Jacobson, Gary C. 2013. "Partisan Polarization in American Politics: A Background Paper." Presidential Studies Quarterly 43(4): 688-708. 
Jalonick, Mary Clare. 2020. "Too Big to Read: Giant Bill a Leap of Faith for Congress." U.S. News \& World Report. https:/www.usnews.com/news/politics/articles/2020-12-21/toobig-to-read-giant-bill-a-leap-of-faith-for-congress

Jankowicz, Mia. 2020. "'It's hostage-taking.' AOC lashed out after lawmakers got only hours to read and pass the huge 5,593-page bill to secure COVID-19 relief." Business Insider https://www.businessinsider.com/aoc-angry-representatives-2-hours-read-covid-19stimulus-bill-2020-12

Jamieson, Kathleen Hall and Erika Falk. 2000. "Continuity and Change in Civility in the House." In Polarized Politics: Congress and the President in a Partisan Era. Ed. Jon R. Bond and Richard Fleisher. Washington, DC: Congressional Quarterly Press: 96-108.

Jenkins, Jeffrey., and Sean Gailmard. 2007. "Negative Agenda Control in the Senate and House: Fingerprints of Majority Party Power.” Journal of Politics 69(3): 689-700.

Jenkins, Jeffrey A, and Nathan Monroe. 2012 "Buying Negative Agenda Control in the U.S. House.” American Journal of Political Science. 56(4): 897-912.

Jones, David R. 2001. "Party Polarization and Legislative Gridlock." Political Research Quarterly, 54(1) 125-141.

Jones, Bryan and Frank Baumgartner. 2005. The Politics of Attention: How Government Prioritizes Problems. Chicago: The University of Chicago Press.

Kalmoe, Nathan P. 2020. With Ballots and Bullets: Partisanship and Violence in the American Civil War. New York: Cambridge University Press.

Keith, Tamara. 2013. "NRA-Driven Gun Provisions Pass Along With Spending Bill.” NPR, March 21st. https://www.npr.org/sections/itsallpolitics/2013/03/21/174969923/nradriven-gun-provisions-pass-along-with-spending-bill/

Kelly, Erin. 2015. 'Democrats block effort to attach cybersecurity legislation to defense bill'. USA Today, June 11th. http://www.usatoday.com/story/news/politics/2015/06/11/cybersecurity-informationsharing-bill-senate-cloture-vote/71077022/

Kim, Jae-on and Charles W. Mueller. 1978. Introduction to Factor Analysis: What It Is and How To Do It (Quantitative Applications in the Social Sciences). Beverly Hills: SAGE Publications.

King, David. 1997. Turf Wars: How Congressional Committees Claim Jurisdiction. Chicago: University of Chicago Press.

Krause, George A., and Anne Joseph O'Connell. 2016. "Experiential Learning and Presidential Management of the U.S. Federal Bureaucracy: Logic and Evidence from U.S. Federal Agency Leadership Appointments.” American Journal of Political Science 60(4): 91431.

Krause, Heather. 2018. "Continuing Resolutions and Other Budget Uncertainties Present Management Challenges." Testimony before the U.S. Senate Homeland Security and 
Government Affairs Federal Spending Oversight and Emergency Management Subcommittee. February 6. GAO-18-368T.

Krehbiel, Keith. 1991. Information and Legislative Organization. Michigan Studies in Political Analysis. Michigan: University of Michigan Press.

Krehbiel, Keith. 1998. Pivotal Politics: A Theory of US Lawmaking. Chicago, IL: University of Chicago Press.

Krutz, Glen S. 2000. 'Getting Around Gridlock: The Effect of Omnibus Utilization on Legislative Productivity’. Legislative Studies Quarterly 25(4): 533-549.

Landis, Richard J. and Gary G. Koch. 1977. "The Measurement of Observer Agreement for Categorical Data.” Biometrics 33(1): 159-174.

Lapinski, John S. 2008. "Policy Substance and Performance in American Lawmaking, 18771994." American Journal of Political Science 52(2): 235-251.

Lawrence, Eric D., Forrest Maltzman, and Steven S. Smith. 2006. "Who Wins? Party Effects in Legislative Voting.” Legislative Studies Quarterly. 31(1): 33-69.

Lee, Frances E. 2008. “Agreeing to Disagree: Agenda Content and Senate Partisanship, 19812004.” Legislative Studies Quarterly 33(2): 199-222.

Lee, Frances E. 2009. Beyond Ideology: Politics, Principles, and Partisanship in the U.S. Senate. Chicago: University of Chicago Press.

Lee, Frances E. 2012. "Individual and Partisan Activism on the Senate Floor." In The U.S. Senate: From Deliberation to Dysfunction Individual and Partisan Activism on the Senate Floor, eds. Burdett A. Loomis. Washington: CQ Press.

Lee, Frances E. 2015. "How Party Polarization Affects Governance." Annual Review of Political Science 18(1): 261-282

Lee, Frances E. 2016. Insecure Majorities: Congress and the Perpetual Campaign. Chicago: University of Chicago Press.

LeLoup, Lance T. 1984. “Appropriations Politics in Congress: The House Appropriations Committee and the Executive Agencies." Public Budgeting and Finance 4(4): 78-98.

Lewallen, Jonathan. 2020. Committees and the Decline of Lawmaking in Congress. Ann Arbor: University of Michigan Press.

Lewis, Jeffrey B., Keith Poole, Howard Rosenthal, Adam Boche, Aaron Rudkin, and Luke Sonnet 2021. Voteview: Congressional Roll-Call Votes Database. https://voteview.com/

Light, Paul C. 1999. The President's Agenda: Domestic Policy Choice from Kennedy to Clinton. Baltimore, MD: Johns Hopkins University Press.

Maltzman, Forrest. 1997. Competing Principals: Committees, Parties and the Organization of Congress. Ann Arbor: University of Michigan. 
Maltzman, Forrest. 1998. "Maintaining Congressional Committees: Sources of Member Support.” Legislative Studies Quarterly. 23(2): 197-218.

Mason, Lilliana. 2015. "I Disrespectfully Agree": The Differential Effects of Partisan Sorting on Social and Issue Polarization." American Journal of Political Science 59(1): 128-145.

May, Peter J., Joshua Sapotichne and Samuel Workman. 2009. "Widespread Policy Disruption and Interest Mobilization.” The Policy Studies Journal 37(4): 793-815.

Mayhew, David R. 2002. Electoral Realignment: A Critique of An American Genre. New Haven, CT: Yale University Press.

Mayhew, David R. 2005. Divided We Govern: Party Control, Lawmaking, and Investigations, 1946-2002, 2nd ed. New Haven: Yale University Press.

McCarty, Nolan. 2007. "The Policy Effects of Political Polarization." In The Transformation of American Politics: Activist Government and the Rise of Conservatism. Eds. Paul Pierson and Theda Skocpol. Princeton: Princeton University Press: 223-255.

McCarty, Nolan. 2016. "In Defense of DW-NOMINATE." Studies in American Political Development 30(2): 172-184.

McCarty, Nolan. 2019. Polarization: What Everyone Needs to Know. Oxford: Oxford University Press.

McCarty, Nolan, Keith T. Poole, and Howard Rosenthal. 1997. Income Redistribution and the Realignment of American Politics. Washington, DC: AEI Press.

McCarty, Nolan M., Keith T. Poole, and Howard Rosenthal. 2006. Polarized America: The Dance of Ideology and Unequal Riches. Cambridge, Massachusetts: MIT Press.

McCarty, Nolan, Keith T. Poole, and Howard Rosenthal. 2013. Political Bubbles: Financial Crises and the Failure of American Democracy. Princeton: Princeton University Press.

McCarty, Nolan and Rose Razaghian. 1999. Advice and Consent: Senate Responses to Executive Branch Nominations 1885-1996. American Journal of Political Science, 43(4): 11221143.

McCarty, Nolan, Keith T. Poole, and Howard Rosenthal. 2013. Political Bubbles: Financial Crises and the Failure of American Democracy. Princeton: Princeton University Press.

McNeal, Gregory S. 2014. “Controversial Cybersecurity Bill Known As CISA Advances Out Of Senate Committee." Forbes, July 9th. https://www.forbes.com/sites/gregorymcneal/2014/07/09/controversial-cybersecuritybill-known-as-cisa-advances-out-of-senate-committee/\#350e474a2f45/

Melki, Mickael and Andrew Pickering. 2014. "Polarization and Government Debt." Economics Letters 125(1): 36-39. 
Meyers, Roy T. 2014. "The Implosion of the Federal Budget Process: Triggers, Commissions, Cliffs, Sequesters, Debt Ceilings, and Shutdown.” Public Budgeting \& Finance. 34(4): 123.

Molvar, Erik. 2015. "Federal plans pave the way to a sage grouse listing." The Hill, July 13th. https://thehill.com/blogs/pundits-blog/energy-environment/247651-federal-plans-pavethe-way-to-a-sage-grouse-listing/

Morrow, William L. 1969. Congressional Committees. New York: Charles Scribner's Sons.

Nelson, Garrison. 1974. "Assessing the Congressional Committee System: Contributions from a Comparative Perspective." The Annals of the American Academy of Political and Social Science 411(1): 120-132.

Office of Law Revision Council. 2020. 'Table III Tool'. http://uscode.house.gov/table3/table3years.htm

Pelosi, Nancy. 2019. Pelosi Statement on Guilty Plea of Michael Cohen for Lying to Congress. https://www.speaker.gov/newsroom/112918-3

Persily, Nathaniel. 2015. "Introduction" In Solutions to Political Polarization in America. Ed. Nathaniel Persily. New York: Cambridge University Press: 1-14.

Peterson, Andrea. 2015. 'Senate passes cybersecurity information sharing bill despite privacy fears'. The Washington Post, October 27th. https://www.washingtonpost.com/news/theswitch/wp/2015/10/27/senate-passes-controversial-cybersecurity-information-sharinglegislation/?utm_term=.9c3ab5016aa6/

Peterson, David A.M., Lawrence J. Grossback, James A. Stimson and Amy Gangl. 2003. "Congressional Response to Mandate Elections" American Journal of Political Science 47(3): 411-26.

Pianin, Eric. 1998. "Budget Negotiations Seen as Key to Gingrich's Downfall." Washington Post November 7th. https://www.washingtonpost.com/wpsrv/politics/govt/leadership/stories/budget110798.htm

The Policy Agendas Project at the University of Texas at Austin, 2021. Hearings. www.comparativeagendas.net/us

The Policy Agendas Project at the University of Texas at Austin. 2021. Public Laws. www.comparativeagendas.net/us

Polsby, Nelson W. 1968. "The Institutionalization of the U.S. House of Representatives," American Political Science Review 62(1): 144-168.

Poole, Keith T. and Howard Rosenthal. 1984. "The Polarization of American Politics". Journal of Politics 46(4): 1061-79.

Poole, Keith T. and Howard Rosenthal. 1997. Congress: A Political Economic History of Roll Call Voting. New York: Oxford University Press. 
Poole, Keith T. and Howard Rosenthal. 2006. Ideology and Congress: A Political Economic History of Roll Call Voting. 2nd Edition. New York: Routledge.

Price, David. 1972. Who Makes the Laws?: Creativity and Power in Senate Committees. Cambridge, Massachusetts: Schenkman Publishing Co.

Price, David E. 1981. "Committees in the Policy Process." In Dodd and Oppenheimer, eds, Congress Reconsidered. 3rd ed. Washington, DC: CQ Press.

Price, David. 2013. “The Twilight of Appropriations?” Politico, September 22nd. http://www.politico.com/story/2013/09/budget-twilight-appropriations-david-price097171

Rohde, David W. 1974. "Committee Reform in the House of Representatives and the Subcommittee Bill of Rights." Annals of Political Science 411(1): 39-47.

Ryan, Mary P. 1971. "Party Formation in the United States Congress, 1789 to 1796: A Quantitative Analysis." The William and Mary Quarterly 28(4): 523-542.

Schaffner, Brian F. 2011. "Party Polarization." In The Oxford Handbook of the American Congress. Ed. George C. Edwards III, Frances E. Lee, and Eric Schickler. Oxford: Oxford University Press: 527-549.

Schick, Allen. 1981. "The Three-Ring Budget Process: The Appropriations, Tac, and Budget Committees in Congress." In The New Congress ed. by Thomas E. Mann and Norman J Ornstein. D.C.: American Enterprise Institute: 288-328.

Shipan, Charles R. 2004. "Regulatory Regimes, Agency Actions, and the Conditional Nature of Congressional Influence." American Political Science Review. 98(3.): 467-480.

Sinclair, Barbara. 1997. Unorthodox Lawmaking: New Legislative Processes in the U.S. Congress. Washington DC, Congressional Quarterly Press.

Sinclair, Barbara. 2006. Party Wars: Polarization and the Politics of National Policy Making. Norman, University of Oklahoma Press.

Sinclair, Barbara. 2012. "Senate Parties and Party Leadership, 1960-2010." In The U.S. Senate: From Deliberation to Dysfunction. Ed. Burdett Loomis. Washington DC: CQ Press: 85109.

Sinclair, Barbara. 2016. Unorthodox Lawmaking: New Legislative Processes in the U.S. Congress. 5th ed. Washington, DC: CQ.

Sonner, Scott. 1996. “Gore Calls Salvage Logging 'Biggest Mistake’ Admission Comes In TV Interview Scheduled To Air Tonight." https://www.spokesman.com/stories/1996/sep/27/gore-calls-salvage-logging-biggestmistake/

Smith, Steven S. 2014. The Evolution of Procedural Warfare in the Modern U.S. Senate. Norman: University of Oklahoma Press. 
Spies, Thomas A, Jonathan W Long, Susan Charnley, Paul F Hessburg, Bruce G Marcot, Gordon H Reeves, Damon B Lesmeister, Matthew J Reilly, Lee K Cerveny, Peter A Stine, and Martin G Raphael. 2019. "Twenty-five years of the Northwest Forest Plan: what have we learned?" Frontiers in Ecology and the Environment 17(9): 511-520.

Sundquist, James L. 1988. "Needed: A Political Theory for the New Era of Coalition Government in the United States." Political Science Quarterly 103(4): 614-24.

Theriault, Sean. 2008. Party Polarization in Congress. New York: Cambridge University Press.

Theriault, Sean M. and David W. Rohde. 2011. "The Gingrich Senators and Party Polarization in the U.S. Senate." The Journal of Politics 73(4): 1011-1024.

Titus, Dina. 2016. "Is Congress the "Broken Branch" of Government?" Political Science \& Politics 49(3): 490-494.

Volden, Craig and Alan E. Wiseman. 2014. Legislative Effectiveness in the United States Congress: The Lawmakers. New York: Cambridge University Press.

Walker, Jack L., Jr. 1977. "Setting the agenda in the US Senate: A theory of problem selection." British Journal of Political Science 7(4): 423-45.

Wawro, Gregory. 2000. Legislative Entrepreneurship in the US House of Representatives. Ann Arbor: University of Michigan Press.

Williams, Margaret and Lawrence Baum. 2006. "Questioning Judges About Their Decisions; Supreme Court Nominees Before the Senate Judiciary Committee. Judicature 90(2): 7380.

Wilson, Woodrow. 1885. Congressional Government. Boston, Massachusetts: Houghton Mifflin Company.

Wolf, Michael R., Cherie Strachan, and Daniel M. Shea. 2012. "Forget the Good of the Game: Political Incivility and Lack of Compromise as a Second Layer of Party Polarization." American Behavioral Scientist 56(12): 1677-1695.

Wolfe, Michelle. 2012. "Putting on the Brakes or Pressing on the Gas?" Policy Studies Journal. 40(1): 109-26.

Woon, Jonathan and Sarah Anderson. 2012. "Political Bargaining and the Timing of Congressional Appropriations.” Legislative Studies Quarterly 37(4): 409-436

Young, Garry and Valerie Heitshusen. 2003. "Party and the Dynamics of Congressional Committee Composition in the US House, 1947-96." British Journal of Political Science 33(4): 659-679.

Zellner, Arnold. 1962. “An Efficient Method of Estimating Seemingly Unrelated Regressions and Tests for Aggregation Bias." Journal of the American Statistical Association 57(298): 348-368.

Zellmer, Sandi. 1997. "Sacrificing Legislative Integrity at the Altar of Appropriations Riders: A Constitutional Crisis." Harvard Environmental Law Review 21(2): 457-535. 
Zurcher, Anthony. 2013. "The ghosts of the 1995-96 shutdown still haunt Washington." BBC News https://www.bbc.com/news/world-us-canada-24342526 